Louisiana State University

LSU Digital Commons

1968

\title{
A Multivariate Analysis of Selected Variables of Manufacturing Business Enterprises.
}

Friedhelm Goronzy

Louisiana State University and Agricultural \& Mechanical College

Follow this and additional works at: https://digitalcommons.Isu.edu/gradschool_disstheses

\section{Recommended Citation}

Goronzy, Friedhelm, "A Multivariate Analysis of Selected Variables of Manufacturing Business Enterprises." (1968). LSU Historical Dissertations and Theses. 1442.

https://digitalcommons.Isu.edu/gradschool_disstheses/1442

This Dissertation is brought to you for free and open access by the Graduate School at LSU Digital Commons. It has been accepted for inclusion in LSU Historical Dissertations and Theses by an authorized administrator of LSU Digital Commons. For more information, please contact gradetd@lsu.edu. 
This dissertation has been microfilmed exactly as received . $68-16,310$

GORONZY, Friedhelm, 1938-

A MULTIVARIATE ANALYSIS OF SELECTED

VARIABIES OF MANUFACTURING BUSINESS

ENTERPRISES.

Louisiana State University and Agricultural and Mechanical College, Ph.D., 1968

Business Administration

University Microfilms, Inc., Ann Arbor, Michigan 
A MULTIVARIATE ANALYSIS OF SELECTED VARIABLES

OF MANUFACTURING BUSINESS ENTERPRISES

\section{A Dissertation}

Submitted to the Graduate Faculty of the Louisiana State University and Agricultural and Mechanical College

in partial fulfillment of the requirements for the degree of Doctor of Philosophy

in

The Department of Management and Marketing

by

Friedhelm Goronzy

Ing. (grad.), Staatliche Ingenieurschule Essen, Germany, 1962 M.B.A., Louisiana State University, 1965 May, 1968 
To

my mother Auguste Goronzy and my late father Rudolf Goronzy 


\section{ACKNOWLEDGEMENTS}

The writer is indebted to many teachers and friends who prepared and encouraged him to undertake this research project. Special thanks go to Professor Herbert G. Hicks, not only for supervising this research, but also for sharing with me five years of stimulating disputations and discussions during my service as his research assistant. Professors Vincent E. Cangelosi and Bill R. Darden were especially helpful with the quantitative analyses of this study. Professors Thomas R. Beard, Edmund R. Gray and Leon C. Megginson made many suggestions for improvement in relation to the general field of management. Mr. Richard W. Bowlen, Manager of Administration at Markem Machine Company in Keene, New Hampshire, and William Penick, Partner of Arthur Andersen and Company, Certified Public Accountants, New Orleans, Louisiana, made helpful suggestions on the questionnaire.

Professor Bill B. Townsend and his staff at the Louisiana State University Computer Research Center deserve great credit for providing very efficient computer facilities 
and programming assistance. Professor Ralph M. Dreger made available the oblique factor rotation program and Miss Judith Fiehler, doctoral candidate in Musicology, gave permission to use her single linkage cluster analysis program for preliminary analyses. Professor Robert R. Sokal and Mr. Ronald Bartcher from the Department of Entomology of the University of Kansas, generously contributed their time to analyze the data on which Appendix B is based.

The writer wishes to express his sincere gratitude to the participating companies who spent much time and effort to supply him with the information on which this study is based. Without their cooperation this research would not have been possible.

Mrs. Mildred Gill helped him to express many thoughts and ideas in plain English, Mrs. Patricia Barnes read all of it for style and grammar, and Mrs. Helen Delatte typed it efficiently. The writer remains responsible for errors and omissions.

This project was supported through a dissertationyear fellowship granted by the Graduate School of Louisiana State University in Baton Rouge. 
TABLE OF CONTENTS

CHAPTER

Page

ACKNOWLEDGMENTS . . . . . . . . .

IIST OF TABLES . . . . . . . . . .

viil

LIST OF FIGURES . . . . . . . . . . غ

ABSTRACT . . . . . . . . . . xi

I. INTRODUCTION . . . . . . . . . . I 1

Some Dimensions of Organizational Phenomena. I

Classical Organization Theory. . . . . 2

Behavioral Organization Theory . . . . 5

Purpose of this Research . . . . . . . 9

Methodology. ............. 13

Nature of the Variabies.. . . . . . 13

Questionnaire. . . . . . . . . 14

Sample and Response. . . . . . 16

Problems of Randomness . . . . . . 17

Methods of Analysis. . . . . . . 18

Preview. . . . . . . . . . . 19

II. THE INELUENCE OF SIZE ON THE RELATIVE

IMPORTANCE OF MANAGERIAL OBJECTIVES, THE

NATURE OF THE SPAN OF EXECUTIVE CONTROL,

AND RELATED CONCEPTS . . . . . . . .

Objectives of Management . . . . . . 22

Span of Executive Control. . . . . . . 30

Average Number of Subordinates . . . . . 38

Unit of Supervision ........... . . 41

Division of Labor . . . . . . . . . . 44

Efficiency Relative to Size. . . . . . . 47

Conclusions............. 51 
CHAPTER

III. MULTIVARIATE ANALYSIS OF ORGANIZATIONAI

PHENOMENA. . . . . . . . . . . . . .

Nature of Factor Analysis..........

Factor Analysis of the Data. . . . . . .

Intercorrelation of Organizational

Variables ............

Varimax Factor Rotation. . . . . .

Interpretation of Orthogonal Factors .

Canonical Correlation of Orthogonal Factors.

Interpretation of the Canonical Analysis Nature of Oblique Factor Rotation. . . . .

Interpretation of Oblique Factors. . . Conclusions. . . . . . . . . ...

IV. COMPARATIVE ORGANIZATIONAL ANALYSIS. . .

Analysis of Technological Variables. . . Comparative Factor Analysis. . . . . . .

Differences in Manpower Allocation . . . .

Conclusions . . . . . . . . . . .

V. CONCLUSIONS AND PERSPECTIVES . . . . . .

Hypotheses: The Results of this Research. . Perspectives for Future Research . . . .

B. TOWARD A NUMERICAI TAXONOMY OF MANUFACTURING BUSINESS ENTERPRISES . . . . • •

Estimation of Resemblance of Business Enterprises. . . . . . . . . . Coefficients of Association. . . . . Measures of Distance......... Coefficient of Correlation . . . . . Standardization of Data. . . . . . . 
Toward a Numerical Taxonomy of Business Enterprises ............ 


\section{LIST OF TABLES}

TABLE

Page

2-1 Relative Importance of Management Objectives .

2-2 Ranking of Management Objectives in Relation to Size....................

2-3 Employment and Efficiency Data in Relation to Size. . . . . . . . . . . . . .

3-1 Means and Standard Deviations of 29 Selected Variables for the Factor Analysis. . . . .

3-2 Intercorrelation Matrix of Selected Organizational Variables ............

3-3 Varimax Rotated Factors and Factor Loadings. .

3-4 Canonical Analysis of 7 Factors. ......

3-5 Maxplane Rotated Factors and Factor Loadings .

4-1 Computation of the Geometric Mean or the Technology-Capacity Index. . . . . . .

4-2 Discriminatory Analysis of Small Batch and High Volume Manufacturers

4-3 Varimax Rotated Factors and Factors Loadings for Small Batch and High Volume Manufacturers.

4-4 Allocation of Manpower in 29 Employment

Categories . . . . . . . . . . .

4-5 Result of the Survey of the American Management Association . . . . . . . .

B-1 Computation of Coefficients of Association . . 
B-2 Means of 29 Selected Variables for 4 Clusters 
LIST OF FIGURES

FIGURE

1-1 The Major Dimensions of Classical Organization Theory . . . . . . . . . . . . .

1-2 Some Dimensions of Behavioral Organization Theory . . . . . . . . . . . . . .

2-1 The Span of Control of Top Management as a Function of Enterprise Size. . . . . . . .

2-2 Average Number of Subordinates as a Function of Size.................... 40

2-3 The Unit of Supervision as a Function of Size.

3-1 Graphical Representation of Varimax Rotated Factor Loadings of Factors Ia Through VIIa. .

4-I Discriminant Analysis of Small Batch and High Volume Firms. . . . . . . . . 100

B-1 Representation of Four OTU's in a ThreeDimensional Space. . . . . . . . . . .

B-2 Dendrogram Based on Taxonomic Distance Coefficients Joined by Average Linkage . . .

B-3 Dendrogram Based on Correlation Coefficients Joined by Average Linkage. . . . . . . .

B-4 Sketch of a Comprehensive Taxonomic System of Business Enterprises . . . . . . . . . 


\begin{abstract}
The behavior of business organizations is influenced by many interrelated qualitative and quantitative factors. The simultaneous interaction of these factors present many problems for a scientific inquiry. Testing of univariate hypotheses under application of the ceteris paribus clause does not appear to be the appropriate research approach to such complex situations. Rather, it seems that multivariate phenomena should be analyzed with multivariate research tools. Such a multivariate analysis on 50 business organizations has been performed in this study.

Empirically derived multivariate hypotheses are scarce in organizational research. Therefore, this study was performed to search for such multivariate hypotheses on the basis of a selected number of characteristics or variables of industrial organizations. The sample of 50 firms was drawn from machinery manufacturing enterprises classified under the Standard Industrial Classification, 35. The data collected for the selected characteristics were primarily objective accounting-type information. Nine hypotheses were derived through repeated application of factor analysis in


confunction with canonical correlation, discriminatory analysis and cluster analysis.

The various analyses of this study in connection with two other research studies reported in the literature Indicated the presence of common factors in industrial organizations: size and technology. The influence of these factors was very pervasive and measurably influenced the basic characteristics of the surveyed business enterprises. Therefore, most hypotheses have been stated with reference to these factors. The research indicated also the presence of two specific factors: resource utilization and product strategy. Because of the exploratory nature of this multivariate research, other specific factors found in this investigation were considered in the formulation of hypotheses, but not regarded as truly independent factors or dimensions:

The nine hypotheses that emerged from this investigation are enumerated below:

Hypothesis 1. The perceived importance of managerial objectives is influenced by the size of the business enterprise.

Hypothesis 2. The span of control of top management 
increases with the size of the enterprise, reflecting the rising importance of subsidiary activities.

Hypothesis 3 . The size of the unit of supervision is independent of the size of the business enterprise, but increases with team-oriented production methods.

Hypothesis 4. Division of labor tends to increase with enterprise size and workflow-oriented production methods. Hypothesis 5. The administrative overhead decreases relative to the increasing size of the enterprise.

Hypothesis 6. The larger companies and the companies manufacturing high complexity products tend to have a lower asset turnover.

Hypothesis 7 . The technological content of a product influences the customer service orientation of the firm.

Hypothesis 8 . Direct sales results in greater information feedback for product improvement.

Hypothesis 9. Sales per employee and sales per production worker increases with enterprise size and the technological complexity of products.

The hypotheses and the common factors should be viewed as guides for further research. Although this study indicated the influence of behavioral variables on the 
characteristics of the organizations, their influence was not explicitly measured. Therefore, further multivariate research should put greater stress on the inclusion of variables indicative of behavioral phenomena. The behavioral variables selected for analysis should also be objective and accounting-type data; e.g., grievances, personnel turnover, and number of suggestions for improvement. Multivariate analysis of organizational performance appears to be a very promising managerial planning and control tool. This writer thinks that periodic multivariate analysis of business operations will become as important and as regular as budgets and other management. reports. 


\section{CHAPTER I}

\section{INTRODUCTION}

Some Dimensions of Organizational Phenomena ${ }^{\text {P }}$

The behavior of business organizations or enterprises is exceedingly complex. These complexities present many problems for a scientific inquiry into their nature. A complete enumeration of all facts, however desirable, is impossible in the case of an organization as complex as the business enterprise. Even if it should be possible to describe such complex systems completely, it is doubtful whether it would be possible to analyze such information meaningfully.

Abstraction to relevant facts, characteristics, or variables is a way to circumvent the difficulty of analyzing complex systems in their entirety. But what is

The first part of this chapter draws heavily on Ralph M. Stogdill, "Dimensions of Organization Theory," in James D. Thompson (ed.), Approaches to Organizational Design (Pittsburgh: University of Pittsburgh Press, 1966), pp. 2-56. 
pertinent and relevant is largely a matter of judgment of the researcher and the hypotheses that he has formulated about organizational phenomena. The researcher who views the business organization as a system of -structures and functions will select different variables than the researcher who thinks of an enterprise as the interaction of subgroups. The theories of the "classical" organization and management theorists and those of "behavioral" scientists provide good examples of the contrasting perceptions of researchers. In order to clearly demonstrate the objectives and the meaning of this research study, a short summary of the major dimensions of organization theory as seen by classical and behavioral students of organization appears to be in order at this point. This brief outline of organization theory may be viewed as a concise review of the pertinent literature.

Classical Organization Theory

The theories of such classical writers as Fayol, Mooney, Urwick and their modern followers ${ }^{2}$ are based on variables

2Much of classical thought is based on Henri Fayol, General and Industrial Management (London: Pitman \& Sons, 1949), James D. Mooney and Alan C. Reiley, Onward Industry (New York: Harper \& Row, 1931), and Lyndal I Urwick, The Elements of Administration (London: Pitman \& Sons, 1943). Modern extensions of classical thought are Harold Koontz and Cyril O'Donnell, Principles of Management, 3rd ed. (New York: McGraw-Hill, 1964) and George R. Terry, Principles of Management, 4th ed. (Homewood, Ill.: Richard D. Irwin, 1964). 
that can be conveniently summarized in a simplified form in three dimensions: structure, departmentation, and operations as shown in Figure $1-1$.

Structure. A large part of classical organization theory is devoted to the question of structure. This concept should not be narrowly understood in terms of the formal organization structure only. It encompasses all formal relationships and processes in the organization. The definition of objectives of the business enterprise and the formulation of policies to achieve the objectives as well as the functions of the manager; e.g., planning, organizing, staffing, leading, and controlling, are all part of the concept of structure. The structure as a system of positions is made operational through the concepts of authority, delegation, and responsibility.

Departmentation. Departmentation reflects the principle of division of labor and is also a pivotal part of classical organization theory. The departments in Figure 1-1 are only illustrative. Departmentation may also take place on the basis of products or product groups, geography, customers, workflow, the state of growth and development, and other considerations. The extent of departmentation is also importantly influenced by the actual size of the 


\section{DEPARTMENTATION}

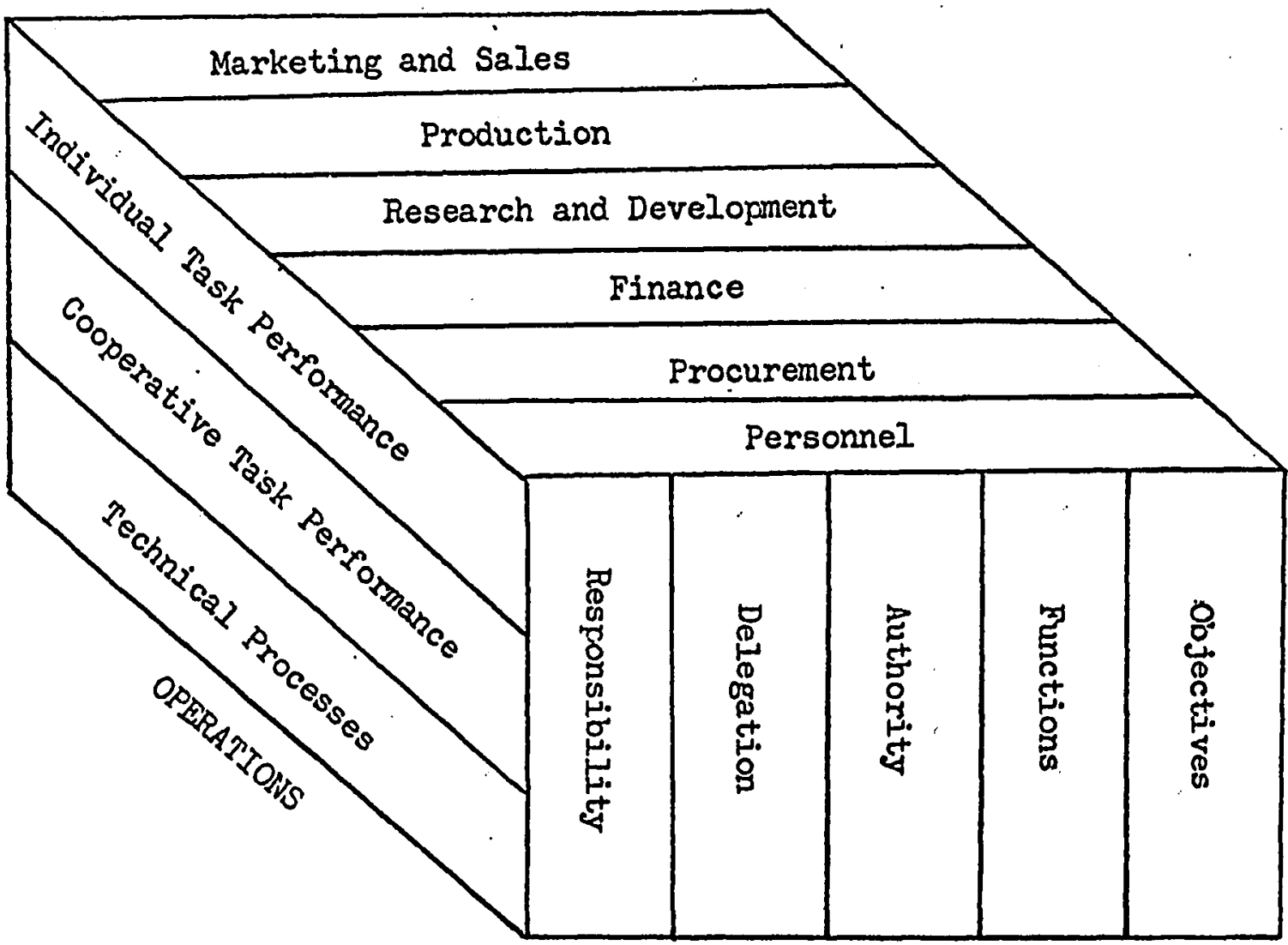

STRUCTURE

Figure 1-1. The Major Dimensions of Classical Organization Theory

(Source: Adapted from Ralph M. Stogdill "Dimensions of Organization Theory" in James D. Thompson, Approaches to Organizational Design (Pittsburgh: University of Pittsburgh Press, 1966) p.7) 
business entexprise.

Operations. Classical organization theory was greatly influenced by the scientific management movement. Consequently, productivity and efficiency considerations such as time and motion studies, production planning and control, cost accounting and cost control are an important part of the classical writings. The various wage payment plans on the piece rate or bonus basis are a direct reflection of this orientation toward operations efficiency and productivity. Depending on the mix of individual and group incentives in wage payment plans both individual and cooperative task performance are emphasized, though individual task performance appears to receive greater consideration.

The preceding outline of classical organization theory is highly simplified. This writer is merely trying to indicate some of the major dimensions which have been analyzed by the classical theorists and their contemporary followers. Below a similar outline of the orientation of behavioral scientists will be presented.

Behavioral Organization Theory

The dimensions of behavioral theories of organization are related to those of the classical writers. However, the 
variables that are being considered for analysis differ considerably. In analogy to the classical theory Figure 1-2 presents a simplified summary of the dimensions of behavioral theories of organization. 3

Behavioral Interdependencies. The study of interactions of organization members constitute a large part of the scientific investigations of behavioral scientists. The analysis of such processes as the interactions of individuals and groups, intercommunications, differing expectations, the interpersonal affects resulting from different personality characteristics of individuals, and the comparisons with the values of reference groups all form the background of the behavioral theories. Behavioral scientists stress the fact that the existence of these behavioral interdependencies has an important influence on the actual make-up of the formal structure and the operation of the technical processes.

Structure. The formal structure of the business organization is decisively modified by the members of the organization. Organizational objectives are not exogenously

3 Examples of behaviorally oriented writers are Douglas McGregor, The Human Side of Enterprise (New York: McGrawHill, 1960), Rensis Likert, New Patterns of Management (New York: McGraw-Hill, 1961), and Keith Davis, Human Relations at Work, 3rd ed. (New York: McGraw-Hill, 1967). 
BEHAVIORAL INTERDEPENDENCIES

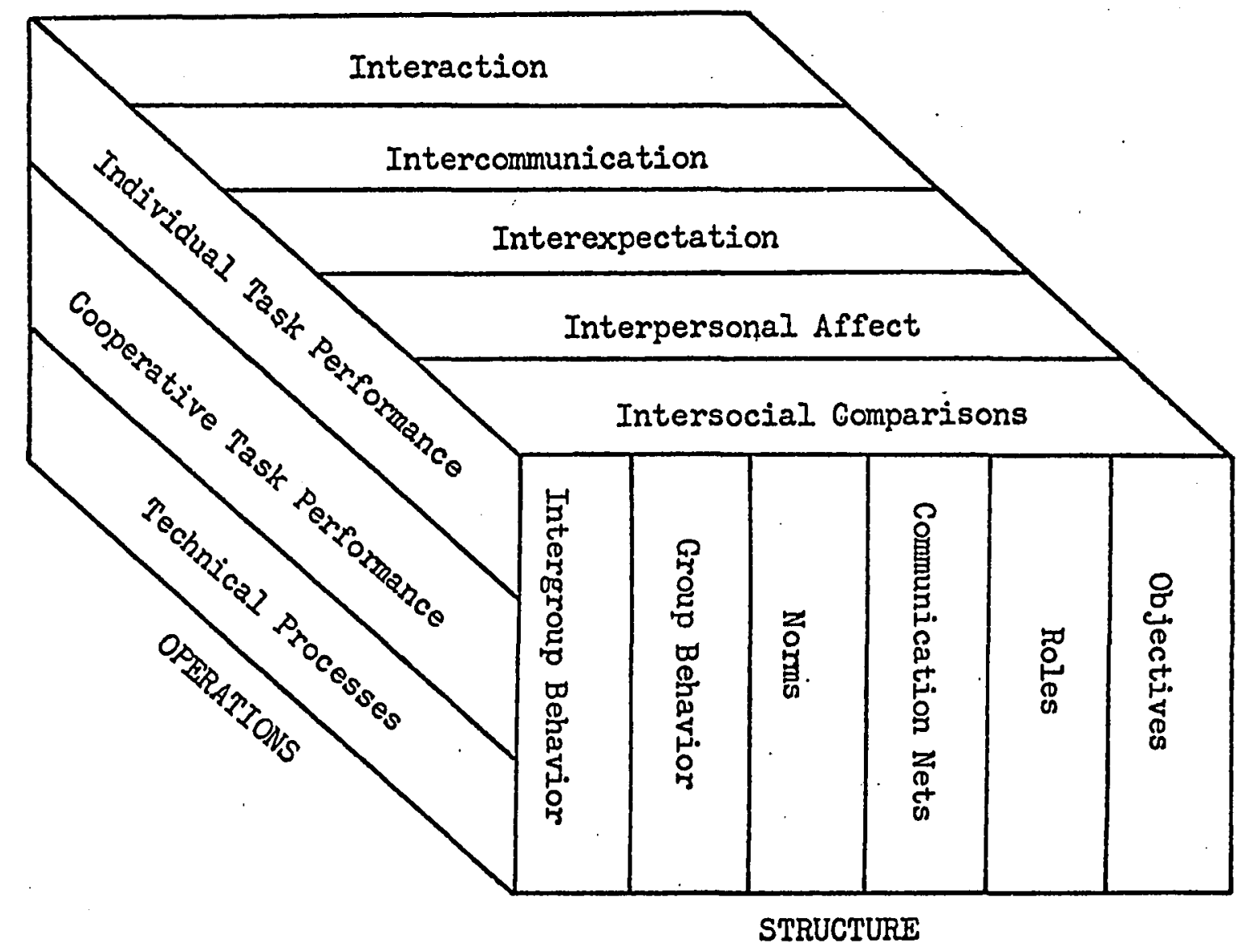

Figure 1-2. Some Dimensions of Behavioral Organization Theory

(Source: Adapted from Stogdill, op. cit., p. 13) 
given parameters but are established through the interactions of organization members. The formal hierarchy bound together by authority and responsibility is altered through roles that different office holders assume (which may be different from the official job description), distortions in the communication process, norms of people and groups, and intergroup behavior. Behavioral scientists focus on the structure in organizations that emerge through the interactions of formal requirements with behavioral variables.

Operations. The operations dimensions although seemingly identical with classical theory stress different aspects. In addition to the material (wage) incentives stressed by classical writers, other motives; e.g., -social, ego, creative, and self-fulfillment, are being analyzed for their influence on individual and cooperative task performance. The technical processes are investigated not solely from productivity and efficiency points of view but primarily for their effect on behavioral variables; e.g., the social consequences of technological changes.

The above outline of the major dimensions of behavioral organization theory is also simplified. This writer, however, thinks that these two outlines are sufficient to indicate the differences in the perception of classical and 
behavioral writers. By considering different variables and applying the ceteris paribus clause different types of organization theories have been developed. What appears to be needed at this point is methods which would contribute to an integration of these theories. Such methods will be applied in this study and are discussed below.

Purpose of this Research

The preceding introduction delineated some dimensions of organization theory. Based on theix different perceptions and objectives classical and behavioral writers investigated different aspects of business organizations and, as a result, formulated different theories. Early writers in management pronounced their theories primarily on the basis of their experience which can be viewed as a sort of casual empiricism.' Recent writers put great emphasis on the hypothesis-testing research methodology, a brief review of which may help to further clarify the purpose of the present research.

Commonly, researchers establish a hypothesis on the basis of a priori reasoning, intuition, and their general 
knowledge about the whole subject matter. ${ }^{4}$ Then they collect data, the analysis of which either tends to refute or not refute the hypothesis. This approach has resulted in much fruitful research; but it appears this method has also some major limitations, especially in behavioral research. Its success depends greatiy on the skill of the investigator to ask the right questions; e.g., formulate the right hypotheses, and collect relevant and representative data to test them. But more often than not, it seems, hypothesis testing is being used to "prove a prejudice with a bias"-a sort of self-fulfilling prophecy. It appears to this writer that hypotheses often are formulated and then tested with data that tends to support the researchers' a priori contentions.

Adequate testing of hypotheses may require data representative of a wide range of variables and such data is often difficult to collect. Consequently, hypotheses are often refuted or fail to be refuted on the basis of unrepresentative data. A well-known example may help to illustrate the difficulties associated with hypothesis

${ }^{4}$ Vincent E. Cangelosi, Compound Statements and Mathematical Logic (Columbus, Ohio: Charles E. Merrill Books, 1967), PP. 1-4 and 95-100. 
testing. When Mayo and his associates began the Hawthorne experiments in the late $1920^{\prime}$ s, they started with a welldefined and what appeared to be reasonable hypothesis: improved lighting conditions will increase productivity or the output of assembled telephones. 5 During the course of the experiments lighting conditions were improved and productivity increased. However, when lighting conditions were gradually worsened, productivity continued to increase until it finally stabilized at a high level. Obviously lighting conditions were not as important on productivity as had been hypothesized. New hypotheses about the reasons for productivity increases had to be sought.

Not all organizational research situations give as unequivocal results as the Hawthorne experiments. Because the human mind is unable to process and evaluate vast amounts of information simultaneously, hypotheses are frequently stated in terms of a few variables, ceteris paribus. Thus, such hypotheses often fail to be refuted on the basis of one-sided data. The recent "Herzberg Controversy" is a good example of this methodological

5 F. J. RoethIisberger and W. J. Dickson, Management and the Worker (Cambridge, Mass.: Harvard University Press, 1939). 
difficulty and illustrates well the exceedingly difficult task of empirical hypothesis testing. 6

The inherent difficulties in hypothesis testing research may be avoided through a greater emphasis on empirical research methodology. This research approach is understood here as the analysis of empirical data in order to formulate hypotheses or propositions. This approach is, of course, not without difficulti.es either. A major one is that the maze of facts that confronts the researchers may present insurmountable obstacles to their analyses. However, this writer thinks that the widespread availability of computers and the advanced state of powerful multivariate. statistical research tools has made this empirical approach an increasingly desirable method of analysis. This does not mean that the writer will disregard hypotheses advanced by other researchers. On the contrary, he will strive to incorporate them in the analysis whenever it appears appropriate. Consequently, the major objective of this study may be stated as the multivariate analysis of empirical data for the purpose of formulating hypotheses

\footnotetext{
${ }^{6}$ Orlando Behling, George Labovitz, and Richard Kosmo, "The Herzberg Controversy: A Critical Reappraisal," Academy of Management Journal, March, 1968, pp. 99-108.
} 
derived from this empirical data through a process of intuitive induction. 7

At this point the writer will explain why a somewhat lengthy introduction preceded the statement of the purpose of this study. The hypotheses that should result from this inductive research may or may not be identical or related to the dimensions of organization theory discussed above. Because of the nature of the accounting-type data that will be utilized, the hypotheses that should emerge will probably be more related to those of classical organization theory than those of behavioral organization theory. However, it is anticipated that the accounting-type data will also reflect certain behavioral phenomena; e.g., implicit objectives of the management of the enterprise.

\section{Methodology}

Nature of the Variables

In the preceding section it was stated that the nature of the selected variables for hypothesis testing has an important influence on the conclusions reached. This, of

7 Morris R. Cohen and Ernest Nagel, An Introduction to Logic and Scientific Method (New York: Harcourt, Brace \& World, 1934), P. 275 . 
course, is also true for inductive research. This writer thinks that research on organizational phenomena preferably should be based on data that is generated in the ordinary course of operating the enterprise, although special effort may be necessary to collect it.

Information that is artifically generated for a research study and which requires considerable judgment on the part of certain organization members may be distorted by their individual attitude and perception. In addition, cross sectional data--data collected from several firms--may be more representative of organizational phenomena than time series data on only one firm. These considerations necessitated the use of a mailed questionnaire because the comprehensive information required for this research is not available in any published form suitable for re-analysis.

\section{Questionnaire}

Since this is primarily a hypothesis seeking research effort, the questionnaire (See Appendix A) was prepared on the basis of general a priori considerations discussed in the course of the review of classical and 
behavioral organization theory. ${ }^{8}$ With the exception of the first section of the questionnaire, which required a subjective ranking of selected managerial objectives, all other questions called for objective "operational" or accounting-type information. The questionnaire was meant to be comprehensive, because only through a wide variety of variables would it be possible to discover and investigate various dimensions of organizational phenomena. A narrow range of variables, especially if they are related, may measure perhaps one or possibly two dimensions and may lead to erroneous conclusions. Consequently, the questionnaire called for sales data, number of customers, extent of research and development, employment of people in various categories, and other diverse information.

This writer is fully aware of the shortcomings of the questionnaire sampling method but the major constraints of costs, geographical distance, and time made this approach necessary. The questionnaire was tested by submitting it for appraisal to several business executives and other knowledgeable persons. No formal pilot study was performed.

${ }^{8}$ Certain parts of the questionnaire are based on Bruce E. Despelder, Ratios of Staff to Line Personnel (Columbus, Ohio: Bureau of Business Research, The Ohio State University, 1962), pp. 77-81. 
Sample and Response

Machinery and equipment manufacturing firms were selected as the universe to be investigated. These manufacturers perform a rather wide range of business activities. Whese activities range from research and development to production and from marketing and sales to financial considerations. A relatively homogeneous group of 580 firms was selected from Poor's Register of Corporations on the basis of the two-digit Standard Industrial Classification Code $35 .^{9}$ The lower limit was set at about 100 employees and the upper around 2,500. The selected firms may be regarded as the complete universe of firms with the indicated characteristics.

The first mailing was made on November 18, 1967, and consisted of a cover letter, the questionnaire, and a business reply envelope. A follow-up mailing was completed by December 16, 1967. By the end of January, 1968, 58 companies had responded with completed questionnaires or 10 per cent of the universe. The returned questionnaires were relatively complete although there were some with missing

${ }^{9}$ Poor's Register of Corporations, Directors and Executives (New York: Standard and Poor's Corporation, 1967). 
data. A total of 46 companies answered but declined participation for several reasons.

Problems of Randomness

- One of the most important assumptions in sampling theory is randomness of response. Statistical tests of significance and other calculations are directly based on this assumption. Has this criterion been met in this research study or is the response biased and self-selected? The writer cannot answer this question with certainty. No formal tests of representativeness or randomness were employed because of the expense and practical considerations. However, the writer thinks that the returned questionnaires are representative of the total universe. An analysis of the comments of the firms which replied but declined to furnish information revealed that no special reason for withholding information prevailed. Foremost among the reasons given was lack of time, the confidential nature of much of the data requested, and special effort necessary to collect the information. These reasons are in accordance with the comments that accompanied the usable replies where some firms did not give all the information because they lacked time to assemble it, others withheld their names, and some indicated special effort to collect the data. 
From this the writer infers that the response was sufficiently random to satisfy the randomness assumption of sampling theory.

Methods of Analysis

Various statistical techniques were employed in analyzing the data. Sections of this research are based on such conventional univariate techniques as regression and correlation analysis and tests of significance. Other problems have been approached with advanced multivariate methods such as factor analysis, canonical correlation, discriminant functions, and cluster analysis. In the case of these newer techniques, a brief explanation of their purpose will be given prior to their application. However, these digressions are neither exhaustive nor rigorous. The reader will be referred to the standard literature for authoritative information. Most of the analyses were performed in the Louisiana State University Computer Research Center consisting of an IBM 7040 system with the necessary peripherial equipment. The cluster analysis contained in Appendix $B$ was performed at the University of Kansas on a General Electric 625 computer system. 


\section{Preview}

The analysis of the empirical data begins in Chapter II. The subjective part of the questionnaire is examined first; the ranking of managerial objectives in the small and the larger companies are contrasted, The next section covers such familiar ground as the span of executive control, the unit of supervision, and the average number of subordinates per superior. The last section deals with a concept to measure the extent of the division of labor. Essentially, the analysis in Chapter II is univariate; it focuses on individual variables. Some data in Chapter II is prepared as input for the multivariate analyses that follow.

Chapter III focuses on the discovery of dimensions of organizational phenomena. Factor analysis and canonical correlation are employed for this purpose. Stress is put on the interpretation of factors and the difficulties inherent in interpreting factors. The analysis will also reveal that it is quite difficult to select variables "representative of a wide range of phenomena" on a priori grounds. A discussion of the possible meanings of the factors concludes Chapter III.

In Chapter IV the multivariate statistics are used to make a comparative analysis of organizational data. The 
enterprises will be classified along technological lines into high complexity and low complexity products manufacturers. This classification will be tested and then the data will again be factor analyzed. Finally, the comparative analysis will be broadened into a taxonomic system of business entexprises.

Chapter $V$ contains the summary and the conclusions of this research in terms of a series of highly tentative hypotheses. Some perspectives for further research are also developed.

The questionnaire is presented in Appendix A. The four types of cover letters that accompanied the questionnaire cannot be disclosed because they may reveal the identity of certain contributors.

The results of the cluster analysis have been included as Appendix B. A numerical taxonomy of the surveyed business enterprises tends to support the findings of Chapters III and IV. 


\section{CHAPTER II}

THE INFLUENCE OF SIZE ON THE RELATIVE IMPORTANCE OF MANAGERIAL OBJECTIVES, THE NATURE OF THE SPAN OF EXECUTIVE CONTROL, AND RELATED CONCEPTS

This chapter introduces the empirical analysis of the data. Much of the collected raw data would not yield very meaningful results if directly subjected to multivariate analysis. A transformation of the data into meaningful concepts like span of control, unit of supervision, and division of labor appears necessary before applying multivariate methods. This preparatory analysis in this chapter is therefore essentially univariate. It will give the reader an opportunity to appreciate the limitations of univariate analysis and to familiarize himself with the specific meaning of certain variables which are repeatedly used in the following chapters. This preparatory analysis will also provide an opportunity to relate some of the data to certain hypotheses proposed in the literature. However, this hypothesis testing should be viewed as an exception to the rest of this research. 
The first part of this chapter deals with the subjective part of the questionnaire. Managerial objectives are analyzed in relation to the size of the firm. In addition to the analysis of managerial objectives, much of this chapter deals with such familiar concepts as span of executive control, unit of supervision, and division of labor. Although the concepts are familiar, the analysis differs somewhat from previous studies.

\section{Objectives of Management}

The assumptions about objectives of management are crucial to any theory of the firm. The neoclassical economic "theory of the firm" rests exclusively on the assumptions of a profit maximizing firm and a utility maximizing consumer. In practice, there are many difficulties with profit maximization as economists define it. Economists assume full knowledge of all economic factors and conveniently assume away risk and uncertainty. Because of these and other simplified assumptions many writers in management have attacked profit maximization as unrealistic on ethical, practical, and moral grounds. This controversy has resulted in much fruitful research and new "managerial" theories of the firm. These theories are based on objectives other than pure profit maximization and have 
been reviewed elsewhere. ${ }^{1}$

In order to gain some empirical support for the various hypotheses about the objectives of management, the questionnaire included a survey of objectives and their relative importance. Cyert and March proposed that managerial behavior and decision making can be explained with essentially five objectives: profit, sales, market share, production level and inventory. ${ }^{2}$ They assumed that managerial behavior is satisficing and that management will strive to have a satisfactory level of profits, sales, and production volume. Further, management will try to maintain a minimum market share and attempt to keep a minimum level of inventory consistent with satisfactory customer service and relative stability of production. In addition to the hypotheses of Cyert and March about

$1_{\mathrm{H}}$. Igor Ansoff, Corporate Strategy (New York: McGrawHill, 1965) contains a good discussion of the contxoversy on objectives in Chapter 3. For a survey of the economic Iiterature on objectives see Herbert G. Hicks and Friedhelm Goronzy, "A Survey of Certain Economic Concepts Revelant to the Study of Management and Organization" and "A Survey of Some Recent Contributions of Economists to a Managerial Theory of the Firm," both in Management International Review (forthcoming).

${ }^{2}$ Richard M. Cyert and James G. March, A Behavioral Theory of the Firm (Englewood Cliffs, N. J.: PrenticeHall, 1963), pp. 40-43. 
managerial objectives, the personnel objective was added following the suggestion of a business executive. Also space was provided for other objectives to be added by the management of the surveyed firms.

The most surprising result of this survey of objectives was the conspicuous absence of some objectives that management was supposed to have. For example, the service objective of the business enterprise is being regarded as the primary business objective by certain writers. ${ }^{3}$ None of the surveyed firms reported anything to that effect. A few companies mentioned goals other than the pre-selected ones but all could be re-interpreted to fit the preselected six. For example, a cost reduction objective has been viewed as a way to maintain or increase profits. The final tabulation of the rankings for 50 companies is presented in Table 2-1. The rank order of objectives is based on the mean of each objective for the 50 companies. Profit has the lowest mean of 1.5; consequently, it has the rank order of 1. Inventory level has the largest mean of

$3_{\text {Ralph C. Davis, The Fundamentals of Top Management }}$ (New York: Harper \& Brothers, 1951), pp. 90-126. See also Keith Davis, Human Relations at Work-The Dynamics of Organizational Behavior (New York: McGraw-Hil1, 1967), Pp. 81-83. 
4.72 and has therefore the lowest rank order of 6 .

$$
\text { TABLE 2-1 }
$$

Relative Importance of Management Objectives

\begin{tabular}{lccc}
\hline $\begin{array}{c}\text { Management } \\
\text { Objectives }\end{array}$ & $\begin{array}{c}\text { Mean of All } \\
\text { Rankings }\end{array}$ & $\begin{array}{c}\text { Standard } \\
\text { Deviation }\end{array}$ & $\begin{array}{c}\text { Rank } \\
\text { Order }\end{array}$ \\
\hline Inventory Level & 4.72 & 1.29 & 6 \\
Market Share & 3.55 & 1.51 & 3 \\
Profit & 1.50 & 0.89 & 1 \\
Stability of Production & 4.45 & 1.18 & 5 \\
Sales & 2.38 & 0.99 & 2 \\
Personel & 4.26 & 1.48 & 4 \\
\hline
\end{tabular}

The result of Table $2-1$ shows what was expected, the primary economic objectives profit, sales, and market share rank highest. However, the standard deviations from the mean are quite large indicating considerable variability in the response. After an additional review of the questionnaire, the writer hypothesized that the size of the business enterprise may have had an influence on the way management interpreted its objectives. This hypothesis was investigated and the results axe summarized in Table 2-2. 
At first glance it may appear that little has changed in the rank order of the larger and the small companies. The first three objectives have the same rank order and only Stability of Production and Personnel have traded places. However, a closer look at the magnitudes of the means and the standard deviations reveals interesting differences. The management of the larger companies shows far greater consensus on the importance of the profit objective; the mean is close to one and the standard deviation is the smallest of any objective. For the smaller companies the means of the profit and sales objectives are relatively close together and the standard deviations are high. In addition to the differences on the profit objective, the larger companies appear to be more "people" oriented and the smaller firms more "production" oriented. While the personnel objective is in a solid fourth place for the larger companies, it is barely in the fifth place for the smaller companies. This difference may be attributable to the fact that the head of personnel in the smaller companies tends to report to the head of manufacturing and in the larger companies to the chief executive officer. The t-test for difference between the means of the objectives does not indicate statistical significance at the 
TABLE 2-2

Ranking of Management Objectives in Relation to Size*

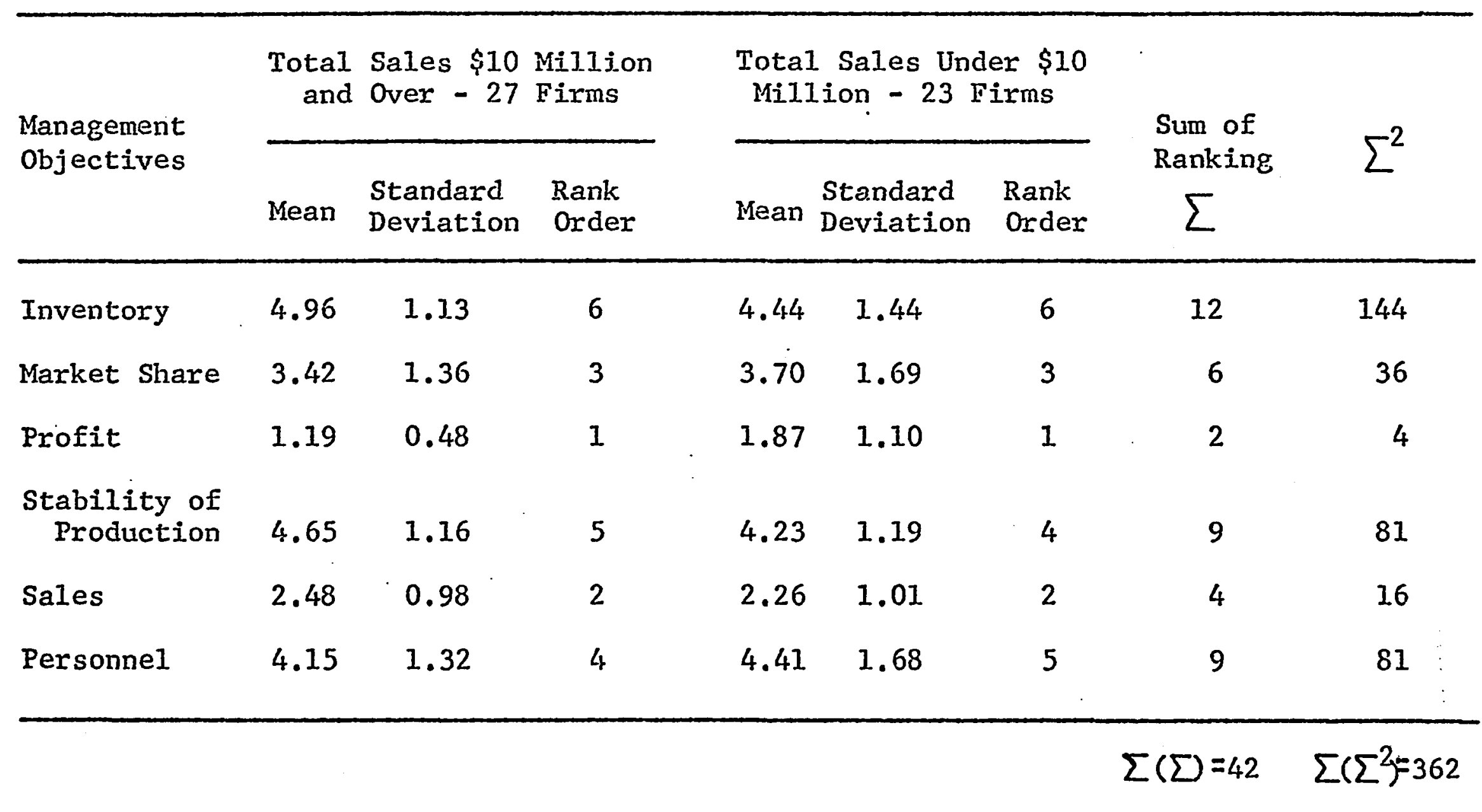

*Differences are not significant at a probability level of $p=0.05$ 
probability level of $\mathrm{p}=0.05$. Nevertheless, this writer thinks that these differences are important enough to warrant consideration. In general, among the management of the smaller firms there is less agreement (as evidenced by the larger standard deviations) what the importance of the individual objectives should be. It would be interesting to know how this condition is reflected in the profitability of the larger and the smaller companies. Some approximate calculations to this effect will be made later in this chapter.

Another investigation that may be of interest is the extent of agreement of the composite rankings of these two groups, the smaller and the larger companies. This degree of agreement can be estimated through Kendall's coefficient of concordance $\mathrm{W}^{4}$ This coefficient ranges from 0.0 to 1.0 and indicates no agreement and perfect agreement respectively. Its calculation is relatively simple:

$$
\begin{aligned}
W=\frac{12 s}{k^{2}\left(n^{2}-n\right)}, \text { where } s & =\sum\left(\Sigma^{2}\right)-\left[\sum(\Sigma)\right]^{2} / n \\
& =362-\left(42^{2}\right) / 6=68
\end{aligned}
$$

$k=2$, number of groups

4Maurice G. KendalI, Rank Correlation Methods (New York: Hafner Publishing Company, 1955), Chapter 6. 
$\mathrm{n}=6$, number of objectives

Therefore, $W=\frac{12 \cdot 68}{2^{2}\left(6^{3}-6\right)}=0.97$

The $F$-test, $F=\frac{(k-1) W}{1-W}=\frac{(2-1) 0.97}{1-0.97}=32.1$, shows statistical significance at the 0.001 probability level. Although this coefficient of concordance shows a high agreement it should be interpreted carefully. Composite measures of this type have a tendency to cover up differences on individual variables and often indicate a greater degree of agreement than may actually prevail. This again indicates how difficult it really is to test hypotheses with empirical data.

The analysis of the managerial objectives would not be complete without an attempt to. interpret the rankings of the objectives by management. It appears that two very tentative conclusions can be drawn. First, the primary economic objectives of the firm receive the highest consideration of management. This is a reminder to the fact that the raison d'être of the firm still is primarily economic. Only to the extent that the enterprise performs economically can other objectives be fulfilled; e.g., "maintain and upgrade personnel." Second, there are differences in the way the smaller and larger firms conceive 
of their objectives. It appears that the smaller firms on the average put relatively more stress on sales than on profits in contrast to the "arrived" larger companies. This may imply a stronger growth motive on the part of management of the smaller companies. 'The larger firms seem to feel that it is good business to emphasize the personnel objective.

This section concludes the analysis of the subjective information of the questionnaire; i.e., the judgmental ranking of pre-selected objectives. Below the nature of the span of executive control will be investigated as it has been found in the surveyed companies.

\section{Span of Executive Control}

The span of executive control or the span of management is a favorite subject in management literature. Although there have been a number of comprehensive studies of the subject, the issue is far from settled and the evidence conflicting. 5 One of the greatest problems

$5_{A}$ review of studies about the nature of the span of management is found in William H. Starbuck, "Organizational Growth and Development," In James G. March (ed.), Handbook of Organizations (Chicago: Rand McNally, 1965), pp. 500502. Compare also Ralph C. Davis, The Influence of the Unit of Supervision and the Span of Executive Control on the Economy of the line Structure (Bureau of Business Research, 
with empirical studies about the nature of business enterprises lies in the definition and recognition of the boundaries of the inquiry. Many researchers seem to be preoccupied with the idea of finding universally applicable answers. As a consequence, the universe chosen for an Inquiry is seldom homogeneous; many accompanying facts like size, technology, division of labor, and others are not reported or only in passing. This negligence is partially responsible for the conflicting evidence. In this chapter only the influence of size on the span of management will be examined. An attempt to correlate technology with the span of executive control did not yield any conclusive results. It could be that the firms are technologically

The Ohio State University, 1951); Ernest Dale, Planning and Developing the Company Organization Structure (New York: American Management Association, 1952), pp. 32-43; V. A. Graicunas, "Relationships in Organization" in Luther Gulick and L. Urwick (eds.), Papers on the Science of Administration (New York: Institute of Public Administration, Columbia University Press, 1937), pp. 181-187; Michael Polanyi, The Logic of Liberty (Chicago: The University of Chicago Press, 1951), pp. 114-122; W. W. Suojanen, "The Span of Control-Fact or Fable?," Advanced Management, November, 1955, pp. 513; Lawrence S. Hill, "The Application of Queuing Theory to the Span of Control," Academy of Management Journal, March, 1963, pp. 58-69, Harold Steglitz, "Optimizing the Span of Control," Management Record, September, 1962, pp. 121-129, Christian Gasser, "Die optimale Organisationsstruktur," Industrielle Oxganisation, December, 1952, pp. 325-332, and Jon G. Udel1, "An Empirical Test of Hypotheses Relating to Span of Control," Administrative Science Quarterly, December, 1967, pp. 420-439. 
too homogeneous to make the differences significant.

Starbuck who examined the evidence of various contributors formulated a regression equation where the span of top management increases with total employment: 6

$S=2.0 \cdot \log \mathrm{T}$

$S=$ Span of Chief Executive; $T=$ Total Employment

The size dependent relationship certainly is an interesting hypothesis and warranted further investigation. The data collected in this survey indicated that such a relationship apparently does exist. Figure 2-1 shows the span of executive control of top management as a function of total employment. However, the measure of size, whether employment, total sales revenue, total assets, or fixed assets, is not material because all these measures have high intercorrelations, $r>0.90$.

The graph represents the span of the chief executive (President or Executive Vice-President) and is based on information collected in Part III of the questionnaire. The regression equation has been estimated as $S=2.3 \cdot \log T$ and it describes the tendency for the span to rise as the size of the firm increases quite well. The correlation

${ }^{6}$ starbuck, op. cit., p. 500 . 


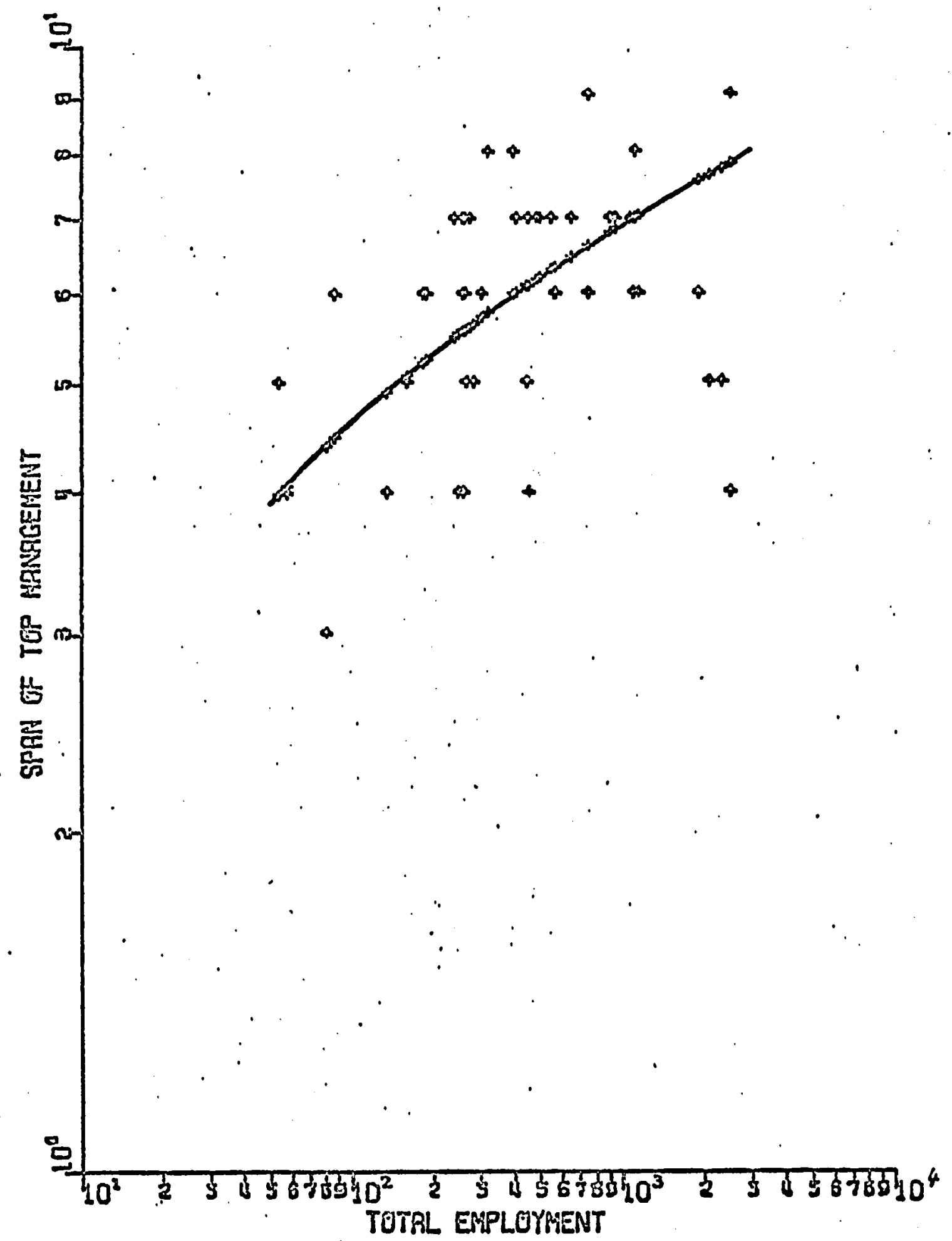

Figure 2-1. The Span of Control of Top Management as a Function of Enterprise Size 
coefficient $r=0.872$ is high but the equation is not significantly different from Starbuck's (at the 0.05 probability level). In view of the scanty information available the formula $S=2.0 \cdot \log T$ may serve as an adequate first approximation.

Mathematical equations can easily give a false sense of security about their reliability. This applies also to the span of management estimation equation. Although the formula appears to be a reasonable estimator in the range of 100 to 15,000 employees it seems to be "way off" beyond that range. Gerald G. Fisch has re-examined the literature in the light of his experience as a management consultant and pleads for larger spans of management than those 4 to 6 often advocated in the Iiterature. ${ }^{7}$ In firms with a total employment of 15,000 to 100,000 employees the chief executive had spans of control that range from 12 to 30 . There may be good reasons for such large spans in the large companies. Urwick and Graicunas and the others who advocated small spans were concerned about the human interrelationships resulting from large spans. The modern supermanager is not closely controlled. Where

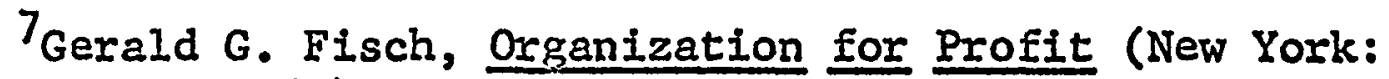
McGraw-Hill, 1964), Chapter 8. 
decentralization is extensive he may be in a so-called "go, no go" situation and judged by the results he achieves. Consequently, the premises of Urwick and Graicunas are not applicable in such situations. ${ }^{8}$ on the other hand, in situations where human interactions are numerous and complex, a small span of control may indeed be prevailing. The controversy about the appropriate span of control is another good example of the danger of testing hypotheses on the basis of only one aspect of the total picture or analyzing essentially multivariate situations with univariate data.

In addition to larger spans as a result of decentralization, Davis' theory of staff differentiation may be another plausible explanation for the rise of the span of top management. Several stages of this evolutionary process can be identified: ${ }^{9}$

1) line integration, a staff function is performed by line men; e.g., the foreman hires and fires.

2) distinct staff differentiation, staff employees report

${ }^{8}$ Ibid., p. 96.

${ }^{9}$ Ralph C. Davis, The Fundamentals of Top Management (New York: Harper \& Brothers, 1951), pp. 376-384. 
to the same line foreman as the direct production workers; e.g., maintenance workers report to the production (Iine) foreman.

3) complete staff differentiation; one or more full time supervisors are overseeing the staff function; e.g., head of maintenance, head of in-plant transport.

4) staff integration; separate staff functions have emerged and it offers an advantage to group them together; e.g., the head of manufacturing services may be responsible for tools and fixtures, maintenance, inplant transport, etc.

5) staff elevation, the staff department is separated from the lower echelons and attached to higher echelons; this is particularly true for multi-plant operations when the staff function is concentrated at the headquarters.

6) staff decentralization, the company has grown so large that the individual plants need their own staff. departments in addition to the corporate general staff.

7) complete staff separation, this is often true only for very large corporations and even there only for some functions; e.g., research may have a life entirely of its own and completely separate from the rest of the 
company.

The analysis of the replies to this survey indicated that staff elevation may be the most plausible reason for the increase of the span of the top executive as a function of size. In the smaller companies, the $R$ \& $D$ function, personnel, and purchasing often report to the head of manufacturing. As the companies increase in size these departments tend to be elevated and report to the chief executive officer. Similarly, many activities that are carried out by multiple assignment units in smaller companies, gain independent status in the larger companies. This process. tends to increase the span of control of the top executive.

The concept of span of control is multi-faceted. This analysis indicates that multiple causes seem to have an influence on the actual size of the span of control. The degree of decentralization and the process of staff differentiation as a result of the growth of the enterprise, appear to lead to larger spans of control of the chief executive officer. Below the analysis will be extended to the average number of subordinates per superior. 


\section{Average Number of Subordinates}

An interesting corollary to the span of control of the chief executive is the average number of subordinates per superior. This relationship is not equivalent to the span of executive control of top management. The analysis of the span of control was based on the actual number of subordinates reporting to the top executive. The number of subordinates is based on averages computed from information supplied in Part II of the questionnaire. Direct production personnel has been excluded from these computations because the unit of supervision in direct production will be treated separately.

The number of superiors was calculated as follows:

First-line supervisors for all functions +Managerial personnel 2nd level and above -First-line supervisor of direct production Total number of superiors

The number of subordinates was found by the following tabulation:

Total Employment

-Total number of superiors

-First-line supervisors of direct production

-Direct production workers

Total number of subordinates

Therefore,

$\begin{aligned} & \text { Average Number } \\ & \text { of Subordinates }\end{aligned}=\frac{\text { Total number of subordinates }}{\text { Total number of superiors }}$ 
Analogous to the span of control, the average number of subordinates per superior increases with increasing size of the firm. It is the small company that has relatively more "chiefs than Indians." Figure 2-2 depicts this relationship graphically. However, an attempt to compute a regression equation of the form $y=a \cdot x^{2}$ or other mathematical relationships did not yield any usable results.

Why has the small firm on the average fewer subordinates per superior? One possible explanation may be the tendency among small firms to imitate the formal organization structure of the larger firms. The analysis of the information in Part II of the questionnaire gave-certain clues to that effect. For example, in the large firms costaccounting may be handled by a supervisor and six or eight clerks, in the small company cost accounting may also be a separate activity with a supervisor and one or two clerks. It appears that this type of imitation has a tendency to inflate the supervisory overhead of the small companies.

The increase in the average number of subordinates per superior as a function of size has important implications with respect to the administrative overhead. The analysis of this aspect will be deferred to the end of this chapter. Below the unit of supervision will be analyzed as a function 


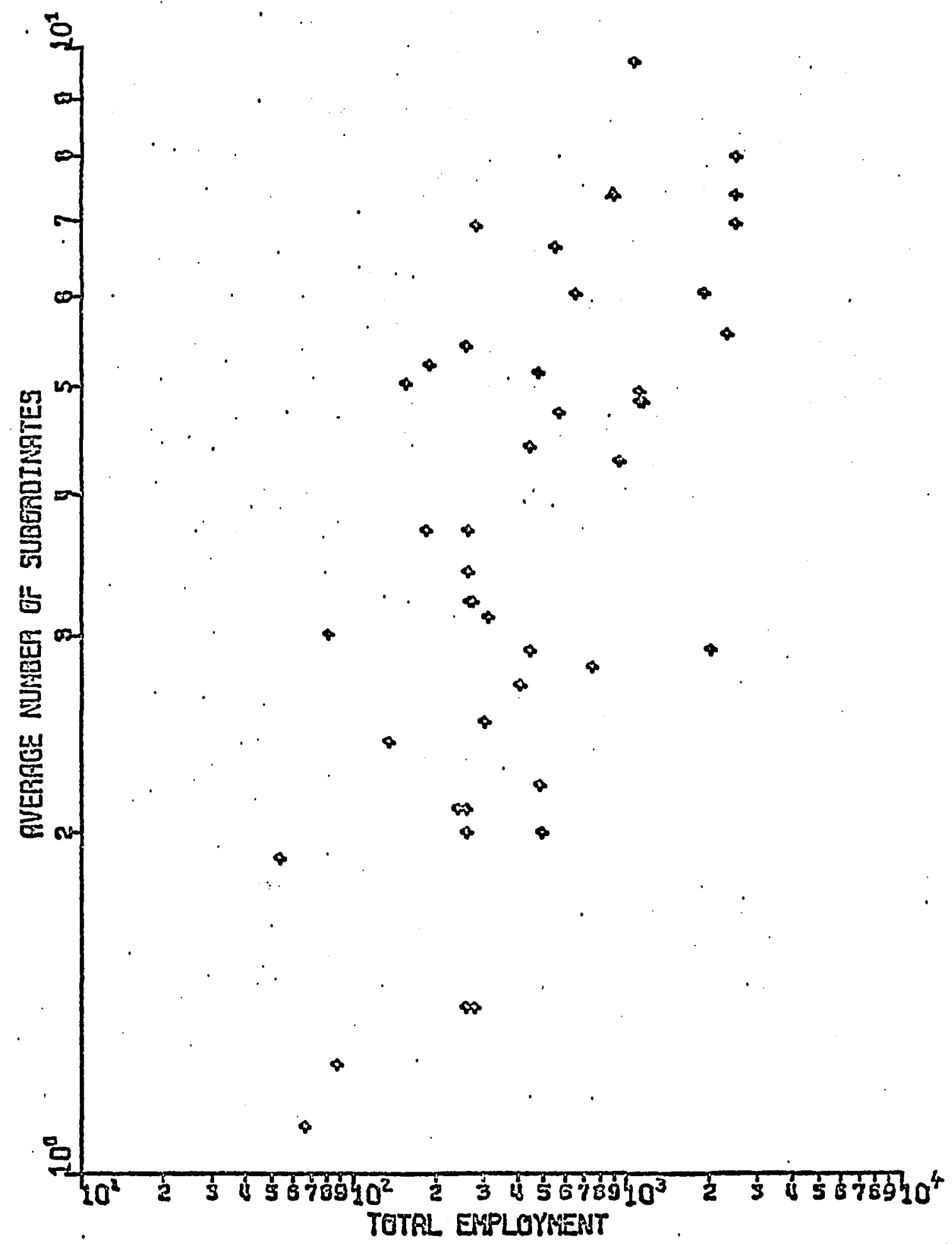

. Figure 2-2. Average Number of Subordinates as a Function of Size 
of enterprise size.

\section{Unit of Supervision}

The management literature seems to be in general agreement that the first-line supervisor can supervise more men than higher echelon managers. To distinguish this supervisory role from the span of control of top management, the span of the first-line supervisor is often called "unit of supervision." Despite this theoretical distinction there are few studies that report on the actual size of this unit of supervision. Joan Woodward reported on 100 British firms and found that "the number employed [the size of the firm] did not have as much effect on the size of the span of control of the first line supervisor... as might be expected."10 Mason Haire reported: "The ratio of supervisors to supervised does not go up as the company grows. On the contrary, as the line increased, each supervisor was responsible for more men."11 Woodward's study was based on cross-sectional data. Haire's empirical data came

10 Joan Woodward, Industrial Organization: Theory and Practice (London: Oxford University Press, 1965), P. 31, compare pp. 30-33.

${ }^{11}$ Mason Haire, "Biological Models and Empirical Histories of Growth of Organizations" in Mason Haire (ed.), Modern Organization Theory (New York: Wiley, 1959), p. 296? 
from a time series analysis. It appears that the method of data collection influences the conclusion reached. Crosssectional and time series studies seem to give different results which might be an indication that there are many factors other than size that may contribute to the differences; e.g., historical and traditional patterns in the firm and perhaps technology.

The information about the size of the unit of supervision for this study stems from a cross-sectional inquiry. This may be the reason that it shows that same inconclusive picture that Woodward reports. Figure 2-3 depicts the relationship between unit of supervision and size of the firm. The points vary in a broad range from 10 as the lower limit to 50 as the upper limit.

Visual inspection does not suggest any meaningful trend for which a regression line could be calculated. This tends to reinforce the writer's impression that factors other than size make for larger or smaller units. These factors could to be traditional patterns within the company and perhaps technology. Unfortunately, tradition is hard to assess with a one-shot cross-sectional data collection method. The influence of technology on the size of the unit of supervision will be analyzed in Chapter IV and in 


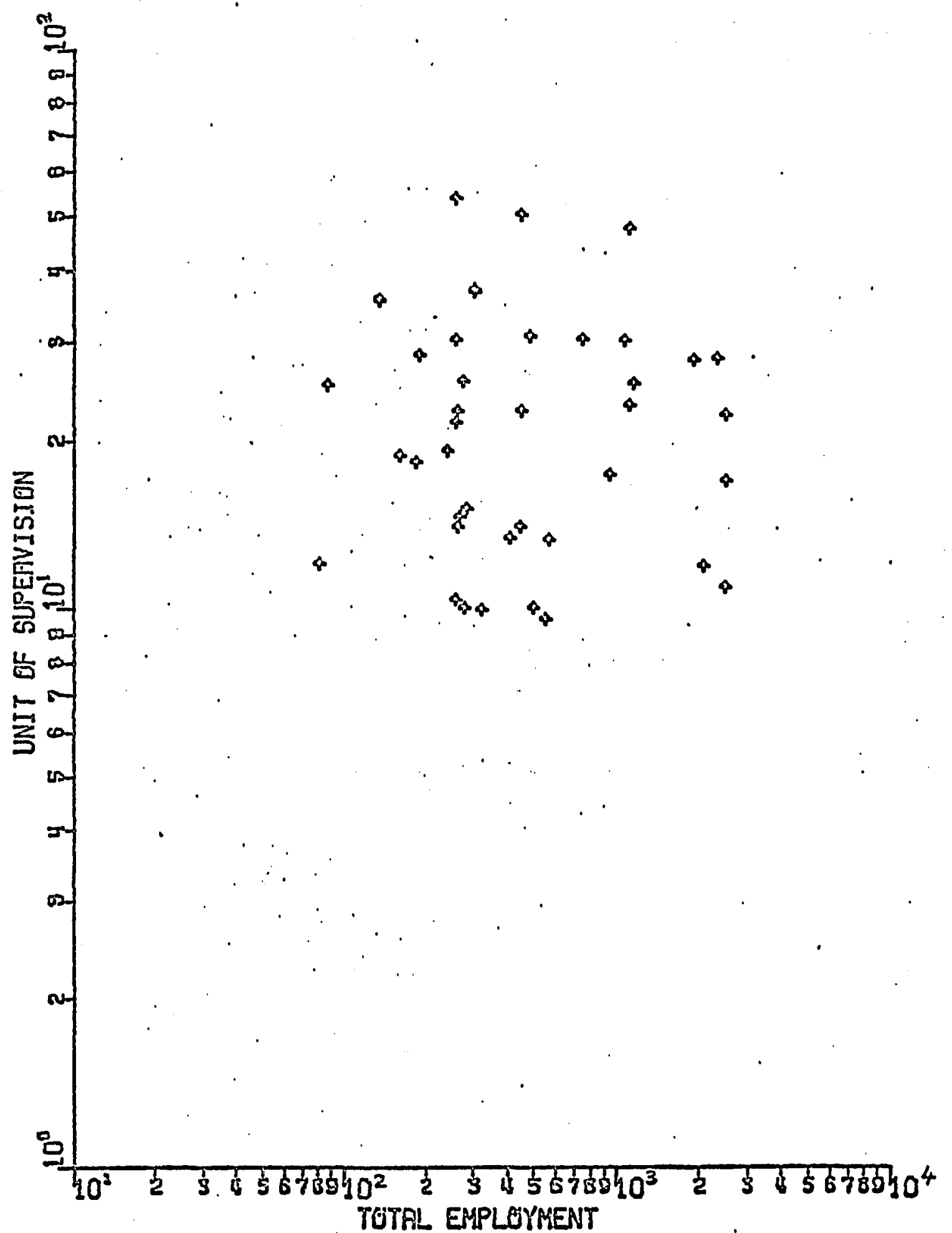

Figure 2-3. The Unit of Supervision as a Function of. Size 
Appendix B, Table B-2. Other studies that shed some light on the influence of technology have been reviewed by Starbuck. ${ }^{12}$

The analysis of the unit of supervision shows that the search with univariate methods for causes of seemingly simple relationships is not at all simple. AIthough the varying sizes of the unit of supervision do not seem to be related to any readily apparent factor, the concept Itself can be used to estimate the extent of division of labor within the surveyed companies. This will be attempted next.

\section{Division of Labor}

Division of labor is a familiar concept of everyday speech. Ever since Adam Smith, division of labor has been praised for contributing to efficiency and higher output and damned for degrading man's faculties and causing boredom and monotony on the job. The meaning of this concept is widely understood but an operational definition capable of measurement has been lacking. Recently Gibbs and Martin proposed a measure to estimate

${ }^{12}$ Starbuck, op. cit., pp. 502-505. 
the extent of division of labor of economies and societies. 13 Rushing applied this concept to evaluate the effects of industry size and division of labor on the size of the administrative component of industries. 14 In this study the Gibbs-Martin formula will be applied to estimate the extent of division of labor within the surveyed companies. A value of $D=$ Division of Labor close to. 0 implies little division of labor, a value close to 1 , high division of labor.

The Gibbs-Martin equation is $D=1-\frac{\Sigma X^{2}}{(\Sigma X)^{2}}$ $x=$ the number of persons in an occupation, e.g., lathe operators, mechanics, and assemblers.

$\Sigma x=$ all individuals belonging to a company, an industry, or a society.

The questionnaire did not call for a detailed enumeration of all occupations within a firm. However, the writer thinks that the occupational categories can be

13 Jack P. Gibbs and Walter T. Martin, "Urbanization, Technology, and the Division of Labor: International Patterns," American Sociological Review, October, 1962, p. 669 .

14 William A. Rushing, "The Effects of Industry Size and Division of Labor on Administration, "Administrative Science Quarterly, September, 1967, pp. 273-295. 
approximated, at least in direct production. The unit of supervision of a first-line foreman generally will be quite homogeneous with respect to occupations. For example, lathe operators will probably belong to units of supervision made up primarily of other lathe operators, similarly assemblexs will also tend to belong to homogeneous units of supervision. If this holds true, then division of labor may be estimated by

$$
D=1-\frac{U^{2} \cdot n}{(U \cdot n)^{2}}
$$

whers, $U=$ average unit of supervision

$\mathrm{n} \quad=$ number of first-line supervisors

$U \cdot n=$ total number of direct production workers.

To be sure, this is a rough approximation depending very much on the assumption about homogeneous occupational units of supervision. Nonetheless, this measure seems to point out differences about division of labor and related concepts in the smallex and larger companies. The larger companies show greater diviston of labor than the smaller companies, 0.94 versus 0.82 . Although division of labor by itself is not very meaningful, it can be combined with other information for further analysis of differences between large and small firms.

At this point it may be appropriate to summarize the 
survey results with respect to the differences between large and small firms. What influence have varlations in span of control, average number of subordinates, etc. on the relative size of the administrative component in the small and large companies? In conjunction with information indicative of productivity and resource utilization some preliminary statements about the relative efficiency of the small and large firms can be made.

\section{Efficiency Relative to Size}

Some of the foregoing investigations pointed to the fact that the large companies may have a relatively smaller administrative overhead due to larger spans of control, more subordinates per superior and so forth. In order to facilitate the discussion, information thought relevant in this respect has been summarized in Table 2-3.

At first glance several important differences are apparent from Table 2-3. The larger companies allocate less manpower to manufacturing and administration and achieve higher sales per employee and production worker. The marketing and the $R \& D$ activities both of which help to strengthen the competitive position of the firm receive a larger share of the manpower in the larger firms. Also, division of labor is greater in the larger firms and fixed 
TABLE 2-3

Employment and Efficiency Data in Reiation to Size*

\begin{tabular}{|c|c|c|c|c|}
\hline \multirow{2}{*}{ Characteristics } & \multicolumn{2}{|c|}{$\begin{array}{c}\text { Total Sales } \$ 10 \text { Million } \\
\text { and Over }-27 \text { Firms }\end{array}$} & \multicolumn{2}{|c|}{$\begin{array}{l}\text { Total Sales Under } \$ 10 \\
\text { Million }-23 \text { Firms }\end{array}$} \\
\hline & - Mean & $\begin{array}{l}\text { Standard } \\
\text { Deviation }\end{array}$ & Mean & $\begin{array}{l}\text { Standard } \\
\text { Deviation }\end{array}$ \\
\hline Employment Data: & & & & \\
\hline $\begin{array}{l}\text { Sales/Marketing } \\
\text { Manufacturing } \\
R \& D \text {, Engineering } \\
\text { General Administration } \\
\text { Efficiency Data: }\end{array}$ & $\begin{array}{r}11.3 \% \\
73.5 \% \\
6.8 \% \\
8.4 \% \\
100.0 \%\end{array}$ & $\begin{array}{r}10.7 \% \\
14.9 \% \\
6.1 \% \\
.4 .1 \%\end{array}$ & $\begin{array}{r}8.7 \% \\
76.5 \% \\
5.2 \% \\
9.6 \% \\
100.0 \%\end{array}$ & $\begin{array}{r}6.8 \% \\
12.8 \% \\
7.1 \% \\
7.1 \%\end{array}$ \\
\hline $\begin{array}{l}\text { Sales per Employee } \\
\text { Sales per Production Worker } \\
\text { Fixed Assets per Production Worker } \\
\text { Division of Labor } \\
\text { Capital-Output Ratio }\end{array}$ & $\begin{array}{r}\$ 28,640 \\
\$ 60,015 \\
\$ 9,596 \\
0.94 \\
0.69\end{array}$ & $\begin{array}{l}\$ 13,230 \\
\$ 35 ; 705 \\
\$ 6,374 \\
0.05 \\
0.17\end{array}$ & $\begin{array}{r}\$ 20,200 \\
\$ 48,222 \\
\$ 11,288 \\
0.82 \\
0.63\end{array}$ & $\begin{array}{c}\$ 5,350 \\
\$ 54,096 \\
\$ 16,177 \\
0.15 \\
0.27\end{array}$ \\
\hline
\end{tabular}

*Differences are not significant at a probability level of $p=0.05$ 
assets expended per production worker is lower. This indicates that the larger firms are able to streamline their production process through higher division of labor and thus utilize their fixed assets better. All of this apparently leads to higher sales revenue per employee. The evidence of Table 2-3 seems to indicate that the large companies enjoy economies of scale or more simply: it appears to be advantageous to be big.

The only measure of relative efficiency where smaller companies seem to have advantages is the Capital-Output Ratio (CO Ratio) or the reciprocal of the CO Ratio, the asset turnover. The Capital-Output Ratio = Total Assets/ Total Revenue is a measure of total asset utilization regardless of whether the assets are contributed by equity holders or creditors. The higher the Co Ratio the lower the asset utilization. In connection with the operating profit margin the return on assets can be calculated. However, size in terms of dollar sales may not be the most appropriate variable to relate the Co Ratio to. There have been a number of hypotheses which infer that the CO Ratio is dependent on the degree of diversification. The greater the diversification the more assets are being tied up to support the diverse operations of the firm; $1 . e .$, the 
higher the Co Ratio. This relationship will be more fully discussed in Chapter IV when the influence of technology will be investigated.

Although there are indications that the larger firms have advantages, the proportional increase of the CapitalOutput Ratio in relation to size, points out that the advantages have their limits. Even so, increasing plant size may initially have favorable effects, increasing diversification as a result of this growth may well act to offset the initial advantages. In addition, another final word of caution should be added. The mean is simply an average and not a performance yardstick. The differences from company to company, as reflected in the standard deviation, were quite large. Also, statistical tests of significance indicated that the differences could be chance variations.

The preceding analysis of the relative efficiency of large and small firms concludes this chapter and the analysis of individual variables in relation to other individual variables. The results thus far point out that variables in industrial organizations are highly interrelated. Treating individual variables in isolation may easily lead to erroneous conclusions. It appears that 
meaningful analyses of highly interrelated systems have to be approached with tools of analysis that can handle numerous variables simultaneously and not with univariate methods. Such multivariate analyses will be performed in the next two chapters.

\section{Conclusions}

The analysis of the empirical information collected for this study resulted in some interesting though very tentative findings. First, the relative importance of managerial objectives is influenced by the size of the business enterprise. The management of smaller companies appears to put more emphasis on sales than on profits. The larger firms are more people-oriented and smaller firms put more emphasis on production. This may imply stronger growth motivation among smaller companies. Second, the span of control of the chief executive has a tendency to increase as the size of the firm increases. This rise may be attributable to decentralization and staff differentiation. Third, the average number of subordinates per superior tends to rise as a function of size. This relatively larger supervisory overhead of the small firms, may stem from a tendency to imitate the organizational structure of large firms. Fourth, the size of the unit of 
supervision appears to be unaffected by size of the enterprise. It may be that the unit of supervision is more affected by traditional pattern or technology in the firm. Fifth, large firms appear to have a greater division of labor which may contribute to better resource utilization. Sixth, large companies tend to have a smaller administrative overhead, are able to generate more sales revenue per employee, and employ less fixed assets per production worker. The advantages of scale are counteracted by lower asset turnover ratios which may be attributable to ill effects of diversification. This, in effect, precludes a final judgment as to whether large companies are on the average more efficient or more profitable.

The analyses of this chapter demonstrated some of the difficulties associated with treating individual variables in isolation. Hypotheses may be refuted or fail to be refuted on the basis of inappropriate data. Since phenomena in industrial organizations are highly interrelated it appears that the influence of many variables has to be analyzed simultaneously. Such a research approach will be taken in the next two chapters. Factor analysis will be applied to isolate factors that may be related to the dimensions of classical and behavioral 
organization theory discussed in Chapter I or may reveal dimensions not considered before. 


\section{CHAPTER III}

\section{MULTIVARIATE ANALYSIS OF ORGANIZATIONAI PHENOMENA}

In the preceding chapter individual variables were analyzed in relation to other individual characteristics of the firm. For example, the relative importance of managerial objectives and the span of executive control were investigated relative to the size of the enterprises. Industrial organizations have literally thousands of such characteristics that can be measured and intercorrelated. Even though such analysis would certainly be comprehensive, it is doubtful that it would yield any meaningful conclusions. One aim of scientific inquiry is the reduction of the dimensions of such problems and the condensation of information in order that phenomena may be described or explained in terms of relatively simple theories. Factor analysis is a useful method in reducing information to manageable proportions. It serves the 
cause of scientific parsimony. ${ }^{I}$ Therefore, factor analysis will be employed here to analyze the data in the search for hypotheses about organizational phenomena.

\section{Nature of Factor Analysis}

Although relatively new in organizational research, factor analysis is a standard method of analysis in psychological investigations. Much of the statistical theory of factor analysis involves advanced matrix algebra and does not lend itself to simple exposition. In addition, many issues in factor theory are not completely settled and still debated among mathematicians and statisticians. For these reasons the reader is referred to the standard literature for authoritative information. ${ }^{2}$ Only an

$1_{\text {Fred N. Kerlinger, Foundations of Behavioral Research }}$ (New York: Holt, Rinehart and Winston, 1964), p. 650 .

${ }^{2}$ References of an introductory nature are Charles $\mathrm{K}$. Ramond, "Factor Analysis: When to Use It," in Abe Shuchman (ed.), Scientific Decision Making in Business (New York: Holt, Rinehart and Winston, 1963), pp. 235-242 and Raymond B. Cattell, "Factor Analysis: An Introduction to Essentials, I. The Purpose and Underlying Models," Biometrics, March, 1965, pp. 190-215. Rigorous and exhaustive treatments of factor analysis are presented in Harry H. Harman, Modern Factor Analysis (Chicago: University of Chicago Press, 1960), M. G. Kendall, A Course in Multivariate Analysis (Hafner Publishing Company, 1957), and Paul Horst, Factor Analysis of Data Matrices (New York: Holt, Rinehart and winston, 1965). 
intuitive understanding of what factor analysis does will be given here.

Essentially factor analysis seeks to discern from the vast amount of data that confronts the researcher, some fundamental dimensions or factors which may be responsible for the variation in the data. Used this way, factor analysis is a hypothesis or model-seeking research tool. ${ }^{3}$ The first step toward the discovery of these more fundamental dimensions is the intercorrelation of all variables ( $n$ ) that have been selected for analysis. This will generally lead to groups or clusters of variables that are highly intercorrelated. A factor is an abstract measure of these groups of intercorrelated variables. If one envisions the intercorrelations as points in a n-dimensional space (hyperspace), then the highly correlated variables will form a number of clusters in this hyperspace.

3 Factor analysis as used in this research actually is principal component analysis. In principal component analysis, the research works from the data to the model. The correlation matrix contains $I^{\prime}$ 's in the main diagonal and the resulting components are based on the total variance. This approach avoids the so-called communality problem; i.e., the estimation of the variance attributable to common factors. Good treatments of the problems connected with communality estimation are found in Kendall, op. cit., Chapters 2 and 3 and Cattell, op. cit., pp. 198-204. 
The purpose of the factor analysis is to place m "principal axes" or principal factors through these clusters in the hyperspace so that these principal axes will account for most of the variance of the variables, $m<n$. The extent to which a variable measures a factor is the degree to which it is saturated or loaded with the factor. The factor loadings should be viewed as correlations between factors (as abstract measures) and the variables.

After the principal axes or principal factors have been located it is often desirable to transform them mathematically. This transformation is the so-called factor rotation. There are orthogonal and oblique rotational methods. In an orthogonal rotation the factors, as reference vectors, remain independent, uncorrelated, or rectangular. An oblique rotation leads to dependent or correlated factors. The researchers who view the dimensions of organizational phenomena as correlated prefer oblique rotations, others who search for independent dimensions plead for orthogonal rotations. For purposes of comparison, both types of rotations have been performed in this study.

Factor Analysis of the Data The preceding section introduced some theoretical concepts of factor analysis. This section deals with the 
factor analysis of the 50 business enterprises that have been surveyed. Actually the material presented here is the residue of several factor analytic studies that preceded this one. In the process of an exploratory analysis such as this, a number of unforeseen circumstances arise that call for a change in the approach. One such change that appeared appropriate was the mathematical transformation of the raw data to a different scale.

Table 3-1 contains the means and standard deviations of 29 selected variables that have been analyzed. An inspection of the means and standard deviations of the raw data matrix indicated that the sample data does not follow the normal distribution. The standard deviations are large and exceed the mean in several cases. Such characteristics are more indicative of a Poisson distribution. In order to better approximate the normality theorem of correlation theory a transformation of the raw data seemed indicated. A number of transformation methods are reported in the literature: square root, logarithmic, inverse sine, and reciprocal. 4 For this data, the logarithmic transformation

${ }^{4}$ Allen I. Edwards, Experimental Design in Psychological Research (New York: Holt, Rinehart and Winston, 1964), pp. 128-131. 
TABLE 3-1

Means and Standard Deviations of the 29 Selected Variables for the Factor Analysis

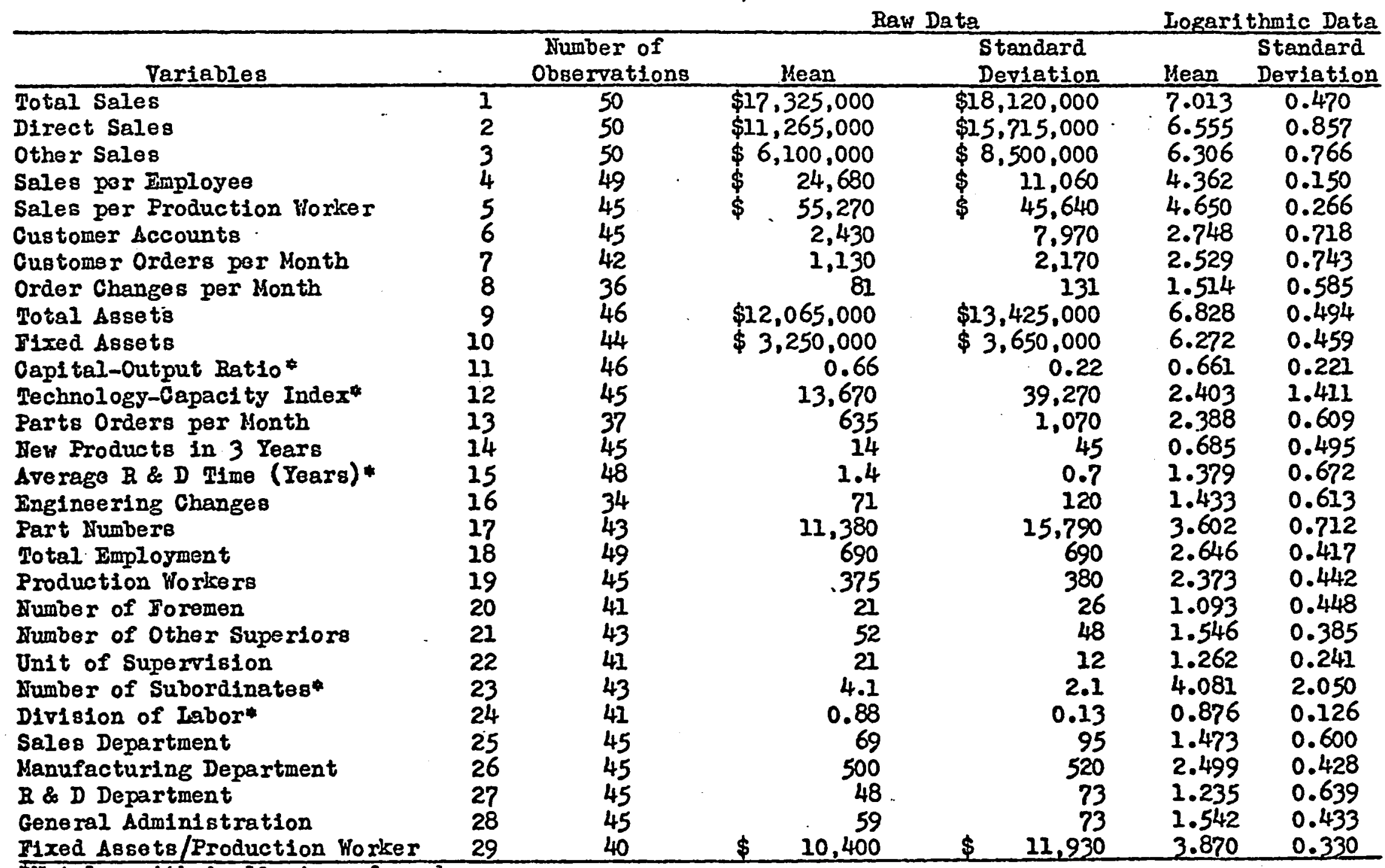

- Irot logarithmicelig transformed. 
gave the desired approximation of the normal probability curve as can be seen from Table 3-1. All analyses in this chapter are therefore based on logarithmically transformed data.

Intercorrelation of Organizational Variables

The intercorrelations of the logarithmically transformed data are presented in Table 3-2. The sheer size of the correlation matrix indicates the difficulties associated with the interpretation of intercorrelations. All correlations coefficients $r \geqslant 0.27$ are statistically significant at a probability level $\mathrm{p}=0.05$. The great number of significant (though not necessarily high) correlations prohibits a realistic analysis of all variables on an item by item basis. However, the correlation matrix contains some clusters of variables which are rather highly intercorrelated. For example, variables that could be regarded as measures of size have high intercorrelations ( $r>0.85)$ : Total Sales, Total Assets, Fixed Assets, and Total Employment. But there are also several other variables; e.g., Production Workers, Number of Foremen, Number of Other Superiors, which correlate highly with the measures of size. It appears that size has a strong influence in the intercorrelation matrix. 
TABIE 3-2

Intercorrelation Matrix of Selected Organizational Variables Based on Iogarf thmically Transformed Data*

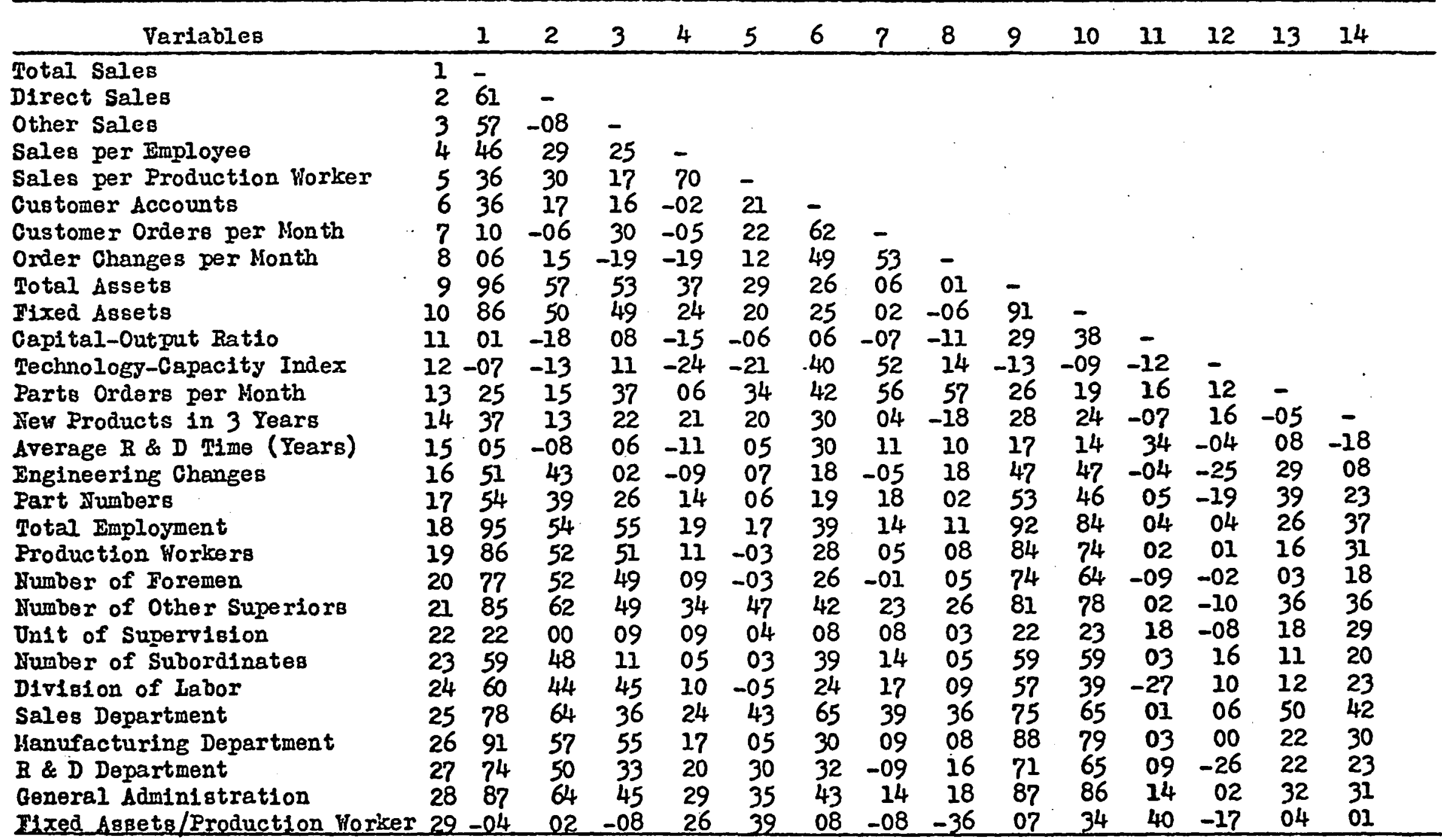


TABLE 3-2 (continued)

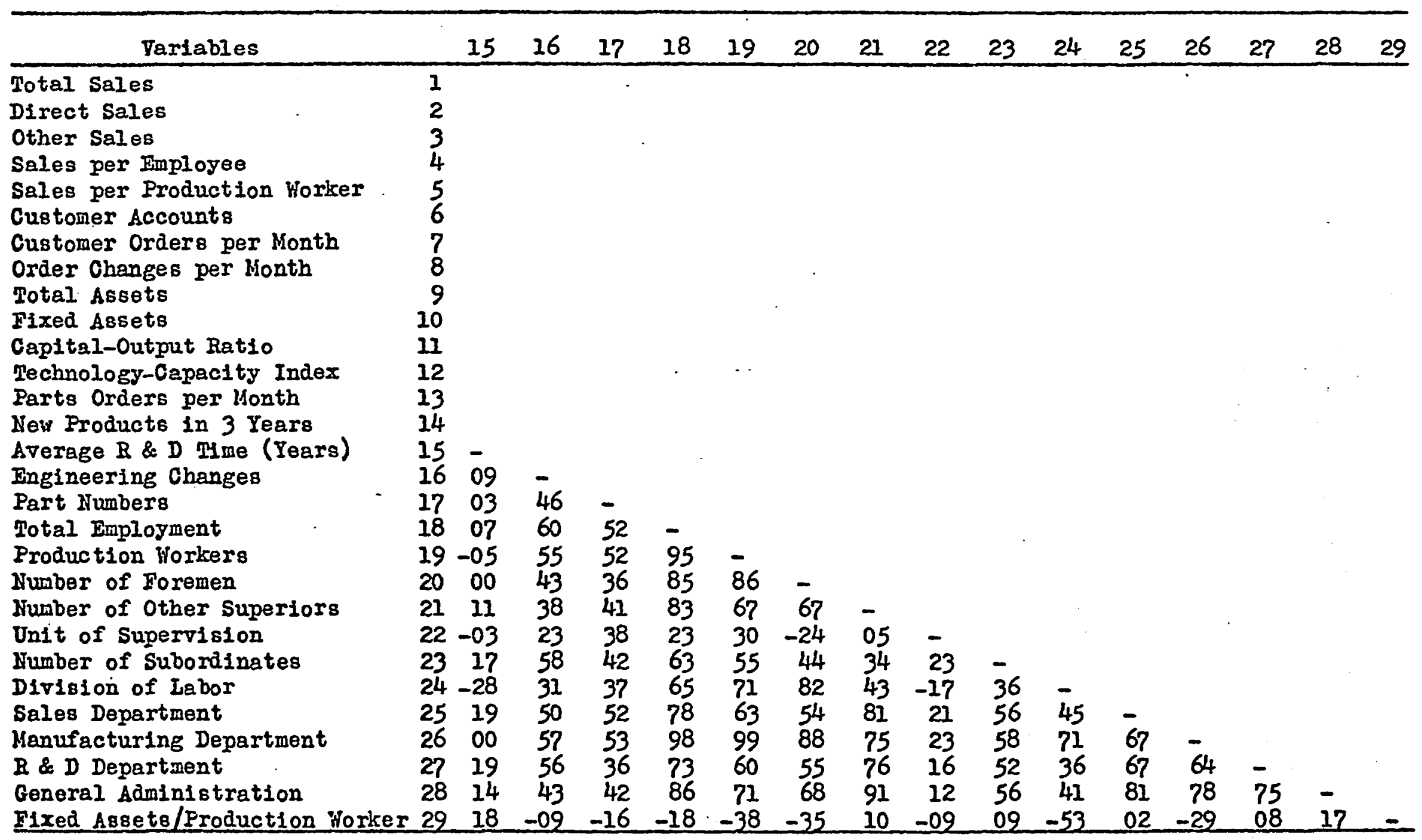

- Decimal omitted. Correlation coefficients $r \geqslant 0.27$ are significant at a probability level $p=0.05$. 
There are also indications of other clusters in the matrix; e.g., Sales per Employee and Sales per Production Worker; Customer Accounts, Customer Orders per Month, Order Changes per Month, though these clusters are not as pronounced as the size cluster. These clusters are formed with lower correlation coefficients indicating a lower degree of interrelationship. The inconclusive picture of the correlation matrix calls for further analysis of the data. Therefore the factor analysis of the intercorrelations is present below. But in the interpretation of the factors, reference will also be made to the correlation matrix of Table 3-2.

\section{Varimax Factor Rotation}

The factor analysis of the correlation matrix resulted in the rotated factor matrix given in Table 3-3. The seven rotated factors account for 84.1 per cent of the variance which is sufficient for meaningful interpretation. Factor loadings below 0.40 have been deleted from the matrix because they are generally considered insignificant in orthogonal rotations. The orthogonal factor structure of Table 3-3 was 
obtained by employing the varimax rotation criterion. 5 This mathematical criterion has several attributes that merit explanation. First, the factors, as reference vectors, remain essentially uncorrelated or independent after the rotation. Thus, the factors can be regarded as independent dimensions of the analyzed organizational variables. Second, varimax solutions tend toward invariance. This means that the varimax rotated factor structure exhibits stability; the factors tend not to change with changes in the number and composition of variables. This is a most important property if the investigator was unfortunate to select variables that are not "representative of a wide range of phenomena." Third, varimax has a tendency to simplify the columns or the factors of the matrix rather than the rows or variables. This results in high loadings for a few variables and low or near zero loadings for most others. In summary, varimax has a tendency to define mathematically the idea of simple structure.

The notion of simple structure in factor analysis

5H. F. Kaiser, "The Varimax Criterion for Analytic Factor Rotation," Psychometrika, September, 1958, pp. 187-200. 
stems from the psychologist Thurstone. It is simply the desire to explain the multitude of psychological phenomena in simpler terms. This is in accord with the general aim of science to describe a wide range of phenomena with the simplest theories. In terms of factor analysis this means that each variable measures fewer factors than are contained in the data and each variable measures a different combination of factors. This is achieved when the variables have high loadings on one factor and small loadings on others. And this is what varimax tends to accomplish. Interpretation of Orthogonal Factors

The interpretation of factors is based on the loadings pattern of the variables and is always highly tentative. The researcher will carefully examine the variables with the highest loadings and then hypothesize about the causes of the variability of the data. Such inferential or "explanatory" factor interpretation leads to factors with theoretical meaning beyond that contained in the empirical facts. Strictly "descriptive" factor analysis views the identified factors as parsimonious description of the variability of the data. ${ }^{6}$ Although this writer would

6s. Henryson, Applicability of Factor Analysis in the Behavioral Sciences (Stockholm: AImquist \& WickseIl, 1957), Stockholm Studies in Educational Psychology I, p. 86. 
have liked to limit himself to descriptive factors, the nature of the variables selected on a priori considerations made it necessary to hypothesize beyond the empirical facts.

Factor Ia. A cursory glance at Table 3-3 quickly reveals some difficulties of identification. Factor Ia accounts for almost 39 per cent of the total variance and is highly loaded on many variables instead of the few required for simple structure considerations. The loading pattern of this factor seems to be indicative of a fundamental problem in the design of this survey. The writer who selected the variables on a priori grounds hoped that they would be representative of a great variety of forces that shape business enterprises. The loading pattern of Factor Ia indicates that he was not that fortunate. The many loadings with magnitudes of 0.40 and greater indicate that all these variables measure largely one factor. Because the variables Total Sales, Total Assets, Fixed Assets, and Total Employment show the highest loadings, this factor may be indicative of the size of the firms.

The test of whether Factor Ia actually is strongly influenced by only one real factor; e.g., size, rest on the "confactor" or "proportionate profile" principle, some 
Varimax Rotated Factors and Factor Loadinga Based on Logar1thmically Transforwed Data*

\begin{tabular}{|c|c|c|c|c|c|c|c|c|}
\hline Variables & & Ia & IIa & II Ia & IVa & $\nabla a$ & $\nabla I a$ & VIIR \\
\hline $\begin{array}{l}\text { Total Sules } \\
\text { Direct Sales } \\
\text { Other Sales } \\
\text { Sales per Employee } \\
\text { Sales per Production Worker } \\
\text { Customer Accounts } \\
\text { Customer Orders per Monti } \\
\text { Order Changes per Month } \\
\text { Totel Assets } \\
\text { Fixed Assets } \\
\text { Capital-Output Ratio } \\
\text { Technology-Capacity Index } \\
\text { Parts Orders per Month } \\
\text { New Products in } 3 \text { Years } \\
\text { Arerage B \& D Time (Years) } \\
\text { Engineering Changes } \\
\text { Part Numbers } \\
\text { Total Enployment } \\
\text { Froduction Workers } \\
\text { Wumber of Foremen } \\
\text { Number of Other Superiors } \\
\text { Unit of Supervision } \\
\text { Number of Subordinates } \\
\text { Division of Labor } \\
\text { Sales Department } \\
\text { Manufacturing Department } \\
\text { R \& D Department } \\
\text { General Administration } \\
\text { Fixed Assets/Production Worker }\end{array}$ & $\begin{array}{l}1 \\
2 \\
3 \\
4 \\
5 \\
6 \\
7 \\
8 \\
9 \\
10 \\
11 \\
12 \\
13 \\
14 \\
15 \\
16 \\
17 \\
18 \\
19 \\
20 \\
21 \\
22 \\
23 \\
24 \\
25 \\
26 \\
27 \\
28 \\
29\end{array}$ & $\begin{array}{l}.59 \\
.51 \\
.97 \\
.92 \\
.90 \\
.82 \\
.63 \\
.69 \\
.74 \\
.95 \\
.76 \\
.86\end{array}$ & $\begin{array}{l}-.55 \\
-.73 \\
-.87\end{array}$ & $\begin{array}{l}.82 \\
.88\end{array}$ & $\begin{array}{c}.79 \\
.67\end{array}$ & $\begin{array}{r}. .82 \\
. .56\end{array}$ & -.92 & $\begin{array}{r}-.48 \\
.78\end{array}$ \\
\hline Percentage of Pariance ( $\left.\tilde{\rho}^{\prime}\right)$ & & 20.8 & 9.9 & 9.1 & 8.0 & 6.5 & 6.3 & 5.6 \\
\hline
\end{tabular}


technical difficulties of which, are not yet completely solved. This test requires a second experiment with the same variables on two distinctly different populations. Perhaps, an experiment in which size of all firms is. relatively uniform in each sample but the sample means are quite different. If size is really the responsible factor, then a proportionate change in the loadings of this factor should take place from experiment A to experiment B. This is because the magnitude of the influence of this factor changes by performing these two experiments. 7

The experimental design required by the confactor principle was approximated by dividing the survey returns into small and large companies. The 23 firms with sales under $\$ 10$ million formed the small group and the 27 firms with sales of $\$ 10$ million or more, the large group. A factor analysis on these two samples did indeed reduce the effect of size measurably. For the sample of the small firms the variance accounted for by the size factor was reduced to 23 per cent (from 39). For the large firms the reduction was not that marked, from 39 to 30 per cent. Because not all of the requirements of a confactor

${ }^{7}$ Cattell op. cit., pp. 207-208. 
experiment were strictly fulfilled, the loadings pattern did not correspond to a proportional change. Although this experiment did not give conclusive results with regard to the confactor principle it points out some important considexations for the selection of the sample and the variables. Further factor analyses should give greater attention to the confactor principle in the experimental design.

At the time this writer was working on this research project--data collection and analysis--he was unaware of other investigators working in the same general area of factor analysis of organizational phenomena. Recently two publications appeared which allow an interesting comparison of the findings of this study with those of the other two studies. Seashore and Yuchtman who analyzed time series data on independent insurance agencies reported a factor named "business volume."8 This factor appears to be very closely related to the size: factor of this study. Eddy, Boyles, and Frost who worked with time series data of an appliance maker reported also a factor that is highly

${ }^{8}$ Stanley E. Seashore and Ephraim Yuchtman, "Factorial Analysis of Organizational Performance," Administrative Science Quarterly, December, 1967, pp. 377-395. 
loaded on variables indicative of size; e.g., direct and indirect labor force, and number of salaried personnel. 9 Although Eddy et.al. interpreted their factor as indicative of efficiency in the light of the Seashore-Yuchtman study and this research project, it seems more appropriate to view their factor also as measuring size.

The factor analysis of this data appears to reinforce the general impression formed in Chapter II. Size has an important influence on the characteristics of business enterprises. The comparison with the other two factor analytic studies shows that the method of data collection does not have as much influence on the factors extracted as this writer initially suspected. This study based on crosssectional data as well as the other two studies based on time series data all reveal size (and two other factors discussed below) as an important force. Perhaps size can be viewed as a common factor (a factor measured by many varlables) for further factor analytic study of organizational phenomena. ${ }^{10}$

${ }^{9}$ William B. Eddy, B. R. Boyles, and Carl C. Frost, "A Multivariate Description of Organization Process," Academny of Management Journal, March, 1968, pp. 49-61.

${ }^{10} \mathrm{~A}$ factor that is present in all variables of an experiment is called a general factor. Factors that are being measured by several variables simultaneously (but not all) are called group factors. Both the general factor and the group factors are referred to as common factors. 
However, because each of these three different studies used different variables, each led also to a series of specific factors, peculiar to the variables considered. Therefore, in the analysis of the other factors of this research project, only when a relationship to apparently comon factors exists, will the other two studies be brought into the discussion.

Eactor Ila. The variables most highly loaded on this factor are Customer Accounts, Customer Orders per Month, Order Changes per Month, Parts Orders per Month, and Sales Department. It seems that these variables indicate the extent of customer orientation of the firm. Customer order changes are frequently delivery date changes to accommodate customers. Parts orders can be taken as an indication of the technical service rendered after the sale of a machine or equipment. Order changes and parts orders are, of course, also dependent on the number of customers a firm has. The incoming orders and the necessary order changes will also influence the number of people employed in the sales department. However, Factor $\mathrm{Ia}$ is higher loaded on Sales Department (0.74) than Factor IIa (0.41) demonstrating that the size of the firm has a greater influence on the size of the sales department than the extent of 
customer orientation does. At this point it is not clear why the variables loaded on Factor IIa represent an independent dimension. In the next chapter the analysis of these variables will be continued by investigating the influence of technology.

Factor IIIa. This factor seems to measure the extent of resource utilization. Sales per Employee and Sales per Production Worker both reveal the ability to utilize manpower resources efficiently: The loading on Fixed Assets per Production Worker, however, can be interpreted two ways. High fixed assets per worker could be a measure of mechanization. A high fixed asset per worker ratio could under certain circumstances; e.g., in small firms, Indicate Inefficient plant asset utilization relative to labor. At this point it is not clear what this loading pattern indicates. Further analysis of this loading pattern in the next chapter and in Appendix B is necessary before conclusions can be reached.

The dimension of resource utilization is also present in the Seashore-Yuchtman study who reported a "member productivity" factor. ${ }^{11}$ Similarly Eddy : et.al.

${ }^{11}$ Seashore and Yuchtman, op. cit., pp. 386-387. 
productivity factor loaded on such varlables as units per man-hour and factory overhead variance. ${ }^{12}$ It could very well be that these productivity factors reflect the monetary objectives of business organizations.

Factor IVa. This factor is loaded on the variables Capital-Output Ratio, Average R \& D Time, Division of Labor, and Fixed Assets per Production Worker. The negative loading on Division of Labor and the positive loading on Fixed Assets per Production Worker underlines the findings in the preceding chapter. There it was shown that lower division of labor was associated with higher fixed assets expended per worker, a fact which was attributed to the inability of the smaller companies to streamline their production systems as much as the larger companies. Moreover the negative loading of the variable Division of Labor on this factor is in accordance with the positive loading of this variable on the size Factor Ia.

The loading of the Capital-Output Ratio on Factor IVa underlines the importance of capital utilization in the business enterprise. The positive correlation of the Capital-Output Ratio and Fixed Assets per Production Workex could mean that firms which employ a lot of fixed capital in 12Eddy, et. 르., p. 57. 
relation to labor tend to have a low asset turnover (or a high capital-output ratio). The positive loading of Average $R \& D$ Time in connection with the other variables could mean that capital intensive firms have longer $R$ \& $D$ times or long $R \& D$ times tend to tie up a lot of capital. This aspect will be more fully explored in the next chapter. In view of the variables loaded on this factor it may be appropriate to relate this factor to the capital resource utilization in the business enterprise. Seashore and Yuchtman reported a production cost factor which has some resemblance to this Factor IVa. 13

Factor Va. This factor is loaded on the variables Customer Accounts, Customer Orders per Month, TechnologyCapacity Index (more fully explained in the next chapter), and New Products in 3 Years. A high Technology-Capacity Index indicates high volume output of low complexity products. Products that are technically not very complex are easier to develop and may therefore also have a higher rate of obsolescence. Consequently a larger number of new products may have to be introduced into the market. It appears, that this factor is related to the product strategy

${ }^{13}$ Seashore and Yuchtman, op. cit., p. 387. 
of the firm. The strategic decision as to what type of product to manufacture has several consequences. The nature of the product often determines the methods of distribution. A high volume product generally is correlated with a large number of customers. (There are exceptions; $0.8 .$, a high volume automotive parts production may be sold to only a few firms or plants). Again, the influence of technology will be more fully investigated in the next chapter.

In the other two studies there is also reference to a product strategy factor. Eddy et.al. reported a factor that is loaded on variables indicating the extent of company brand appliance production relative to contract brand production. Seashore-Yuchtman also reported a "business mix" factor. ${ }^{14}$ Their factor referred to the diverse types of insurance (products) that were marketed.

Factor VIa. This factor is loaded on the variables Part Numbers and Unit of Supervision. The connection of these two variables is not easy to see. However, in the next chapter and in Table B-2 of the Appendix it will be shown that the variable Part Numbers reflects a high technological content of the products. Thus there appears

${ }^{14}$ Ibid., p. 386 and Eddy, et.․‥, p. 58 . 
to be a relationship between technology and the size of the unit of supervision independent of the size of the firm. The appearance of Unit of Supervision as a separate factor indicates that differences in the supervisory style on the shop floor level are indeed important considerations and importantly influenced by technology. However, a factor loaded on only one or two variables should be interpreted with great care.

Factor VIIa. The smaller the variance for which a factor accounts, the greater the possibility of chance and error elements to play a role. Factors are usually interpreted in descending order of the magnitude of variance accounted for. Consequently, the last few factors are often the most difficult in terms of meaning. This factor is loaded on Engineering Changes, Other Sales, and Direct Sales. The relationship between Engineering Changes and the other two variables becomes only clear in conjunction with Table B-2 of Appendix B. Firms that tend to sell their products directly tend to have more engineering changes than firms which select other channels of distribution. This may be attributable to exposition of salesmen to customer wishes and pressure or more positively, direct selling may lead to more feedback for product 
improvement.

Discussion. At this point it may appear desirable to relate the orthogonal factors as discussed above to the dimensions and concepts of organization theory as they have been briefly reviewed in Chapter I. For example, are these orthogonal factors related to the dimensions of classical and behavioral organization theory? Although such a comparison may be very tempting at this point, this writer believes that further analysis of the data is necessary before this should be done. These additional investigations will involve canonical correlation, an oblique rotation of factors, and a detailed examination of the influence of technology.

Canonical Correlation of Orthogonal Factors

In the preceding section factor analysis and factor interpretation was discussed in some detall. It was stated that orthogonal rotations yielded factors with a maximum degree of independence. However, the discussion revealed also that many of the variables selected on a priori grounds measured only one factor--size. Several variables selected were factorially quite complex and measured more than one factor.

The notion of orthogonal rotation is often 
misinterpreted. Although the factors themselves (as reference vectors) are orthogonal; $1 . e .$, uncorrelated, the sets of variables, as estimators of the factors, may well be correlated. As a matter of fact, orthogonal factors may not necessarily be the most desirable rotational schemes for interpretation. It has been argued that the factors that reflect "natural" phenomena are interdependent or correlated. Such a methodological approach would lead to the search for correlated or oblique factors.

The uncertainty about the extent of which each of the loaded variables are estimators or their respective factors poses an interesting problem. A simple method of testing the degree of interdependence of factors is a graphical representation of the loadings of the rotated factors. This is depicted in Figure 3-1. Only the three highest loadings of the many highly loaded variables have been selected as estimators of Factor Ia: Total Sales, Total Assets, and Total Employment. The loadings of these three variables have been charted in relation to the loadings of the variables representing Factors IIa through VIIa. Visual inspection of the distribution of the loadings reveals that some of the varlables selected as estimators of Factors IIa through VIIa have substantial loadings on 

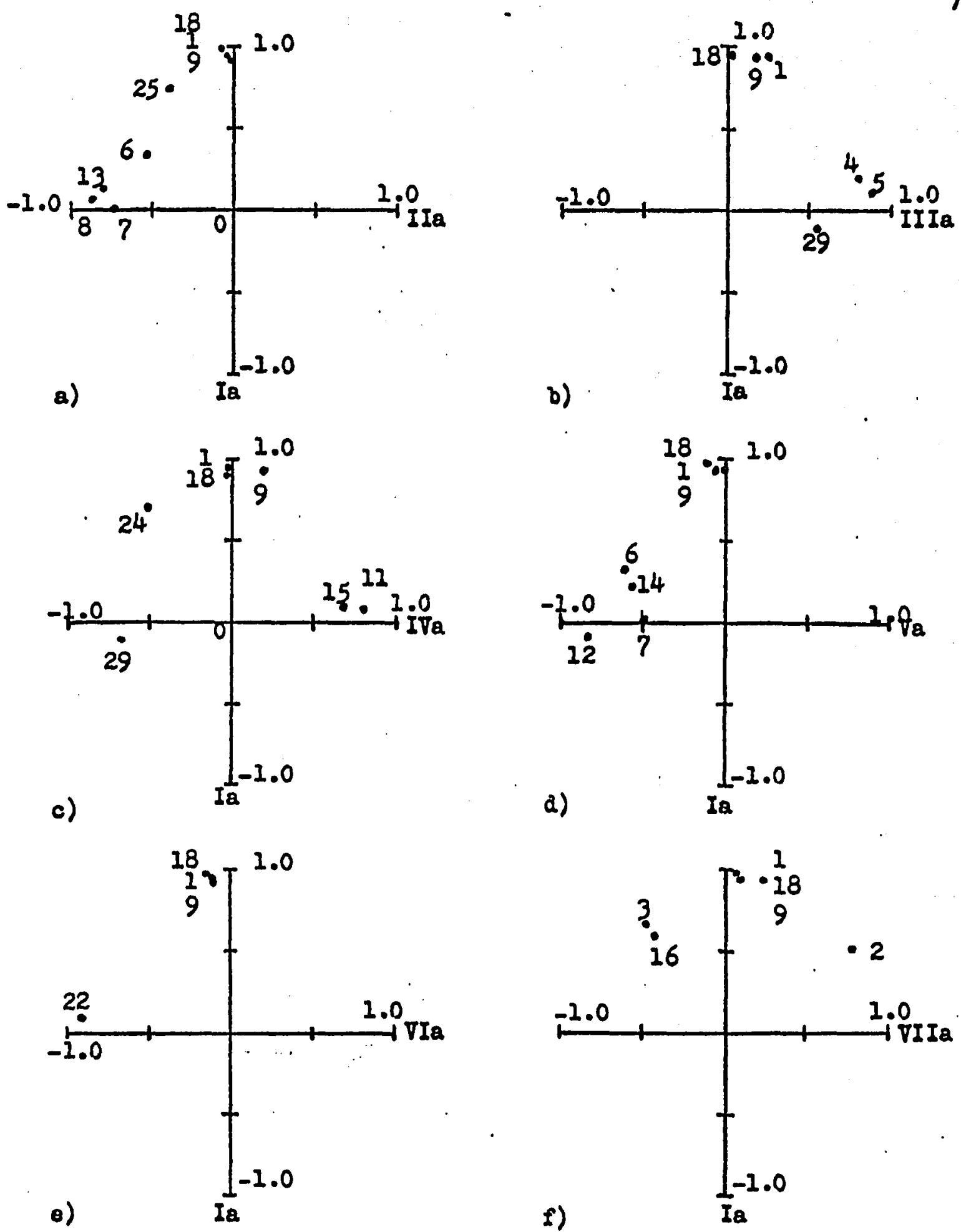

Figure 3-1. Graphical Ropresentation of Rotated Factor Ioadings of Varsmax Factors Ia Through VIIa (Numbers represent rarlables. For full name of variables compare rable 3-3) 
Factor Ia. This is a good indication that the variables as estimators of the factors may be correlated. In the case of 7 factors 21 intercorrelation coefficients are possible. However, the analysis will be limited to the 6 pairs of factors charted in Figure $3-1$.

Simple correlation measures the degree of relatedness between two individual variables-- one named dependent, the other independent variable. Multiple correlation techniques yield correlation coefficients between one dependent variable and a set of independent variables. Thus, in multiple correlation on one side of the equation multivariate statistics is being performed and the other side (the dependent variable) is treated as if it were univariate. This is clearly unsatisfactory for phenomena that cannot be reduced to one dependent variable. And this is the case in the interpretation of most factors. Thus, simple and multiple correlation methods are inappropriate to measure the extent of relatedness of sets of variables that estimate factors.

The method that yields correlation coefficients between two or more sets of variables is canonical analysis. It was only in 1935 that this method was developed by Hotelling and not until 1959 that it was extended to the case of more than 
two sets of variables. ${ }^{15}$ Although canonical correlation involves considerable matrix algebra, available computer programs have made this type of analysis feasible and desirable. A summary and an interpretation of the results of the canonical analysis is given below.

Interpretation of the Canonical Analysis

A glance at Table 3-4 reveals that the sets of variables which are highly loaded on Factors IIa, IIIa, IVa and VIIa are highly correlated with the set of variables loaded on Factor Ia. In other words there is a strong interdependence of the sets of variables that estimate the factors. This is in accordance with Figure 3-1. The sets with the highest correlation naturally are those that contain variables which are highly loaded on both factors. For instance, the high correlation between the variables loaded on Factors Ia and IIa, $r=0.904$, is largely attributable to the high loading of the varlables Sales Department and of Customer Accounts on Factor Ia. The degree to which each variable contributes to the correlation

15 Hotelling, "Relation Between Two Sets of Variables," Biometrika, Volume 28, 1936, pp. 321-377 and Paul Horst, "Relations Among m Sets of Measures," Psychometrika, June, 1961, pp. 129-149. 
TABIE 3-4

Canonical Analysis of 7 Factors Associated With the First Elgenvelue* Based on Logarithmically Transformed Data

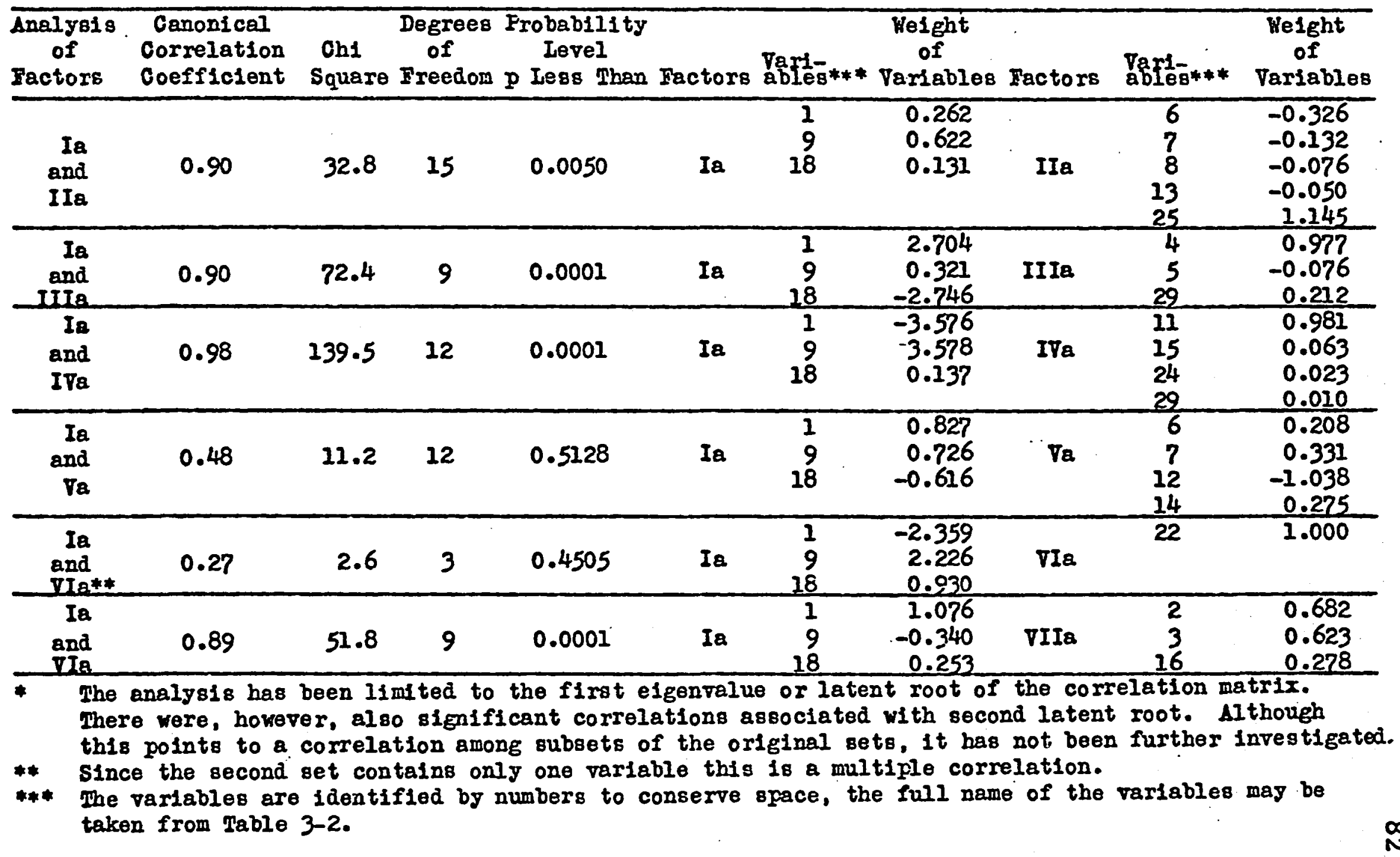


of the two factors can be estimated from the weights associated with the variables. Table 3-4 shows that the variable 25 (Sales Department) has a weight of 1.145. This is by far the largest weight of the four variables. In other words this variable contributes most highly to the maximum correlation between the two factors. Correlation coefficients between other factors and the respective graphical representation can be interpreted similarly. Table 3-4 shows that those factors that are highly correlated are also statistically significant at probability levels of $\mathrm{p}<0.005$ and $\mathrm{p}<0.001$. $^{16}$ Conversely the correlation of variables loaded on Factor Ia with those sets of variables loaded on Factors Va and VIa is low and also statistically not significant. This may suffice to demonstrate that the sets of variables that estimate the orthogonal factors are actually interdependent. The next logical step would be an oblique rotation of the component matrix to obtain correlated factors. A simple explanation

16The statistical significance of canonical correlations can be approximated with chi square, $x^{2}$, statistic and the statistic Wilks lambda $\lambda$. See $S$. Bartlett, "The Statistical Significance of Canonical Correlations," Biometrika, Volume 32, 1941, pp. 29-37. See also William W. Cooley and Paul R. Lohnes, Multivariate Procedures for the Behavioral Sciences (New York: John Wiley, 1962), Chapter 3 . 
of the nature of oblique rotations and the interpretation of the resulting oblique factors is given below.

Nature of Oblique Factor Rotation

Just as there are several criteria for orthogonal

factor rotation, there are also several criteria for

oblique factor rotation. One of the latest oblique

rotational criterlails maxplane. Developed by Cattell and

Muerle and perfected by Eber, it appears to become a standard

method of oblique rotation. ${ }^{17}$ Maxplane possesses several

features similar to varimax; e.g., it tends to rotate

factors according to simple structure considerations. In

addition, maxplane does include orthogonality as a special

case.

$17_{R}$. B. Cattell and J. L. Muerle, "The 'Maxplane' Program for Factor Rotation to Oblique Simple Structure," Journal of Educational and Psychological Measurement, Autumn, 1960, pp. 569-590. This original program was written for the Illiac computer at the University of Illinois. Dr. Eber of Birmingham, Alabama, improved and rewrote the program for the IBM 7094 computer system. The latter program was modified by the staff of the Louisiana State University Computer Research Center to be usable on the IBM 7040 model. See Herbert W. Eber, "Toward Oblique Simple Structure: Maxplane," Birmingham, Alabama, Unpublished Manuscript, 1965; accepted for publication by Multivariate Behavioral Research. 
The case for oblique factor rotation rests on the assumption that not only the variables but also the dimensions of organizational phenomena are correlated. Psychologists who subscribe to this view have designed elaborate experiments to show that relatedness of dimensions or factors is the case in nature in general and not only in psychology. ${ }^{18}$ Even so such arguments may appear plausible, they entail the danger of deriving conclusions to the effect that "everything is depending on everything else." Whether a researcher subscribes to the superiority of the oblique case or not, oblique rotated factors are always useful for comparison purposes.

Like orthogonal factors, oblique factors have to be interpreted with great care. Since this is the first oblique rotation on factors extracted from organizational data, the interpretation is even more speculative than in the orthogonal case. The results of the oblique rotation are presented in Table 3-5. In addition to the factor loadings, the correlation coefficients between the factors as reference vectors are also reproduced and could be used

$18_{R}$. B. Cattell and K. Dickman, "A Dynamic Model of Physical Influences Demonstrating the Necessity of Oblique Simple Structure," Psychological Bulletin, September, 1962, pp. 389-400. 
TABIT 3-5

Maxplane Hotated Factors and Factor Ioadings Based on Iogarithmically Transformed Data*

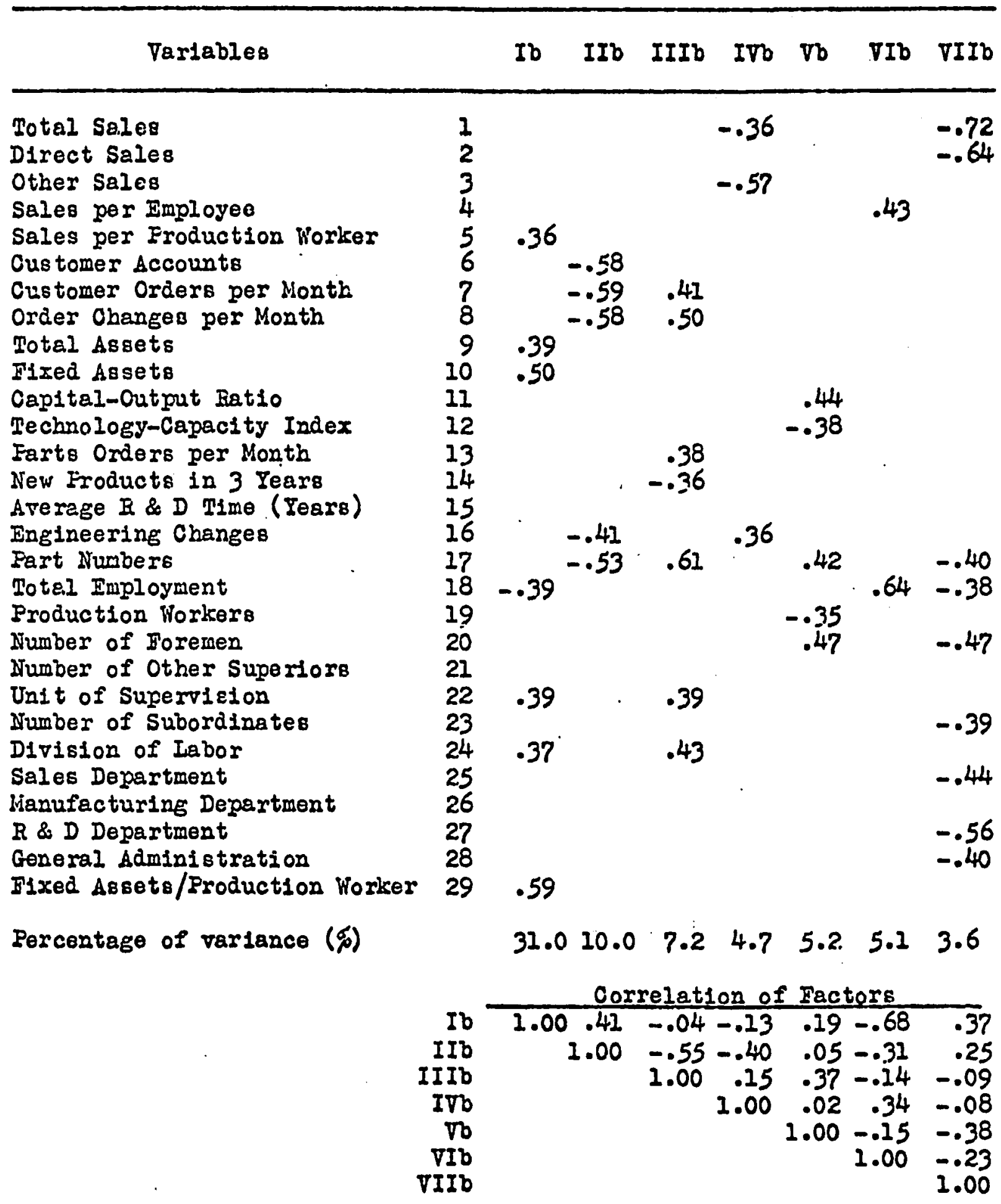

* Factor loadings amalier 0.35 omitted. 
for second-order general factor extraction. These correlation coefficients in the table are identical with the cosines of the reference vectors. On the average, the loadings are lower than in the orthogonal case. This may be due to the nature of the data but it may also stem from the different allocation of the variance under the maxplane rotation criterion. Since the discussion of the oblique factors will be in highly tentative terms, the oblique factors will be related back to their orthogonal counterparts where it seems appropriate.

Interpretation of Oblique Factors

Factor Ib. This factor does not seem to be related to Factor Ia of the orthogonal solution. The variables Total Assets, Fixed Assets, and Total Employment are indicative of size. The variables Sales per Production Worker, Unit of Supervision in conjunction with Division of Labor and Fixed Assets per Production Worker are indicative of manpower productivity and utilization. It appears that this factor measures the relationship between size and manpower utilization. In Chapter II is was shown that the larger firms had higher productivity figures for their employees. It could be that this factor reflects this condition especially since Total Employment is negatively loaded in 
contrast to the positive loading on the other variables.

Factor IIb. This factor resembles the orthogonal

Factor IIa quite closely. The variables Customer Accounts,

Customer Orders per Month, Order Changes per Month, and

Parts Orders per Month are the same as the variables loaded on Factor IIa. The addition of Engineering Changes per Month may even underline the extent of customer orientation. Engineering changes could be taken as a commitment on the part of management to improve products in response to customer wishes.

Factor IIIb. This factor contains variables that were also loaded on the preceding Factor IIb and the orthogonal Factor IIa. The relationship to Factor IIb is underscored through the fairly high correlation coefficient $r=-0.55$. The variables Customer Orders per Month, Order Changes per Month, Parts Orders per Month, and Part Numbers again seem to indicate the relationship between a substantial parts order business and the repercussions in the form of high parts inventory and a high volume of customer orders and order changes and possibly additional personnel to handle this service business. The negative loading on New Products in 3 Years indicates that this parts order business with all its ramifications seems to be related to products are 
technically more complex - fewer are developed in a 3 year period. The loading of Unit of Supervision and Division of Labor on this factor is related to the level of technology and will be investigated in the next chapter.

Factor IVb. This factor is related to the orthogonal Factor VIIa. The negative loading on Total Sales, Other Sales (sales through other channels than company salesmen), and the positive loading on Engineering Changes appears to indicate that firms which sell primarily through other channels receive less feedback for engineering changes or product improvement.

Factor $\mathrm{Vb}$. This factor may have some relationship with the orthogonal Factor Va. The inverse relationship between Technology-Capacity Index and Capital-Output Ratio reveals the tendency to higher asset utilization of the high volume firms. This is also underscored by the negative loading on Part Numbers. Low complexity-high volume products need fewer parts in inventory and may therefore tie up less. capital or have a more favorable Capital-Output Ratio. Thus, this factor may be indicative of the technological influences on the efficiency of asset utilization. The loading of the variables Production Workers and Number of Foremen on this factor appears to underscore this picture. High volume 
firms have a greater division of labor.

Factor VIb. This factor appears to show the relatively simple relationship between size and manpower utilization. The larger companies have on the average a higher sales per employee. It is also a highly correlated with Factor Ib, $r=-0.68$.

Factor VIIb. This factor resembles the orthogonal Factor Ia in a few aspects. It is loaded on the size variables Total Sales and Total Employment and then on a variety of other variables. However, in view of the fact that it accounts for only 3.6 per cent of the variance an interpretation of these loadings does not seem appropriate. Discussion. The interpretation of oblique factors proved just as difficult as the interpretation of orthogonal factors. Overall the transformation of the principal factor matrix by orthogonal and oblique rotations resulted in similar factor structures. Also, the correlation between the oblique factors (as reference vectors) was less than was expected after the canonical analysis. The similarities between the orthogonal and the oblique factor structure call for a summary of the findings. However, because technology tended to influence most factors in both rotations without clearly emerging as an independent factor, further analysis 
is necessary. The analysis of the influence of technology will be presented in the next chapter.

\section{Conclusions}

The multivariate analysis above is a logical extension of the analysis in Chapter II. The application of factor analysis and canonical ocrrelation has resulted in factors and or dimensions that describe phenomena taking place in industrial organizations. Some of the factors identified in this investigation of cross-sectional data seem to be identical with factors discovered by analyzing time series data. Also it appears that orthogonal and oblique rotations are complementary rather than alternative solutions. Both types of analysis have produced essentially the same basic factor structure. However, in view of the obscuring influence of technology only a highly tentative account of the preliminary findings will be given here. This study together with two other factor analytic investigations points to the existence of at least three factors: size, resource utilization, and product strategy. First, size appears to be a very important factor in business organizations. Many characteristics or variables seem to be substantially influenced by size. Second, a factor indicative of efficiency, or resource utilization 
seems to permeate industrial organizations. The presence of this factor may be indicative of the orientation of business enterprises toward monetary objectives. Third, a factor reflecting the strategic decision of management to produce a certain product line instead of another is present in industrial organizations. The strategic product decision regarding the extent of diversification has also several implications with regard to customer orientation and customer service.

Technology appears to be also an important influence in industrial organizations. However, the analysis of this aspect will be performed in the next chapter. The data will be divided along a technological dimension and again factor analyzed on a comparative basis. This comparative analysis will tend to reinforce the assumption about the three factors described above. Later the comparative analysis will be generalized through the application of cluster analysis (see Appendix B). 
CHAPTER IV

COMPARATIVE ORGANIZATIONAL ANALYSIS

The search for factors as dimensions of organizational phenomena, so far, did not yield any conclusive results. The analysis in the preceding chapter indicated the existence of several common factors but the interpretation remained highly tentative or even speculative. One reason for this inconclusive picture could be the fact that the sample is not as homogeneous with regard to size and technology as may be necessary to yield more meaningful factors.

A better understanding of the actual factor structure may be obtained by dividing the total sample into more homogeneous subsamples and then repeating the factor analysis. A comparison of the two resultant factor structures may give important clues to more meaningful interpretations of the dimensions of organizational phenomena. Such an approach to organizational research would be in accordance with the comparative method 
advocated by Ernest Dale. ${ }^{1}$

In the preceding chapter it was found that size seemed to be an important factor in organizational analysis despite the fact that a subdivision of the sample into large and small companies did not lead to more meaningful interpretation of the factor structure. It could be that size in conjunction with technology leads to these inconclusive results. Unfortunately, splitting the samples four ways to obtain homogeneous subsamples with respect to size and technology reduces the sample size of each subsample and precludes factor analysis. (Some findings on the basis of such a four-way classification through cluster analysis are presented in Appendix B). However, an attempt to make a comparative analysis along technological lines was moderately successful. This comparative analysis will be presented in this chapter.

Prior to the presentation of the results of the comparative factor analysis, a discussion of "technology" appears to be in order. Although much is being said and written about technology, there are no accepted measures of technology or technological complexity of products or

I Ernest Dale, The Great Organizers (New York: McGrawHill, 1960), Pp. 11-15. 
manufacturing processes. Consequently, a measure had to be devised that would effectively discriminate between different levels of technology prevailing in the various companies of this sample. This measure of technological complexity is described below.

\section{Analysis of Technological Variables}

The questionnaire contained a question about the nature of the production system of the firm: small batch, intermediate batch, or large batch production. Being a judgmental question the results are not readily comparable. Iiterature on the measurement of technological complexity and production capacity is scarce. ${ }^{2}$ Everyday expressions

${ }^{2}$ Economists have written a great deal about measurement of technology and technological change. Most of these works relate to the production function and its influence on the optimum growth path and the distribution of income. The treatment of technology in this type of literature is nonoperational for the purpose of this study. See W. E. G. Salter, Productivity and Technical Change (Cambridge: The University Press, 1967) and Murray Brown, On the Theory and Measurement of Technological Change (Cambridge: The University press, 1966). The managerial literature is also beginning to deal with the impact of technology on the activities of business firms. However, little is being said about the measurement of technology. See James R. Bright, Research, Development, and Technological Innovation (Homewood, III.: Richard D. Irwin, 1964). Studies that point out the important influence of technology on organizational variables are Joan Woodward, op. cit., and Elmar H. Burak, "Industrial Management in Advanced Production Systems: Some Theoretical Concepts and Preliminary Findings" 
like "space-age technology" do not provide for meaningful yardsticks for precise measurement of levels of technology. One interesting suggestion for an objective measure of technical variables stems from R. C. Brewer. ${ }^{3}$

Brewer noted correctly that technological complexity of products is generally closely associated with production capacity. To use his example, a firm producing 800 automobiles a day certainly has a large capacity; however, a firm producing 800 cigarettes a day could not remain in business for long. Similarly, there is an inverse relationship between the level of technology of an automobile and that of a cigarette. Thus, when speaking about production capacities, firms are generally classified into similar product categories and then compared according to capacity. Such an approach certainly is valid but the finer the distinction between products, the larger is the number of categories and the fewer is the number of firms in each category. For this survey such an approach is not applicable; the number of firms surveyed is too small and

Administrative Science Quarterly, December, 1967, pp. 479500 .

$3_{R}$. C. Brewer, "The Measurement of Technical Variables," in Joan Woodward, op. cit., pp. 268-274. 
their product lines too diverse. Consequently, a different approach to the measurement of production capacity and technological complexity had to be found.

Most of the surveyed companies supplied their monthly production rates for their most important product IInes (see Part I, Section D, Question 2 of the questionnaire). Cursory investigation showed that firms with low unit output; e.g., 5 to 100 units per month, generally produced relatively complex machinery, often custom built. Conversely, firms that reported unit production rates of several hundred to several hundred thousand items per month generally produced low complexity items. In clear cut cases, "high volume" or "low volume" manufacturer may have been the appropriate classification. However, of the multiple product line firms some had both types of products. Consequently, a measure had to be devised that would adequately account for these "conglomerates." The actual classification of these conglomerates is then a matter of formal discriminatory analysis to be described below.

of all the measures tried, the simple geometric mean of the production rates of the different product lines had the highest discriminant power. Three hypothetical examples will illustrate the computation of the new variable named 
"Technology-Capacity Index" or short TC Index.

This Technology-Capacity Index certainly is a crude measure and the writer does not attempt to justify its use by any abstract theoretical argument. However, as long as better measures are not available its retention seems warranted. The test of its usefulness is a pragmatic one-will this measure discriminate on the basis of technology or not? In terms of the three hypothetical examples in Table 4-1 Case 1 is a low volume-high complexity manufacturer, Case 2 represents the opposite extreme, and Case 3 falls into the conglomerate category.

In order to separate the Technology-Capacity Index from size effects a second dimension is necessary. Brewer chose the pay-back period of investment. This may be theoretically desirable but this measure is not always available and is difficult to estimate. The variables Total Sales, Total Assets, and Fixed Assets were found to be suitable second dimensions. Since sales data were more complete than the other two, they were selected on practical grounds. Figure 4-1 depicts the distribution of firms with regard the Technology-Capacity Index and size. There appears to be a logical break in the clustering of the points dividing them into two distinct groups: small batch and high volume 
Table 4-1

Computation of the Geometric. Mean or the Technology-Capacity Index

\begin{tabular}{|c|c|c|c|c|c|}
\hline \multicolumn{2}{|c|}{ Case 1} & \multicolumn{2}{|c|}{ Case 2} & \multicolumn{2}{|c|}{ Case 3} \\
\hline $\begin{array}{l}\text { Product } \\
\text { Line }\end{array}$ & $\begin{array}{c}\text { Units per } \\
\text { Month }\end{array}$ & $\begin{array}{l}\text { Product } \\
\text { Line }\end{array}$ & $\begin{array}{l}\text { Units per } \\
\text { Month }\end{array}$ & $\begin{array}{l}\text { Product } \\
\text { Line }\end{array}$ & $\begin{array}{l}\text { Units per } \\
\text { Month }\end{array}$ \\
\hline a) & 3 & a) & 10,000 & a) & 100 \\
\hline b) & 6 & b) & $1,000,000$ & b) & 5 \\
\hline c) & 1.5 & c) & - & c) & 10,000 \\
\hline d) & - & d) & - & d) & 200,000 \\
\hline GEME $\Lambda N=$ & $\sqrt[3]{3 \cdot 6 \cdot 1.5}$ & $\sqrt[2]{10,00}$ & $1,000,000$ & $\sqrt[4]{100 \cdot 5 \cdot}$ & $000 \cdot 200,000$ \\
\hline$=$ & 3 & $=100$, & & $=1,000$ & \\
\hline
\end{tabular}




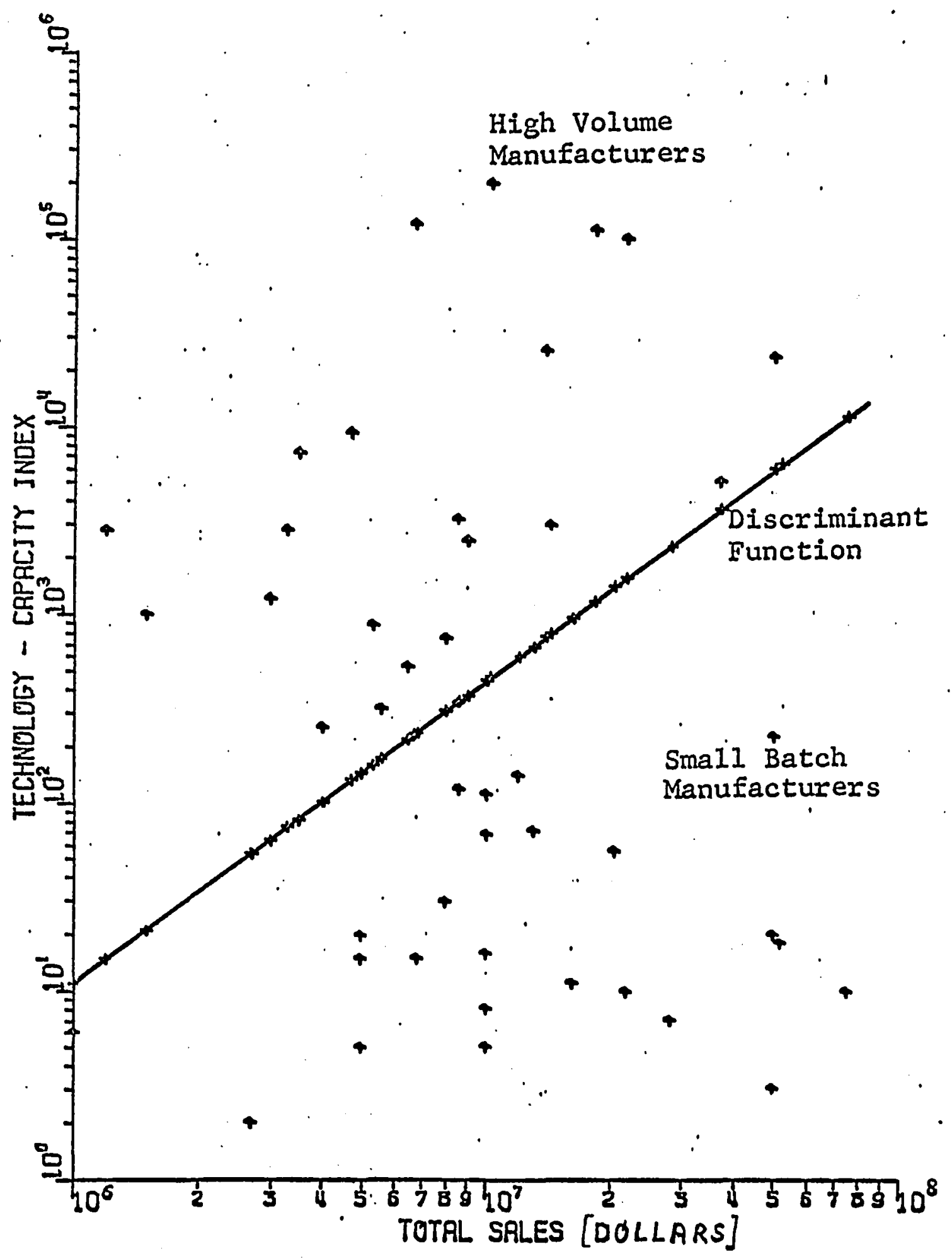

Figure 4-1. Discriminant Analysis of Small Batch and High Volume Firms 
manufacturers.

Properties of the Discriminant Eunction

If there are real differences between firms producing low complexity products (high volume) and those producing high complexity products (small batch) then it should be possible to separate these two groups of manufacturers on the basis of the variables or characteristics of these firms. Discriminant analysis is a method that assigns weights to the variables of the firms according to their contribution to the separation into these groups. The equation which yields the composite scores ( $f$ ) that provide the basis for classification is the discriminant function: ${ }^{4}$

$$
f=c_{1} x_{1}+c_{2} x_{2}+\ldots c_{n} x_{n}
$$

$x_{i}=$ variable selected for discrimination, $i=1,2, \ldots n$, e.g., Total Sales, Technology-Capacity Index, Division of Labor.

$c_{i}=$ weights assigned to each variable proportional to its contribution to the discrimination $i=1,2, \ldots \mathrm{n}$.

${ }^{4} \mathrm{~A}$ good introduction to discriminatory analysis is Henry Garrett, "The Discriminant Function and Its Use in Psychology," Psychometrika, June, 1943, pp. 65-79. A rigorous treatment is found in T. W. Anderson, An Introduction to Multivariate Analysis (New York: John Wiley \& Sons, 1958), Chapter 6. Compare also Cooley and Lohnes, op. cit., Chapter 6. 
The discriminant analysis confirmed the pre-classification into small batch and high volume manufacturers as depicted in Figure 4-1. There were no misclassified firms. The discriminant function was computed to be

$$
f=-2.426+0.626 \log x_{1}-0.781 \log x_{2}
$$

$x_{1}=$ Total Sales with a weight of 0.626

$\mathrm{x}_{2}=$ Technology-Capacity Index with a. weight of -0.781 The composite scores of the 45 analyzed firms ranged from +2.01 to -2.18 with a cutoff score of +0.14 . Firms above the cutoff score were classified as high volume manufacturers, those below the cutoff score, small batch manufacturers.

The use of logarithmic data gave great weight to the TC Index because of its wide range in logarithmic units. The use of raw data did not give this clear separation, but let to a discriminant function that gave greater weight to the sales dimension. On the basis of raw data some high volume firms were classified as small batch and vice versa. The test of statistical significance of this discriminant analysis is based on the "generalized distance" test $D^{2}$ of the Indian statistician Mahalanobis. $D^{2}$ is proportional to the variance between means of two groups.

$$
D=c_{1} d_{1}+c_{2} d_{2}+\ldots c_{n} d_{n}
$$


$c_{i}=$ refers again to the weights of the characteristics $x_{i}$ or the discriminant function coefficient-see Table 4-2

$d_{i}=$ refers to the differences between the means of each characteristic $1=1,2, \ldots$ of the two groupssee Table 4-2

$\mathrm{D}^{2}$ can be used as test of significance with the F-statistic. Table 4-2, Part I, summarizes the results of the discrimatory analysis for high volume and small batch manufacturer on the basis of the TC Index and Total Sales. It shows that the discrimination is highly significant at the $p<0.0001$ probability level. This underlines the great discriminant power of the TC Index which is a simple geometric mean of the monthly production rates.

Because of the clear separation of the 45 firms into two groups of 24 small batch and 21 high volume manufacturers, further analysis of variables other than Total Sales and the TC Index was indicated. The results are summarized in Table 4-2, Part II, which contains the analysis of 13 variables or characteristics of these two groups. Even on the basis of 13 variables the classification was confirmed for each firm for which full information on all variables was available. Unfortunately, 
TABLE 4-2

Discriminatory Analgsis of Smell Batch and High Volume Manufacturers

Based on Logarithmicallo Transformed Data

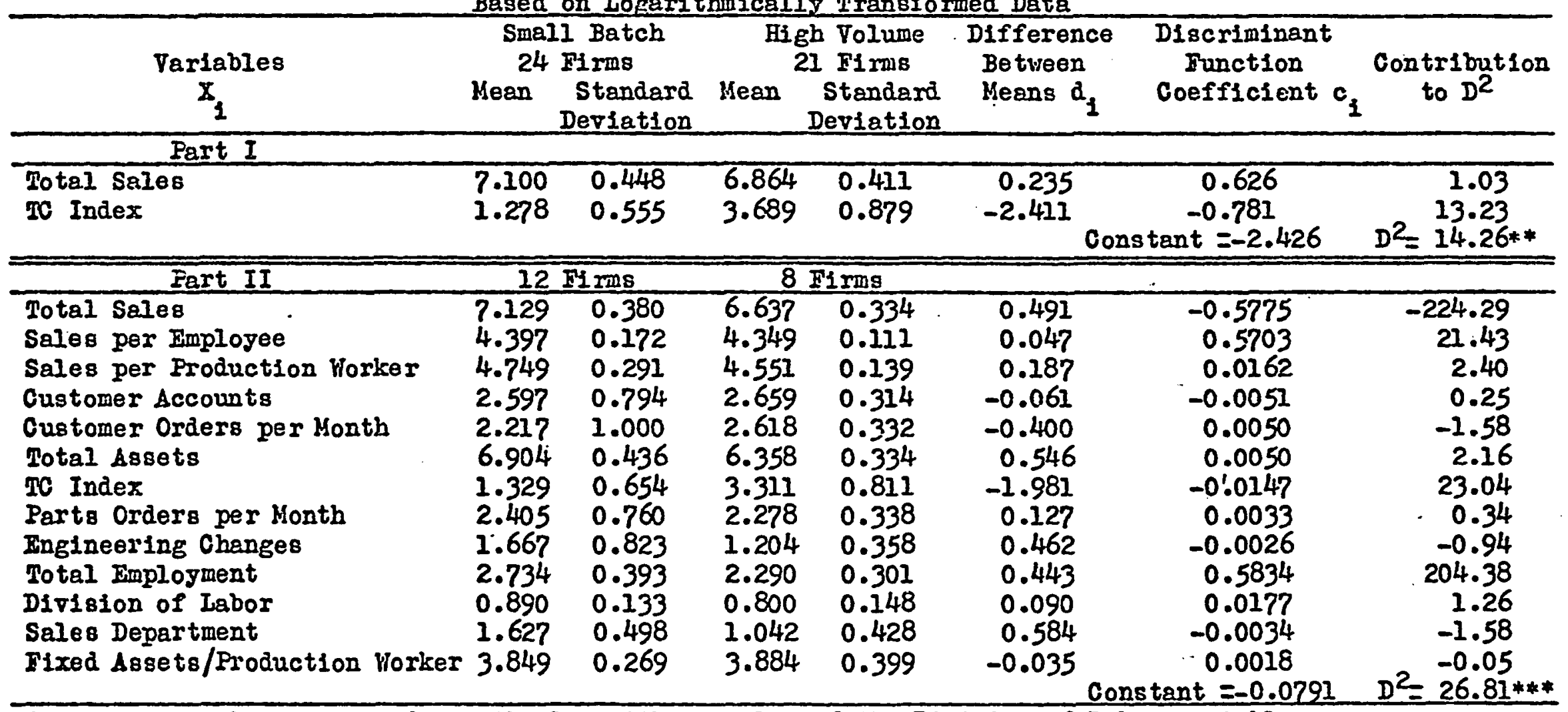

* This 18 the actual and not the logarithmic value of the Division of Labor variable

* Analy8is on the basis of two variables $F_{2}, 42=78.02, p<0.0001$

*** Analysis on the basis of 13 variables $5_{13.6}=3.40, p<0.0757$ 
25 firms had to be deleted from the computations because of incomplete data (the computex program had an automatic deletion feature). Nevertheless, of the remaining 20 firms, 12 fell into the small batch and 8 into the high volume category just as they had been pre-classified. The small sample of 20 firms and the relatively large number of variables reduced the degrees of freedom from $(2,42)$ in the previous analysis to $(13,6)$ for this one. Mahalanobis generalized distance $D^{2}=26.81$ makes this analysis significant at a probability level of $p<0.0757$.

Table 4-2 contains the discriminant function coefficients $c_{j}$ and the contribution of each variable to the generalized distance $D^{2}$. The size effects measured by Total Sales and Total Employment nearly cancel each other out and the discrimination is based on other characteristics. For these reasons further analysis of differences seemed indicated.

\section{Comparative Factor Analysis}

The preceding section dealt with a method to test the homogeneighty of pre-classified groups. The application of discriminatory analysis showed that a classification of firms on the basis of technology is possible and has merit. Table 4-2, Part II, indicates also, that firms which can be 
differentiated on technological grounds differ also with respect to other characteristics. In this section the comparative analysis is continued by performing a factor analysis on the small batch and high volume manufacturers. The investigations will be restricted to orthogonal rotations.

The result of these two analyses is shown in Table 4-3. At first glance it appears that the results are not very different from the factor analysis on the total sample presented in Table 3-3. However, the loading patterns show some important differences, though great care should be exercised in interpreting them because of the decreased sample size. The factors will be interpreted by discussing and comparing them two at a time.

Factors Ic and Id. These two factors resemble Factor Ia very much and appear to indicate again the strong influence of size. In the case of the small batch manufacturers over 38 per cent of the variance can be attributed to this factor and in the case of the high volume firms over 31 per cent. Thus, in both subsamples size has the strongest single influence on the characteristics of the businesses. The interpretation of Factor Ia in the preceding chapter seems to apply here too. 
TABLT $4-3$

Varimax Rotated Factors and Factor Londings for Small Batch and High Volume Manufacturers*

Based on Iogarithmically Transformed Data
24 Small Batch Firms
21 High Volune Firms

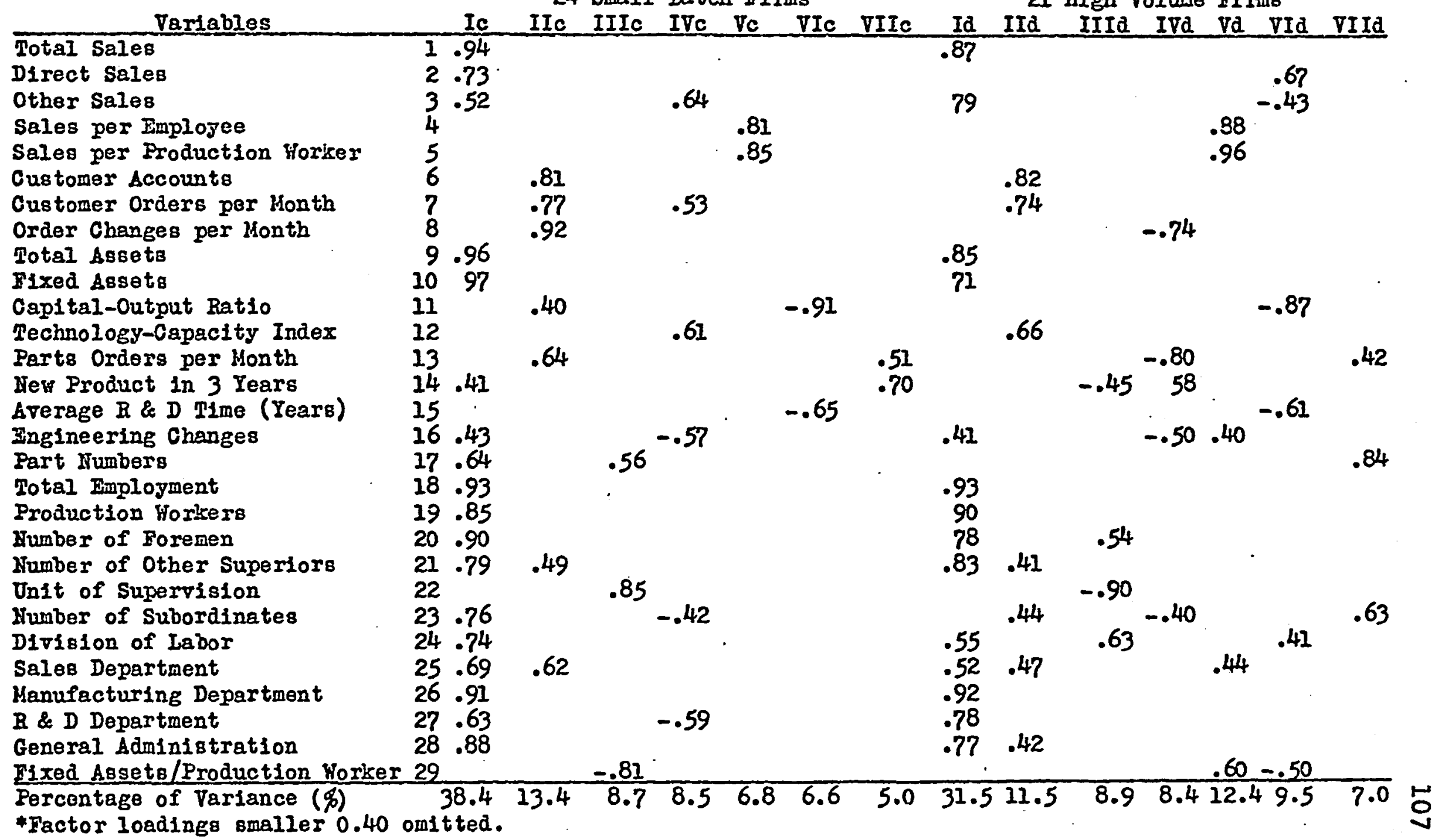


Factors IIc and IId. There are both similarities and differences in the loading pattern of these two factors which seem to be important. Factor IIc is highly loaded on Customer Accounts, Customer Orders per Month, Order Changes per Month, Parts Orders and Sales Department and smaller loadings on Number of Superiors and Capital-Output Ratio. This loading pattern of the small batch manufacturers appears to be indicative of the type of business these firms do. The manufacture of high complexity machinery (low TC Index) is connected with considerable service after the sale or a substantial parts order business. This leads to the great number of orders, order changes, and part order shipments. A service business of this type may also tie up capital and increase the CO Ratio. Possibly the service business may also account for the employment of a large number of people in the sales and marketing department with a corresponding increase in superiors.

The loading pattern on Factor IId.permits also an interesting interpretation. This factor is highly loaded on Customer Accounts, Customer Orders per Month, TechnologyCapacity Index, and Sales Department. The loading on the TC Index indicates that the number of customers and customer orders is more directly related to high volume 
production and distribution than to parts order business after the sale of machinery. This finding is consistent with the classification of high volume firms as manufacturers of lower complexity products. It appears that the loading pattern of these two factors is in good agreement with the preceding discriminatory analysis.

Factors IIIc and IIId. These two factors seem to indicate somerwhat different phenomena. Factor IIIc is loaded on Unit of Supervision, Part Numbers, and on Fixed Assets per Production Worker. This loading pattern is related to that of Factor VIa and seems to indicate that the size of the Unit of Supervision is influenced by the technical production process. This loading pattern together with the information from Table B-2 shows that makers of high complexity machinery (evidenced by many part numbers) need larger units of supervision (larger teams) and more fixed capital per employee to build a complex machine. This interpretation supports the findings in Chapters II and III. Since the small batch manufacturers represent different size firms this may also explain why size is not correlated with unit of supervision.

Factor IIId has positive loadings on Division of Labor, Number of Foremen and negative loadings on New Products in 
3 Years (disregarded here) and Unit of Supervision. It seems reasonable that high volume manufacturing is related to a greater division of labor, a larger number of foremen and smaller units of supervision. High volume, processtype manufacturing appears to be less team and more workflow oriented. Generally it will call for lower skilled workmen. This may very well necessitate smaller units of supervision or more supervisory control. If this is true, then again, the size of the unit of supervision would be influenced by technical processes. If these interpretations are correct, then the power of multivariate statistics has been convincingly demonstrated.

Factors IVc and IVd. The loading pattern of these two factors is not strictly comparable and not easy to interpret for both factors. For the small batch firms the variables other Sales, Customer Oxders per Month, and TechnologyCapacity Index are positively loaded; and Engineering . Changes, Number of Subordinates, and R \& D Department are negatively loaded. These variables will be considered for the interpretation of Factor IVc. This relationship appears to reflect the high engineering content of high complexity product. As the TC Index decreases engineering requirements increase. This leads to more engineering 
changes which in turn require more engineers and $R \& D$ personnel in general. From the correlation between $R \& D$ personnel with Engineering Changes it may be inferred that $R \& D$ personnel are more occupied with Improvements in existing products, than in the development of new ones. The inverse relationship between sales through other channels and the number of engineering changes and $R$ \& $D$ personnel is also apparent from the loadings. This is in accordance with the loading pattern of Factors VIIa and IVb.

The interpretation of Factor IVd rests on the variables Order Changes per Month, Parts Orders per Month, New Products in 3 Years, Engineering Changes, and Number of Subordinates. Although the high volume manufacturers have a lower parts inventory, they still have a substantial parts order business. It could be that this parts order business is also responsible for most order changes and engineering changes.

Factors $V c$ and $\mathrm{Vd}$. The interpretation of Factor Vc seems straightforward and related to Factor IIIa discussed in the preceding chapter. The variables Sales per Employee and Sales per Production Worker seem to indicate the efficiency of manpower utilization. For the high volume 
firms the situation with respect to manpower utilization is a little more complicated if the variables Sales per Employee, Sales per Production Worker, and Fixed Assets per Production Worker are considered for interpretation of Factor Vd. In high volume firms the ratio of fixed capital expended per production worker may well be viewed as a measure of workflow-oriented production methods. Such interpretation would lead to the conclusion that workfloworiented methods lead to a relatively large labor force. This has a tendency to lower the fixed asset expenditures per worker and also the Sales per Employee ratio. The averages listed in Table $\mathrm{B}-2$ tend to support these results also.

Factors VIc and VId. The loading pattern of these two factors seems to indicate the relationship between $R$ \& $D$ effort and the utilization of capital. A high value of the variable Capital-Output Ratio reflects poor asset utilization or a low asset turnover. A long average $R \& D$ time in product development has a tendency to tie up assets in the form of research facilities and in the form of capitalized $R \& D$ expenditures on the balance sheet. Both these tendencies appear to substantiate the rather common observation that reported earnings drop markedly when heavy 
research expenditures are being incurred and, as is now customary, capitalized. In the case of Factor VId, with loading on Direct Sales, Other Sales, and Fixed Assets per Production Worker, this tendency is even more accentuated. Relatively high fixed asset expenditures per worker in conjunction with long $R \& D$ times and sales through other channels will contribute to low asset turnover. It could be that sales through other distribution channels tend to. increase the asset figures through more accounts receivable outstanding and slower collection.

Factors VIIc and VIId. Factor VIIc will not be interpreted because the loading pattern may be attributable to chance. Chance element probably play also a role in Factor VIId. However, this factor points out the relationship between the size of the inventory and the extent of parts shipments per month. Perhaps this factor reflects the customer service objective of management with respect to inventory.

Discussion. The interpretation of the orthogonal factors in this chapter gave similar results as the interpretation in the preceding chapter despite the small size of the two subsamples relative to the number of variables. Some tendencies which were present in the factors in 
Chapter III became more accentuated in the chapter. It appears that the separation into technologically homogeneous groups is a valid and preferrable method of analysis. Of course, it would also be desirable to divide the two subsamples into homogeneous size groups, but that reduces the sample size substantially and precludes factor analysis. Before leaving the subject of technological differences of firms, one additional analysis is in order. As factor analysis pointed out, small batch and high volume firms allocate their manpower differently. This different allocation of manpower appears to reflect technological necessities. A detailed breakdown of the employment distribution is given below.

\section{Differences in Manpower Allocation}

Much of the preceding analyses indicated differences in the allocation of manpower within the small batch and high volume firms. The breakdown of the employment categories in Table $4-4$ is almost identical with that of the questionnaire (see Appendix A); only Customer Service has been added. Actually, the differences are not as pronounced as this writer expected. For most employment categories the differences are negligible and the standard deviations are very high in relation to the size of the mean. 
Table 4-4:

\section{Allocation of Menpower in 29 \\ Imployment Categories*}

(Oategories are based on the questionnaire in the appondix)

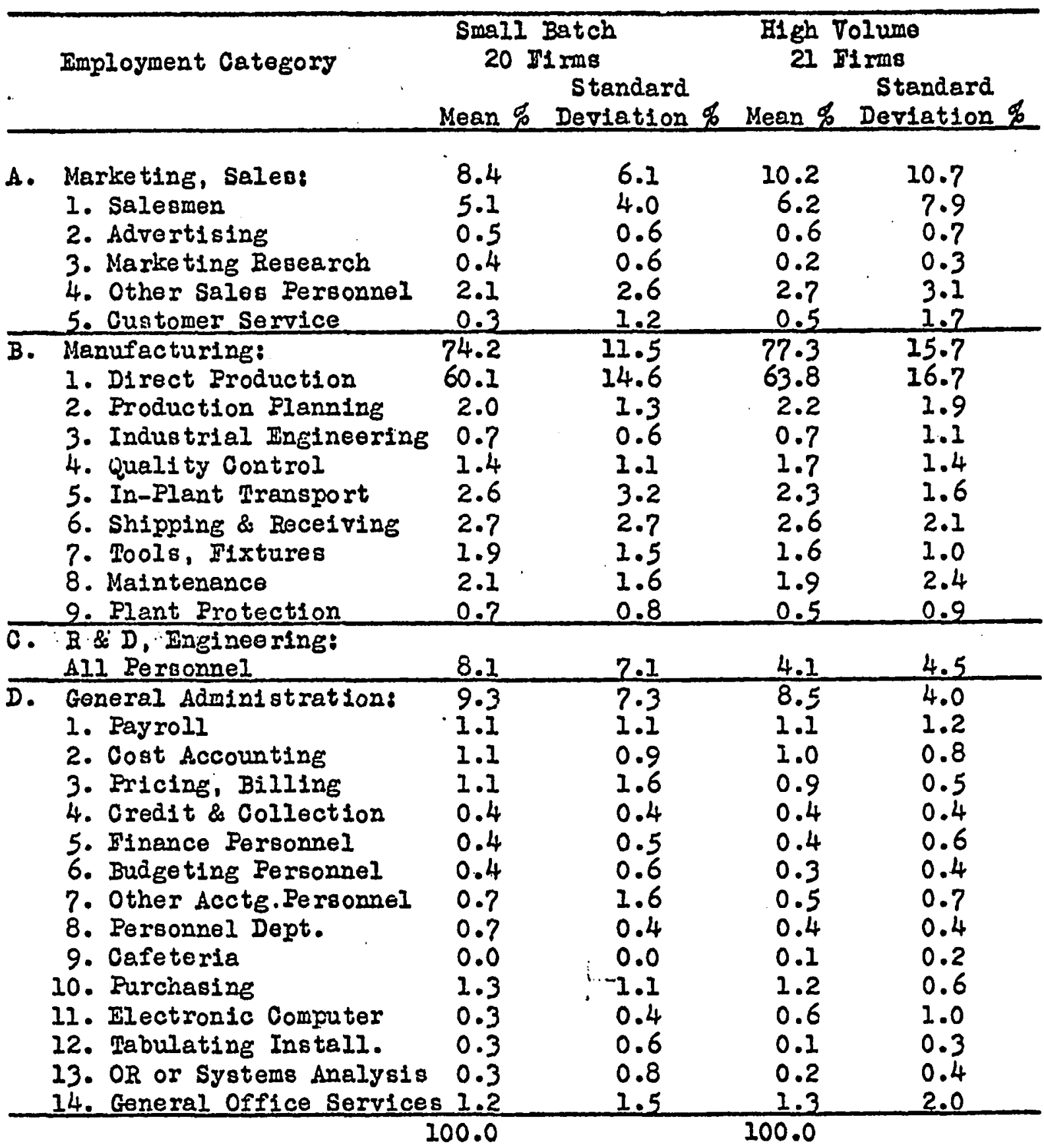

"Differences are statistically not olgnificant at a probability level $p=0.05$. 
A difference that appears to be important and which emerged also from the factor analysis, is the manpower allocation to the $R \& D$ activity. The small batch producers with their complex machinery allocate about twice as many people to $R \& D$ and engineering--8.1 per cent versus 4.1 per cent--as the high volume firms. It was pointed out already that engineering changes are most highly correlated with $R \& D$ personnel. This seems to indicate that machinery builders spend relatively more money on improving existing products than developing new ones.

Somewhat less marked is the difference in the allocation of marketing and sales personnel among the two groups of manufacturers, 8.4 per cent for the small batch and 10.2 per cent for high volume firms. Obviously it takes more personnel to distribute a high volume of production. It has been pointed out already that the number of persons in the marketing and sales activity of the small batch firms was significantly correlated with the parts order volume. The writer thinks that these differences are important when making a comparison between firms. However, the reader is reminded that the standard deviations are high, reflecting the great variation in the data from firm to firm. Also, statistical tests did not show significance at a probability 
level of $p=0.05$ for any of these employment categorles.

For comparison purposes, Table 4-5 has been added, showing the results of the American Management Association (AMA) survey of $1962 .^{5}$ Most surveys about manpower allocation are not compatible because of differing definitions of the employment categories. However, the employment categories of the AMA survey are largely compatible with those of the questionnaire. But there are some differences between the results of this survey and that of AMA. Some of these differences may be due to the different sample. The AMA survey contained a number of very

\section{Table 4-5}

Result of the Survey of the American Management Association

Employment Category
Non-electric Machinery Manufacturers Medians in \%
Manufacturing

Transportation

Research \& Development

Marketing

General Administration
67.2

0.2

8.3

13.0

10.9

Source: "Check Your Management Costs," Nations Business, January, 1962, p. 220.

5 American Management Association, "Check Your Management Costs," Nations Business, January, 1962, p. 128. 
large companies, whereas this survey was based on firms with a total employment ranging from about 100 employees to around 2,500. In addition, the AMA data is based on medians rather than means.

The preceding comparison of differences of manpower allocation ends the formal analysis of the data supplied by participating manufacturing firms. The writer hopes that the various analyses will be of value to the practicing managers for comparing the operations of their firm with those of other firms in the industry. Substantial differences do exist from company to company. The reasons for these differences are not always clear but it seems that size and technology do contribute measurably to these differences. These analyses will not tell a manager what to do if the data for his firm differs from industry averages. However, knowing something about industry averages and being very familiar with the peculiarities of his business he is in a better position to evaluate the "why" of the deviations.

In Appendix B methods for forming homogeneous groups or clusters will be investigated for their applicability to comparative analysis. Although the results of the cluster analysis should be regarded as preliminary, it 
appears that the methods have great potential to establish a taxonomic system of industrial organizations. A Taxonomy of Business Enterprises appears to be a necessary condition for further meaningful comparative analyses of industrial organizations.

\section{Conclusions}

The comparative analysis presented in this chapter is complementary to the factor analytic investigations in Chapter III. Instead of dealing with the complete sample, the firms were divided according to technology-capacity considerations. The geometric mean of the monthly production rates--Technology-Capacity Index--proved adequate for distinguishing manufacturers of low complexity products from makers of high complexity machinery. A factor analysis of these two more homogeneous subsamples tended to clarify the loadings pattern of the basic factor structure found in the preceding chapter.

On the basis of this investigation and together with the preceding analyses the following conclusions can be reached. First, the influence of size permeates industrial organizations. In both technological groups firm size accounted for the largest single percentage of the variance. Technology aside, the large firm seems to be decidedly 
different from the small firm. Second, the decision to manufacture one type of product instead of another has important implications with respect to marketing. Technologically complex products require substantial service after the sale. This leads to a substantial parts inventory and parts order business. The number of customer order changes and the number of people employed in the sales department appear to be directly related to this parts order business. In contrast, makers of products of lower complexity seem to allocate relatively more manpower to outright sales and distribution rather than to service after the sale. Third, technological complexity influences methods of production. Complex machinery leads to team-oriented production methods with larger units of supervision and relatively higher fixed capital expenditures per production worker. High volume production tends to result in more division of labor, and more supervision with lower fixed capital expenditures per production worker. Fourth, technology influences the asset turnover. Products with a relatively large engineering content seem to tie up assets in production and research facilities and in terms of capitalized research expenditures. This increases the assets reported on the balance sheet and tends to lower 
rates of return of capital employed. The high volume firms do not seem to have the high $R \& D$ expenditures; they invest less in production facilities relative to labor and enjoy a more favorable asset turnover.

A comprehensive summary of the conclusions of the analyses of the preceding three chapters is given in the next chapter. The conclusions will be stated in terms of hypotheses to be tested with further research. Some effort will be made to integrate the findings of this research with the dimensions of organizational theory of classical and behavioral researchers. 


\section{CHAPTER V}

\section{CONCLUSIONS AND PERSPECTIVES}

The introduction to Chapter I contained brief outlines of the major dimensions of classical and behavioral organization theory. These two outlines were viewed as a frameworkfor this organizational analysis. How then do the results of this study fit this framework? Do some of the findings resemble the dimensions of classical and behavioral organization theory? The writer thinks they do. The allpervasive influence of size and technology as found in this research is akin to the Operations and Structure dimensions of the theory outlines. Departmentation does not seem to be a truly independent dimension and appears related to Structure. Behavioral Interdependencies were not explicitly measured by the selected variables. Nonetheless, the influence of behavioral variables have been inferred from the nature of some of the findings.

The analysis of the selected variables for the 50 manufacturing enterprises proved more difficult than 
originally perceived. The interdependencies were so manifold that it was very difficult to disentangle the interrelated information by univariate statistics. Only multivariate methods appear to be suited to analyze the maze of facts meaningfully. But even then the interpretation of the diverse findings remains highly tentative and in places even speculative. It is trivial to repeat: correlation does not necessarily imply causation. However, correlation does not preclude causation either. In places intercorrelations have been given causal interpretations. Only through more research of this type can the complex nature of industrial organizations be understood and the reasonableness of this writer's interpretations examined. Apparently no other multivariate analysis of cross-sectional data of business enterprises has yet been undertaken or reported in the literature. Thus a comparison of the findings of this study with other research is not possible at this time. For these reasons it seems appropriate to report the findings of this study in terms of hypotheses. These hypotheses may serve as a guide for other such multivariate studies.

Hypotheses: The Results of this Research Size and technology appear to exert the greatest 
influence on the nature of characteristics of business enterprises. Therefore, most hypotheses will be stated with reference to the influence of size and technology. In several of these hypotheses the influence of size and technology is simultaneously present. In order to enable the reader to refer back to the evidence for the hypotheses page references have been added in parentheses.

Hypothesis 1. The perceived importance of managerial objectives is influenced by the size of the business enterprise (pp. 22-30).

The ranking of managerial objectives revealed that management puts the greatest emphasis on the primary economic objectives of the firm: profit, sales, and market share. However, on the average, the management of smaller firms stresses the sales revenue objective relatively more than the management of the larger firms. This has been attributed to a stronger growth motivation of the smaller companies. The ranking shows that the larger companies are more "people" oriented. This people orientation may stem from the convictions that people are a most vital resource of the business enterprise. ${ }^{1}$

IL. C. Megginson, Personnel: A Behavioral Approach to Administration (Homewood, IIl.: Richard D. Irwin, 1967), Chapter 4. . 
The tendency of the personnel officer to report to the chief executive probably is also a reflection of this stronger personnel orientation.

In Chapter I it was stated that behavioral scientists have repeatedly observed that the formal objectives of the business firm are importantly modified through a bargaining process of interested organization members. Usually the preference of one goal over another is attributed to the various wants, needs, and desires of the people comprising the organization. ${ }^{2}$ Relatively Iittle has been said about what influences human needs, wants, and desires. This analysis of the importance of organizational objectives tends to point out that the thinking of the organization members (their perceived needs, wants, and desires) are influenced by the circumstances that surround them. For example, the size of the industrial organization that they belong to will influence their thinking about the importance of objectives. ${ }^{3}$

Hypothesis 2. The span of control of top management

2 Herbert G. Hicks, The Management of Organizations (New York: McGraw-Hill, 1967), Chapters 3 and 4.

3 For a review of other studies on the influence of size and other factors on the percelved importance of objectives, see Starbuck, op. cit., pp. 454-467. 
increases with size of the enterprise reflecting the rising importance of subsidiary activities (pp. 30-37).

The span of control of the chief executive varies considerably from company to company. Besides the Influence of many variables examined in the literature, size also influences the span of control of the chief executive. When the firm grows decentralization takes place and hitherto subsidiary activities gain more importance; e.g., research and development, purchasing and personnel. This increase in importance is eventually recognized by elevating the reporting status of the activity. The elevation of subsidiary activities and decentralization have a tendency to increase the span of control of top management

These research findings are in accordance with the writings of classical and behavioral researchers. The span of control of top management reflects the departmentation of the firm. ${ }^{4}$ size or the state of growth and development as

${ }^{4}$ The bases of departmentation have been treated in the several studies. See Ernest Dale, Planning and Developing the Company Organization Structure, op. cit., pp. 193-201, Peter F. Drucker, The Practice of Management (New York: Harper \& Brothers, 1954), pp. 193-201, Eliot Chapple and Leonard R. Sayles, The Measure of Management (New York: Macmillan, 1961), pp. 18-37, James C. Worthy, "Organization Structure and Employee Morale," American Sociological Review, April, 1950, pp. 169-179, and Elliott Jaques, "Iwo Contributions to a General Theory of Organization and Management," Scientific Business, August, 1964, pp. 201-214. 
the basis of departmentation is also considered in classical theory. 5 Further the increasing awareness of behavioral interdependencies may contribute to the growing importance of the personnel activity. In the larger firms. This growing importance may be reflected in the higher ranking and in the elevated reporting status of the personnel department in the larger companies. It appears that the accounting-type data does indeed implicitly reflect the presence of behavioral phenomena as was hoped by the writer at the onset of this study.

Hypothesis 3. The size of the unit of supervision is independent of the size of the business enterprise but increases with team-oriented production methods (pp. 41-44, 75-76, 109-110, Table B-2).

An attempt to relate the size of the unit of supervision to the size of the enterprise did not yield any meaningful results. As Figure 2-3 shows, the size

${ }^{5}$ Compare Henri Fayol, General and Industrial Management (London: Pitman \& Sons, 1949), pp. 54-57, H. U. Baumberger, Die Entwicklung der Organisationsstruktur in Wachsenden Unternehmen (Bern: Verlag Paul Haupt, 1961), W. H. Newman and J. P. Logan; Management of Expanding Enterprises (New York: Columbia University Press, 1955), and Alfred D. Chandler, Jr., Strategy and Structure (Cambridge, Mass.: MIT Press, 1962). 
of the unit of supervision can vary widely independent of size of the firm. These findings are in accordance with those reported in other studies. 6

Although enterprise size does not seem to be responsible for the variations in the size of the unit of supervision, technology seems to influence the unit of supervision considerably. The small as well as the large firms with workflow-oriented production methods have relatively small units of supervision. Clusters 1 and 3 in Table $\mathrm{B}-2$ show that 13 and 15 subordinates respectively report to a first-Iine production foreman. This small size has been attributed to the greater division of labor existing among the workflow-oriented high volume firms and the lower skill personnel employed which require more control and supervision.

The small batch firms producing primarily complex machinery appear to use team-oriented production methods. Larger teams of higher skilled labor are required to assemble complex pieces of machinery. Such higher skilled labor probably needs also less supervision and control. Consequently the units of supervision or the teams that

${ }^{6}$ Compare Starbuck, 오. cit., pp. 502-505. 
are engaged in building complex machinery can be larger. Clusters 2 and 4 in Table B-2 show units of supervision of 23 and 27 respectively; this is about twice as large as those in Clusters 1 and 3 .

The size of the unit of supervision as a function of technology is being researched by behavioral writers. However, the findings are not always consistent. Harbison et.al. who analyzed units of supervision in German and American steel mills found also a relationship between skill and size of unit of supervision; higher skilled labor resulted in larger units of supervision. This is in accordance with the results of this study. 7 Woodward in her survey of British firms found a $\mathrm{n}$-shaped relationship. The unit of supervision was 23 in small batch production, reached a peak of 48 in large batch production and dropped to 12 in process-type companies. ${ }^{8}$ Although such comparisons have some value, great care should be exercised in comparing essentially non-comparable situations. Cultural factors in American, British and German plants probably influence the

7F. H. Harbison, E. Kochling, F. H. Cassel, and H. C. Ruebmann, "Steel Management on Two Continents," Management Science, October, 1955, pp. 31-39.

8 Woodward, op. cit., p. 62 . 
size of the units of supervision, too. Also, this writer questions the validity of comparing units of supervision in such non-comparable situations as hospitals and industrial Eirms. 9

Hypothesis 4. Division of labor tends to increase with enterprise size and workflow-oriented production methods (pp. 44-47, 73, 109-110, Table B-2).

The large firms regardless of the nature of their technology have a greater division of labor. This hypothesis is, of course, greatly dependent on the plausibility of the assumption that the firms have homogeneous units of supervision with respect to occupational categories. However, from his general knowledge of production methods, the writer thinks such assumption is reasonable, especially with regard to the larger firms. The greater division of labor among the larger firms may be attributed to the ability to streamline production facilities regardless of technological requirements of the products.

In addition to size, technology has a distinct influence on the extent of the division of labor. A lot of

${ }^{9}$ Starbuck, op. cit., pp. 502-504. 
highly skilled labor is needed to assemble a comparatively large piece of machinery. This tends to increase the unit of supervision and decrease the division of labor. Makers of technologically less complex machinery can be more workflow-oriented. The grade of labor required can be lower but the degree of supervision needed probably higher. Consequently the division of labor increases and units of supervision get smaller:

Division of labor as a function of size and technology is a well worn subject in classical and behavioral organization theory. 10 Until recently these discussions were in general terms due to the absence of adequate measures of division of labor. The application of GibbsMartin formula tends to bring out more clearly some of the contentions of the classical and behavioral writers. Greater division of labor may lead to more technical efficiency but it also results in standardized jobs.

A less demanding job requires less skilled labor and may contribute to monotony and boredom. The combination of lower skilled labor with monotony tends to raise the amount of supervision and control required. Perhaps this tendency

${ }^{10}$ For a review of some of the arguments see Megginson, op. cit., Chapter 6. 
may well be called "social consequences of technological changes;" a field of inquiry of behavioral scientists. 11

Hypothesis 5. The administrative overhead decreases relative to the increasing size of the enterprise (pp. 3840, 47-49, 114-118, Table B-2).

Research studies on the size of the administrative overhead of business firms give, almost without exception, contradictory results. 12 The major reason for these consistently inconsistent results is found in the varying definitions of administrative overhead. The administrative overhead of this study is based on Part II of this questionnaire and, of course, differs from most other definitions.

On the basis of the survey results the large firms of this sample have smaller administrative overheads. This may be attributable to the wider spans of control and more subordinates per superior. The relatively larger overhead of the small firms may also stem from a tendency to imitate the departmentation of the large firms. Technology does

$$
\begin{aligned}
& 11 \text { Ibid., pp. 116-118. } \\
& 12 \text { See Rushing, op. cit., pp. } 273-295 \text { and Starbuck, }
\end{aligned}
$$
op. cit., pp. 499-502. 
seem to influence the administrative overhead; firms manufacturing technologically complex products have larger administrative overheads. However, this tendency is subject to large variations from company to company. Questions of efficiency of administration have been of favorite subject of analysis by classical and behavioral writers. However, it is not entirely clear how this lower administrative overhead of larger firms fits this picture. Certainly, it is contrary to Parkinson's Law. ${ }^{13}$ It may be that a lower administrative overhead simply reflects economies of size or scale. This subject has been repeatedly investigated by economists without conclusive results. 14

Hypothesis 6 . The larger companies and the companies manufacturing high complexity products tend to have a lower asset turnover (pp. 47-51, 73-74, 89-90, 108, 112-113, Table B-2).

13"Work expands so as to fill the time available for its completion." See C. Northcote Parkinson, Parkinson's Law (Boston: Houghton Mifflin Company, 1957), p. 2 .

\section{${ }^{14}$ Martin J. Beckmann, "Some Aspects of Returns to Scale} in Business Administration," The Quarterly Journal of Economics, August, 1960 , pp. $464-471$ and Walther Busse von Colbe, Die Planung der Betriebsgrosse (Wiesbaden: Betriebswirtschaftlicher Verlag Dr.Th. Gabler, 1964) pp. 125-127. 
The examination of the returned questionnaires showed that the larger companies were more diversified than the small companies. Despite some evidence to the contrary, diversification seems to have a tendency to tie up assets. . Diverse operations may require relatively more production facilities and multiple inventories, both of which contribute to larger asset holdings and lower asset turnover. This result appears to be in good agreement with other studies on this subject. 15

The analysis revealed also that high complexity products have long development periods. Much of this product development consist of steady improvements. This is reflected in the large number of engineering changes which tend to increase the parts inventory. In addition, $R$ \& $D$ expenditures are now commonly capitalized. Both large parts inventories and capitalized $R \& D$ expenditures tend to

15 Most empirical studies show an inverse relationship between size and asset turnover. The lower asset turnover has often been attributed to greater vertical integration of the larger firm. A recent study on this subject tends to refute the vertical integration hypothesis but is in good agreement with the findings of this research with regard to the inverse relationship between company size and asset turnover. See John R. Maroney and Jan W. Duggar, "Vertical Integration and Capital-Output Ratios in US Manufacturing Industry," The Quarterly Review of Economics and Business, Sumer, 1967, pp. 23-27. 
raise the assets reported on the balance sheet.

Thus, both diversification as a function of size and strong $R \& D$ efforts as a function of technical complexity of products may serve to reduce the asset turnover or increase the capital-output ratio. If this interpretation is correct, it tends to show that $R \& D$ and diversification can be overemphasized to the detriment of the profit objective of the firm. ${ }^{16}$ It appears that some of these aspects of technology investigated here have not been thoroughly analyzed before and reported in the literature. This analysis indicates that on the basis of strictly objective accounting-type data inferences can be made about the achievement of objectives of management. For example, poorly controlled emphasis on $R$ \& $D$ may well jeopardize the achievement of the profit objective of the firm. In this sense, the analysis reveals also how perhaps unwittingly the objectives of management are being modified through the interaction of conflicting requirements.

16 Bright, op. cit., "How Much Shall we Spend on Research?" p. 402 . Methods to evaluate research proposals are not well developed. There are indications that many research expenditures are wasted or produce diminishing returns to outlay. 
Hypothesis 7 . The technological content of a product influences the customer service orientation of the firm (pp. 71-72, 88, 108-109, .Table B-2).

The analysis of the data showed that companies manufacturing high complexity products were also doing considerable service business. This service after the sale is primarily reflected in the large number of part numbers carried in stock. In cases where the firm is manufacturing only a few machines each month, the sexvice business can also be inferred from the paperwork processed; e.g., customer orders and customer order changes. This type of paperwork was significantly correlated with the number of people in the sales and marketing activity of the firm. Together with a substantial number of engineering changes this seems to reflect the service orientation of the firm. A comparison with Table B-2, Clusters 2 and 4, shows also that firms manufacturing complex products sell primarily direct.

In contrast, the firms with lower complexity products do not seem to exhibit this strong customer service orientation. These firms seem to be more occupied with the direct distribution of their primary products rather than with the service business. The paperwork of these firms, 
e.g., customer accounts and orders, are more directly related to the number of products produced. Consequently, the sales activities appears to be more closely geared to direct distribution rather than service after the sale. This may also be inferred from the fact that a substantial portion of the products are sold through marketing channels-see Cluster 1 in Table $\mathrm{B}-2 .^{17}$

Hypothesis 8 . Direct sales results in greater information feedback for product improvement (pp. 76, 89, 110-111, Table B-2).

This hypothesis is related to the preceding one. The technological content of the product largely determines the marketing strategy. Technologically complex products often necessitate direct selling methods. This may expose company salesmen to customer wishes and pressure for product changes and improvements to customer specifications. In any case, direct selling is significantly correlated with the number of engineering changes processed. Thus, it

17 For a review of other factors that affect the choice of marketing channels see Ralph S. Alexander, James S. Cross, and Ross M. Cunningham, Industrial Marketing (Homewood, Ill.: Richard D. Irwin, 1961), Chapters 7 and 8. 
appears that the strategic decision what kind of product to manufacture has important repercussions. Technologically complex products seem to call for direct selling. Such selling methods, in turn, lead to a greater information feedback for product improvement. The interrelationship of direct selling, engineering changes, and technological complexity is underlined through the significant correlation of these variables with the number of $R \& D$ personnel. The information feedback hypothesis as a result of the selling methods was inferred entirely on the basis of objective accounting data. The analysis of the data suggested such an interpretation. The available literature on industrial marketing appears to be in reasonable agreement with the conclusions reached. Points to be considered for the selection of distribution channels for industrial goods are such technological considerations like installment of the product, technical service, repair, and maintenance necessary, and the importance of quality. Of course, the size and financial position of the manufacturer have also a dominant influence on channel selection. 18 However, the information feedback aspect of direct selling, potentially

${ }^{18}$ Ibid., pp. $271-274$. 
of great value to the firms, does not seem to have received the attention in the literature it appears to deserve. Hypothesis 9. Sales per employee and sales per production worker increases with size and technological complexity of the product (pp. 47-51, 72-73, 90, 111-112, Table B-2).

The larger companies of the sample and the companies manufacturing technologically complex products have, on the average a higher annual sales per employee and per production worker. Whether these two ratios can be taken as measures of productivity depends very much on the assumption that value added per employee and sales per employee have the same proportional relationship among the surveyed firms. Since the questionnaire did not call for value added information the reasonableness of such an assumption is difficult to evaluate. The lack of this information precludes a judgment of the relative efficiency of the various types of firms. If one is willing to assume that sales per employee information can be taken as measures of productivity, then the lower ratios among the smaller firm may be attributable to the inability to streamline production as much as the large firms. The higher ratios among makers of relatively complex machinery 
could be due to less competition commonly prevailing among firms in relatively specialized manufacturing areas. Admittedly, such interpretations are quite speculative and the reader should judge for himself how well these interpretations apply to his particular circumstances. Discussion. The writer believes that this research study has resulted in nine meaningful though very tentative hypotheses regarding the nature of organizational relationships in the investigated 50 industrial organizations. The findings seem to support a multivariate comparative research approach to the investigation of business enterprises. It appears that the general characteristics of the investigated firms are importantly influenced by two group or common factors: size and technology. The influence of size was very pervasive and almost always readily apparent. The effect of technology was more difficult to assess, probably due to the lack of accurate measures of levels of technology. However, the evidence seems sufficient to begin to regard size and technology as group factors for future factor analytic studies on the nature of organizational phenomena of business enterprises. 
Perspectives for Future Research

Psychologists who have used factor analysis extensively have learned much about common factors that will be present in factor analyses involving particular variables. Organizational research which is just beginning to use factor analysis does not have this wealth of information about experimentally determined common factors. Consequently much research of this type is needed to learn more about these common factors in organizations. From this study it appears that size and technology may be regarded as group factors loaded on many variables. The factors resource utilization and product strategy are also loaded on a variety of variables as this research together with the Seashore-Yuchtman and the Eddy et.al. studies disclosed. Perhaps it is appropriate to view these factors as specific factors. Future studies should be able to utilize this knowledge to investigate even more specific factors.

Although this research indicated the existence of several other specific factors the evidence was often contradictory in the four different factor rotations. The small sample together with the lack of knowledge about the existence of common factors at the time of the analysis 
prohibits further interpretations of these specific factors. In order to gain a better understanding about other and specifically behavioral phenomena in organizations an even wider range of variables than those used in this research study is needed. Variables that may better disclose behavioral phenomena could be number of grievances, absenteeism, accident rates, seniority related job changes, bonuses paid, labor cost variances, profit, strike data, machine breakdowns, sick leaves, personnel turnover, number of suggestions for improvements and overtime. Of course, the specific data available will vary from company to company and may not be always readily available for analysis. This writer thinks that multivariate analysis of the wealth of information accummulated in the regular record keeping system of the firm could be of great value to management. A multivariate time series analysis of the suggested variables together with the variables employed in this study could give clues to causal relationships between such vital economic measures as profit and sales and behavioral and other variables. The analysis could be extended to include variables indicative of vendor, customer, and stockholder relations. Because of the high speed of available computers a multivariate analysis of several 
hundred variables over long periods of time is not only feasible but desirable. This writer is convinced that periodic reports of the results of such analyses to top management of progressive companies will in time be just. as common and as usual as the preparation of the annual report and budget and the information probably more valuable for planning purposes and corrective actions. 
APPENDICES $A$ and $B$ 
APPENDIX A

ORCANIZATION STRUCTURE ANAIXSIS SURVEY

\section{DIVISION OF RESEARCH \\ COLTEGE OF BUSINESS ADMINISTRATION}

IOUISIANA STATE UNIVERSITY

BATCN ROUGE, IOUISIANA 70803

CONEIDENTIAL

PART I - GENERAT

Please supply the following information concerning your company:

Company name (optional)

Company address (optional)

Name of person completing the survey (optional)

Please estimate below if necessary. Each firm is different, therefore categories and classifications have to be broad. If your firm does not fit a classification exactly please approximate as closely as you can.

A. Areas of greatest managerial emphasis - Management Objectives

Please rank the following management objectives as being $1,2,3,4,5$, or 6 according to the importance in your company. Assign figure 1 to the most important objective and 6 to the least important. Use each figure only once (no ties). Although management objectives may conflict please establish a reasonable order of importance.

Put figures

in spaces

Objectives

(1) Inventory level - maintain minimum economic inventory consistent with good customer service.

( ) Market share - maintain or increase present market share.

() profit - maintain or increase profits.

( ) Production level - keep production and employment stable without great variation from time period to time period.

( ) Sales - maintain or increase present level of sales.

() Personnel - maintain and upgrade personnel in all departments of the company.

( ) Others, if any:

B. Marketing and sales

1. Gross sales for Einancial year $1966 \$$

Estimated Percentage of Gross Sales

2. How does your company sell?

a) Sales through company salesmen

b) Sales through other channels, middlemen, wholesale. manufacturers' representatives, etc. Total

3. Number of active customer accounts in 1966

4. Average number of customer orders per month

5. Average number of customer order changes per month

c. Finance

1. Total assets for financial year ended 1966 \$

2. Book value of fixed assets (plant, machinery, etc. excluding land) less depreciation \$

D. Production system

1. Which one of the following three classifications describes your production system best? Check only one. Be subjective and approximate. (What is small, medium, or large depends on the conventions in your industry).

( ) Unit or small batch production, made to cistomer's order, job shop operation.

( ) Production in medium-sized batches for stock (finished goods inventory) and for customer's order.

( ) Mass production, large batches, primarily for finished goods inventory. 
2. Please list your most important product lines only (broad classifications) and the average monthly production rate.

Very brief description of product line

a.

b.

c.

d.

3. Average number of (replacement and other) parts orders shipped each month.

Average Production, Number of Units per Month

E. Research and Development, Engineering

1. How many new products did your firm introduce into the maxket in the past 3 years?

2. What is the average time-span of product development from the decision to build a prototype to the decision to put it on the market (estimate)

3. Average number of engineering changes processed per month.

4. How many different types of parts (different part numbers) do you carry in inventory?

F. General Information for Part II and Part III

1. Information for Part II

The personnel in this survey has been classified as operative, supervisory, and managerial. Please list only full time employees (more than $75 \%$ of the time in this capacity) for each function. Avoid double listings. At the end there is a separate category for multiple assignment employees.

Operative personnel are direct production workers, machinists, welders, assemblers, salesmen, bookkeepers, clerical personnel, secretaries, typists, quality inspectors, guards, toolmakers, truckers, and the like paid on an hourly basis or drawing a salary.

Supervisory personnel are all those direct first-level superiors that super$v$ ise the work of operative employees, e.g.. foremen, supervisor of typing pool, tabulating machine room supervisor.

Managerial personnel are all those above the first-level supervisors. These managers are engaged in planning, organizing and controlling the work of supervisors and other managers, e.g. top management, head of departments, general foremen, plant managers.

2. Information for Part III

The chart on the last page is designed to indicate the organizational relationships existing in your company - that is, to show who reports to whom. To be sure, titles vary considerably in organizations so please use the closest title given on the chart. Some titles or departments listed may not exist in your firm - simply cross them out. You may want to add some titles or departments not listed in the chart (use the space "others") to make the chart complete. You may, if you wish, send me an organization chart instead.

Check the appropriate space $(\mathcal{C}$ to indicate your organizational relationships as illustrated in the following sample chart.

\begin{tabular}{|c|c|c|c|c|c|c|c|c|}
\hline$\left\{\begin{array}{r}\text { report } \\
\text { to these } \\
\text { departments } \\
\text { and positions }\end{array}\right.$ & 荡 & 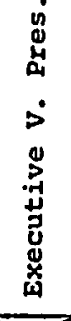 & 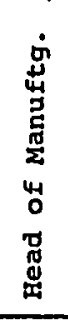 & 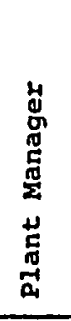 & 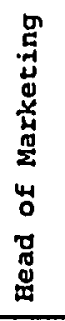 & 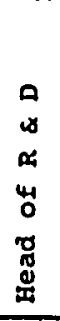 & 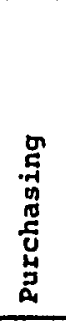 & 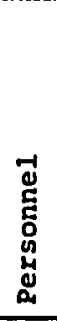 \\
\hline \multicolumn{9}{|l|}{ Executive Vice President } \\
\hline Head of Manufacturing & $\checkmark$ & & 2 & & & $\therefore$ & & \\
\hline \multicolumn{9}{|l|}{ Plant Manager } \\
\hline Production Control & & & $\checkmark$ & & & & & \\
\hline Head of Marketing & 2 & & & & $\geq$ & & & \\
\hline
\end{tabular}


PART II - PERSONIEL DATA

A. Marketing, Sales

1. Salesmen (also in branches)

2. Advertising and Sales promotion, (direct mail, copy. display)

3. Marketing Research (sales planning and forecasting)

4. Other personnel in sales department

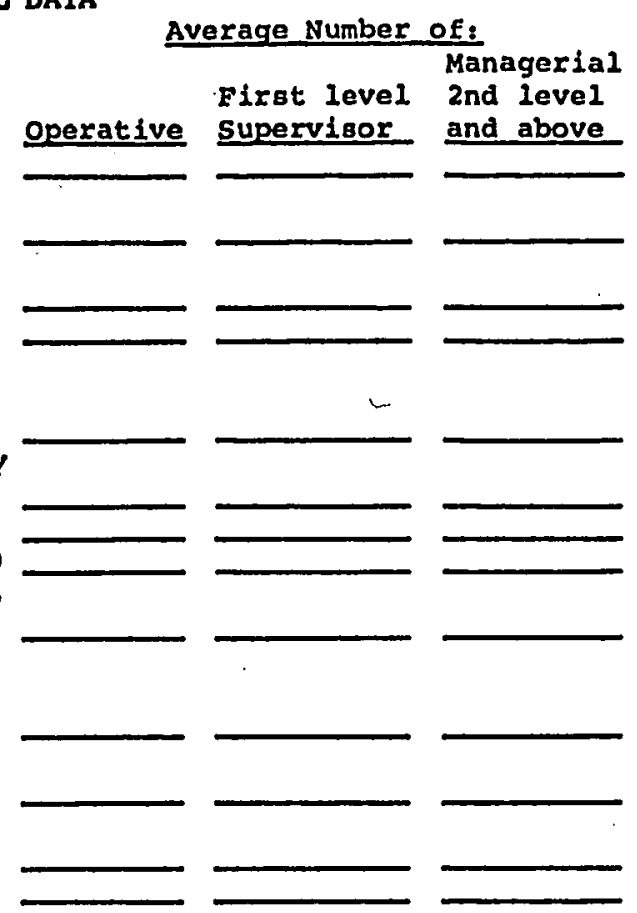

c. Research and Development, Engineering

1. Total Research, Development, and Engineering (product design, development, research and test laboratories, pilot.plant)

D. General Administration

1. Payroll Accounting

2. Cost Accounting

3. Pricing, Billing, Invoicing

4. Credit and Collection

5. Finance (management of cash and capital, securities, bank loans, etc.)

6. Budgeting and planning

7. Other accounting and internal auditing

8. Personnel (recruiting, training, employee relations, wages, safety, etc.)

9. Cafeteria

10. Purchasing and subcontracting

11. Electronic Computer Installation (if available)

12. Tabulating Installation (if available)

13. System and Procedures, Operations Research, General Operations Improvement

14. General Office Services

E. Other functions (not included above)

1. Multiple Assignment Employees

2.

3.

4.

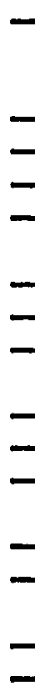

$\longrightarrow$

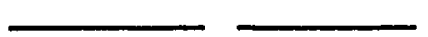

- Total Number of Employees 
PART III - Organizational Relationships

(Please 5111 in as shown in the sample chart)

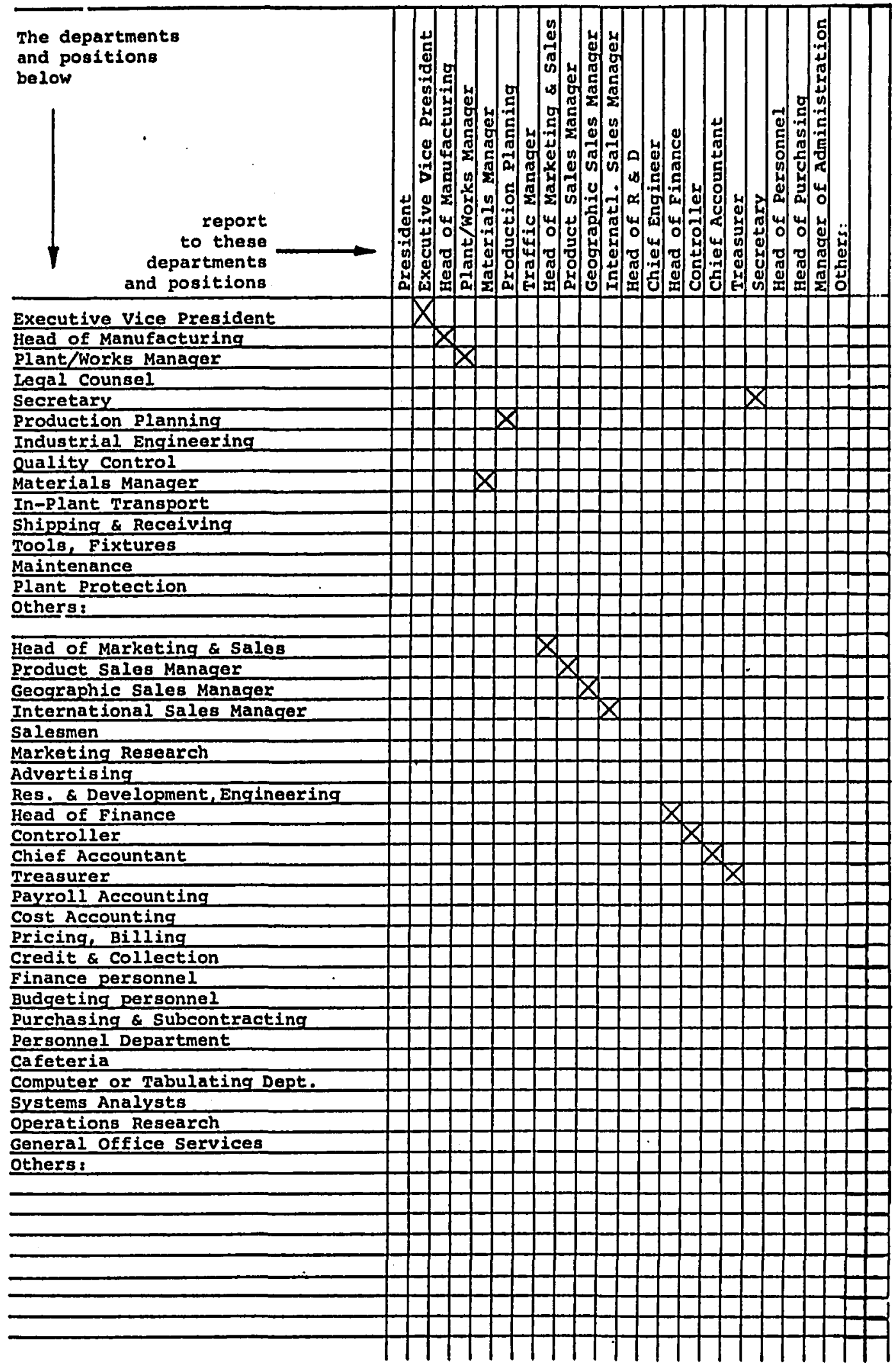




\section{APPENDIX B}

TOWARD A NUMERICAI TAXONOMY OF BUSINESS ENTERPRISES

Chapter IV dealt with the comparative approach to organizational analysis; discriminatory analysis was employed to evaluate the classification of firms according to technology. The geometric mean of the monthly production rates was used as an index of the level technology and the amount of capacity. This TC Index discriminated well between high volume and small batch manufacturers. Factor analysis on these two types of firms gave additional information about the basic factor structure found in Chapter III. Because the analysis of two relatively homogeneous sub-samples proved successful, a further breakdown of the total sample into very homogeneous clusters may yleld even better results.

Since comparative analysis appeared to be a useful approach in organizational research, methods to establish clusters will be discussed in this appendix. The 29 variables or characteristics listed in Table 3-3 will be used as the basis for classification. The variables will 
be converted into coefficients of resemblance or affinity. These coefficients will be compared and evaluated according to various criteria to see if certain subjects can be linked to each other. Through the linkage process clusters may be formed for further investigation.

This appendix attempts to give a general introduction to what cluster analysis does and how the clusters are formed. For a detailed methodology of cluster analysis and numerical taxonomy the reader is referred to the authoritative and comprehensive work of Sokal and Sneath on which this discussion is based. ${ }^{1}$ The last two sections of this appendix deal with the numerical taxonomy of the surveyed business enterprises with some indications of how this scheme could be extended into a general taxonomy of business enterprises.

$1_{A}$ good discussion of the nature and the purpose of numerical taxonomy is contained in Robert $R$. Sokal, "Numerical Taxonomy," Scientific American, December, 1966, pp. 106-116. For an exhaustive treatment see Robert R. Sokal and Peter H. H. Sneath, Principles of Numerical Taxonomy (San Francisco: W. H. Freeman and Co., 1963), especially Chapters 5 and 6 and the Appendix. Methods of numerical taxonomy are rapidly being adapted to problems in marketing research. For a review of applications see Ronald E. Frank and Paul E. Green, "Numerical Taxonomy in Marketing Analysis: A Review Article," Journal of Marketing Research, February, 1968, pp. 83-94. 
The Estimation of Resemblance of Business Enterprises

For the comparative approach to be meaningful, precise measures of resemblance among business enterprises have to be found. Such familiar classification schemes as manufacturing business, mining and extraction industry, service industry, financial institutions, etc., are not sufficient. These broad terms of everyday speech do not lend themselves to scientific analysis. For example, manufacturing enterprises will be markedly different if makers of complex machinery, structural steel products, simple components, and stone and clay products are compared. The discriminatory analysis in Chapter IV illustrated this rather clearly.

Meaningful classification schemes have to be built around characteristics that will distinguish dissimilar business organizations. For a numerical taxonomic analysis these characteristics must be capable of numerical expression. Business organizations have many such characteristics or features. Some can be expressed in a dichotomous or binary manner; either present or absent. Others can be measured on a continuous scale; e.g., sales revenue, employment, number of customers. A large number of characteristics Ieads to a great computational work load and 
makes most of these methods computer-dependent. The analysis in this appendix will be based on two methods of computing resemblances: coefficients of correlation and distance. Coefficients of association will be discussed but not employed in the numerical analysis.

Coefficients of Association.

The estimation of resemblance can be based on the number of features that are present or absent between two organizations (in the language of taxonomists the subjects to be compared are referred to as OTU's -- Operational Taxonomic Units or taxa, singular taxon). Such coefficients of association can be conveniently explained through the use of a $2 \times 2$ table as illustrated in Table B-1.

Based on this table more than a dozen computational methods have been proposed to reduce the table to a single measure of association. The simplest formula to calculate the degree of agreement between present features and absent features of two enterprises may be written as

$$
s=\frac{n_{J K}+n_{j k}}{n_{J K}+n_{j k}+n_{J k}+n_{j K}}
$$

If the presence of a feature is coded 1 and the absence 0 , this coefficient of association can range from 0 to 1 . At 
TABLE B-1

Computation of Coefficients of Association

Business Enterprise - Taxon j

1

0

\begin{tabular}{|c|c|c|}
\hline Business & $\begin{array}{c}\text { number of features } \\
\text { present in both } j \\
\text { and } k \\
n_{J K}\end{array}$ & $\begin{array}{l}\text { number of features } \\
\text { absent in } j \\
\text { present in } k \\
n_{j K}\end{array}$ \\
\hline Taxon k & $\begin{array}{l}\text { number of features } \\
\text { present in } j \\
\text { absent in } k \\
n_{J k}\end{array}$ & $\begin{array}{c}\text { number of features } \\
\text { absent in both } j \\
\text { and } k \\
\mathfrak{n}_{j k}\end{array}$ \\
\hline
\end{tabular}

(Source: Adapted from Robert R. Sokal and Peter H. H. Sneath, Principles of Numerical Taxonomy (San Francisco: W. H. Freeman and Co., 1963) P. 126) 
times it may be more appropriate to disregard the negative matches (agreement on the absence of features), especially when the number of positive matches is relatively large. Then the coefficient reduces to

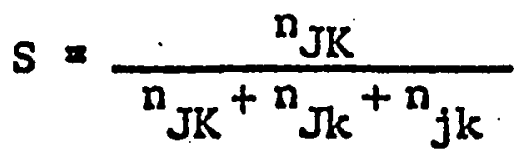

These simple measures of association give equal weight to all features. There are extensions and elaborations of these measures which give different weights to matched and unmatched features and to some features which are considered more important than others. For example, it can be argued that the technological complexity of a product has a greater impact on the organization of the business than the fact that plant protection is sub-contracted. There are numerous ways to weigh features and combine cells of the $2 \times 2$ table into measures of association. An important disadvantage of these transformations is the subjective element contained in the weighting process.

Measures of Distance.

The simple matching coefficients of association recognize only two possible states: either present or absent, 1 or 0 . Most features of business enterprises are 
not of such a dichotomous quality; rather, they are of a continuous nature. Continuous variables lend themselves to a geometrical model of resemblance or better nonresemblance or distance as depicted in Figure B-1.

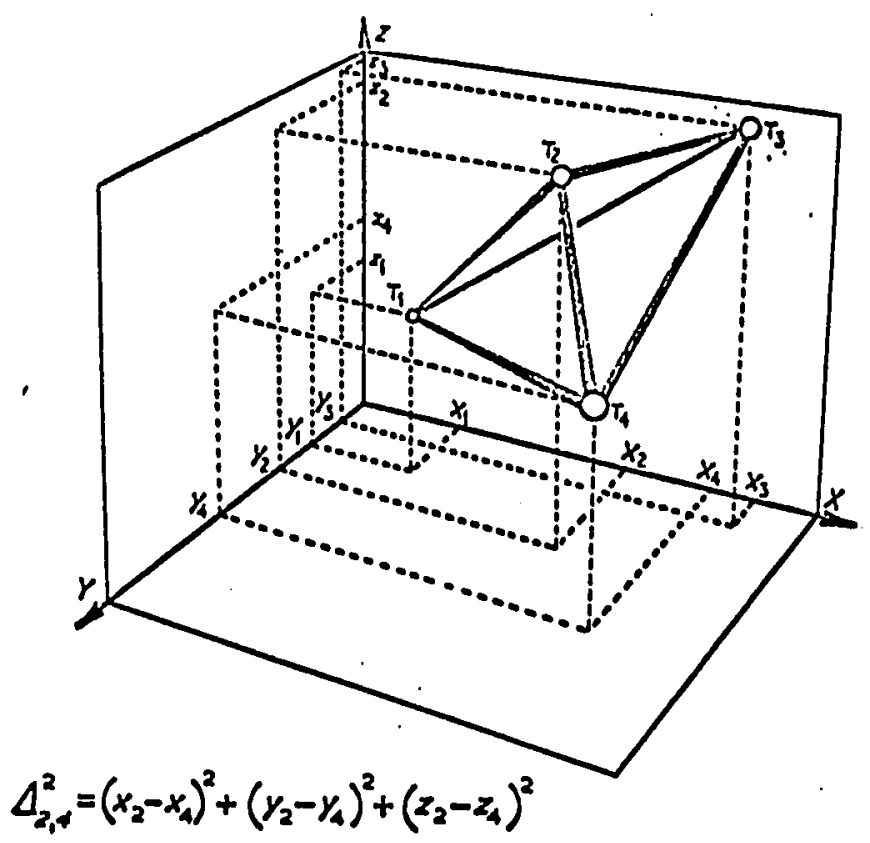

Figure B-1. Representation of Four OTU's in a ThreeDimensional Space (Three Characteristics X, Y, Z). If more than three characteristics are used, a multi-dimensional space--hyperspace-would be necessaxy to depict the relationships between OTU's.

(Source: Sokal and Sneath, op. cit., p. 144)

This model can be used to develop two measures of distance: the mean character difference and the taxonomic distance coefficient.

Mean Character Difference. This coefficient measures 
the average difference between two enterprises $j$ and $k$ when compared on a certain feature or characteristic X. Because comparisons can be made on $1=1,2 \ldots$ characteristics, the mean character difference (MCD) is defined by

$$
M C D_{j k}=\frac{1}{n} \sum_{i=1}^{n}\left|x_{i j}-x_{i k}\right|
$$

Although this measure is easy to compute it has several major disadvantages. It may lead to serious misclassification when some characteristics are large and others are small. And this is the case in this study; e.g., sales revenue is a very large measure when compared with the Capital-Output Ratio. The mean character difference will always underestimate the true Euclidean distance between enterprises in the space. Nonetheless, this measure is appealing because of its simplicity.

Taxonomic Distance Coefficient. Some of the difficulties with the mean character difference can be circumvented by computing the true Euclidean distance between OTU's based on selected characteristics $i=1,2 \ldots n$. For two orU's $j$ and $k$ and $n$ characteristics this may be expressed as

$$
\Delta_{j k}=\sqrt{\sum_{i=1}^{D}\left(x_{i j}-x_{i k}\right)^{2}}
$$


However, since $\Delta_{j k}$ increases with the number of characters measured, the average taxonomic distance is commonly employed

$$
d_{j k}=\sqrt{\frac{\sum_{i=1}^{n}\left(x_{i j}-x_{i k}\right)^{2}}{n}}
$$

The greater the dissimilarity between taxa, the greater the distance is between them. Of course, if more than two taxa are employed the problem is one of computing $m$ distances in an $n$-dimensional space. But through the availability of computers this is no serious problem.

The Coefficient of Correlation.

The coefficient of correlation is a well-known statistical technique in the investigation of business phenomena and needs little elaboration.

$$
x_{j k}=\frac{\sum_{i=1}^{n}\left(x_{i j}-\bar{x}_{j}\right)\left(x_{i k}-\bar{x}_{k}\right)}{\sqrt{\sum^{n}\left(x_{i h}-\bar{x}_{1}\right)^{2} \sum^{n}\left(x_{1}-\bar{x}_{1}\right)^{2}}}
$$

The symbols $x_{j}$ and $x_{k}$ stand for the average of all characThe symbols $\bar{x}_{j}$ and $\bar{x}_{k}$ stand for the average of all characteristics $i=1,2 \ldots n$ for taxon $j$ and taxon $k$ respectively. Thus certain large characteristics may have an overbearing 
influence on the average on the basis of their absolute magnitude. This poses somewhat the same problem as in the computation of the mean character difference.

Standardization of Data.

The difficulty inherent in comparing characteristics of differing magnitudes makes transformation of data desirable. The analyses in the preceding Chapters III and IV were based on logarithmically transformed data. Numerical taxonomy studies in other fields have been based on standardized data. This convention has been followed in this study. Prior to the analysis and the computation of coefficients of resemblance the raw data has been standardized

$$
x_{i j}^{\prime}=\frac{x_{i j}-\bar{x}_{i}}{s_{i}}
$$

$X^{\prime}{ }_{i j}=$ standardized characteristic or variable $i=1,2 \ldots n$ of taxon $j$

$x_{i j}=$ raw data of characteristic $i=1,2 \ldots n$

$\bar{x}_{1}=$ mean of characteristic $i=1,2 \ldots n$

$s_{i}=$ standard deviation of characteristic $i=1,2 \ldots n$. Studies have shown that standardized data produces higher correlation coefficients but this does not adversely affect the actual classification. 
Missing Data.

One of the great plagues of the empirically inclined researcher is missing data. Fortunately, the companies that responded to this survey by and large submitted rather complete questionnaires. Nevertheless certain information was omitted on several questionnaires. Rather than reject the whole questionnaire a provision in most sophisticated computer programs (including the one used to analyze this data) have provisions to account for missing data. This means that comparison is made on all aspects of the questionnaire except the missing ones. In many instances it is not appropriate to code missing data as zero. This may give a serious bias, especially if the missing characteristic is frequently omitted from the data.

\section{Establishing a Taxonomic System}

There are several methods of constructing a taxonomic system. Some are very familiar to the student of business administration; e.g., frequency distributions and stratification of a universe prior to a sampling procedure. Others, such as cluster analysis, are almost completely. absent from the ordinary literature. Because cluster analysis appears to have a unique appeal for the classification of business enterprises it will be employed in this 
study to establish a taxonomic system. The four methods that have been used to join taxa into homogeneous clusters are elementary clustering, single linkage, average linkage, and full linkage. All of these methods are based on grouping taxa on the basis of the similarity of their taxonomic coefficients. The clusters can be formed with the coefficients of association, the mean character difference, the taxonomic distance, or the correlation coefficient. Clustering on several coefficients is preferable for comparison purposes.

Elementary Cluster Analysis. This method is based on, the arbitrary selection of a level of similarity to form a cluster. For example, correlation coefficients 0.9 to 0.99 would form one cluster, those of 0.80 to 0.89 another, and so forth. This method is analogous to constructing a topographic map of a mountain range. The higher the admission criterion, the fewer the taxa that comprise a cluster. The lower the criterion, the more taxa join the clusters. Because this method leads to overlapping clusters it is not used frequently.

Single Linkage. This clustering method begins with pairs of the two most correlated taxa. The next taxa are admitted on the basis of a high correlation or a link with 
any taxon already in the cluster. The admission is on the basis of the magnitude of the coefficient, e.g., first those with a coefficient of 0.99 , then 0.98 , 97 , etc. Under single linkage taxa may join a cluster on the basis of a link to only one other taxon in the cluster. This can mean that an admitted taxon may not be closely related to other taxa already in the cluster. Also, links can be overlapping. This disadvantage can be corrected by requiring linkage with other taxa, too.

Complete Linkage. In order to join a cluster under this criterion the taxon must have a link with each taxa already in the cluster above a certain level of the similarity. This method may yield overlapping clusters and this may lead to combining two clusters into a larger one. Also, this method may yield differing clusters according to the level of the similarity coefficient selected. For these reasons, Sokal and Sneath recommend average linkage as preferable.

Average Linkage. The clustering process begins with pairs of the highly related taxa. Other taxa are admitted to these clusters of two if they do not lower the average similarity coefficient by a specified decrement; e.g., 0.03 . If the joining of a taxon to a cluster would lower the 
average coefficient of similarity below the admissable level, all clusters are recalculated to determine which cluster the taxon should join. Average linkage is a superior linkage criterion, but it involves greater programming and computational effort.

A Numerical Taxonomy of the Surveyed Companies

The brief review of cluster analysis indicated enormous computational effort. Therefore, any real life problem in numerical taxonomy is computer-dependent. The cluster analysis of the 50 manufacturing enterprises was performed with the NT-SYS computer programs developed by Sokal and his associates at the University of Kansas. ${ }^{2}$ For purposes of comparison the cluster analyses are based on taxonomic distances and correlation coefficients and the results are

2 The writer is greatly indebted to Professor Robert R. Sokal and Mr. Ronald Bartcher for analyzing the data with the NT-SYS computer programs. For a write-up of the programs see F. James Rohlf, John Kishpaugh and Ron Bartcher, "Numerical Taxonomy System of Multivariate Statistical Programs," The University of Kansas, Lawrence, Kansas, July, 1967. Preliminary analyses of the data were performed with a single linkage cluster analysis computer program developed by Miss Judith Fiehler of the Louisiana State University School of Music and a program developed by G. F. Bonham-Carter, "FORTRAN IV Program for Q-Mode Cluster Analysis of Non-quantitative Data Using IBM 7090/7094 Computers," State Geological Survey, University of Kansas, Lawrence, Kansas, 1967. 
presented in the form of dendrograms in Figures B-2 and B-3. A dendrogram is a graphical representation of relationships between taxa and clusters. The dendrogram oversimplifies the existing multidimensional relationships, but it 1llustrates well which taxa form clusters.

An inspection of Figures $B-2$ and $B-3$ shows that the clusters that have been formed by using taxonomic distances and correlation coefficients are not identical although there is some overall resemblance between the two dendrograms. In Figure B-2 many taxa join between the taxonomic distances $d=0.2$ and $d=0.6$. However, the formation of larger clusters takes place only at greater taxonomic distances. It is therefore fairly difficult to decide which of the linked taxa belong to a cluster. Because clustering based on taxonomic distance did not result in the desired cluster formation, Figure B-2 will not be further analyzed.

Figure B-3 depicts the clusters based on correlation coefficients. Many taxa join at correlation coefficients $r>0.7$. If the cutoff is arbitrarily set at $r=0.0$ four distinct clusters of unequal size emerge. These clusters, by themselves, are of little use to the researcher. But since the taxa or enterprises were joined into clusters on 
Taxonomic Distance

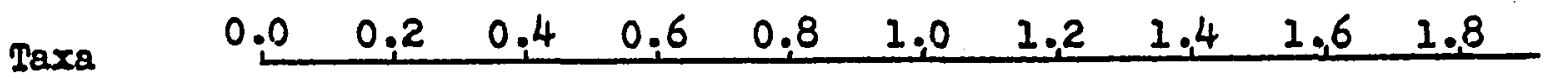

Company

$$
\begin{aligned}
& 1 \\
& 38 \\
& 16 \\
& 28 \\
& 18 \\
& 20 \\
& 47 \\
& 34 \\
& 48
\end{aligned}
$$

49

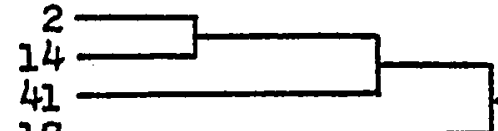

17

23

42

82

25

30

39

36

32

26

10

37

2

11

21

19

31

35

24

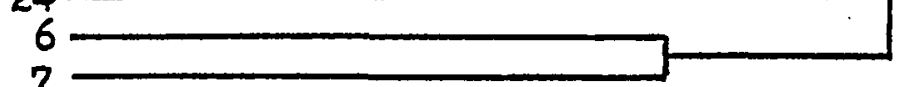

43

44

46

50

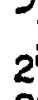

4

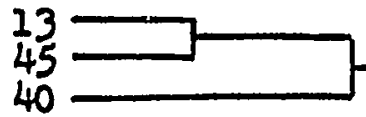

Figure B-2. Dendrogram Based on Taxonomic Distance Coefficients Jo1nod by Aterage Llnkege (Applying Spearman's Sums of Varlables Method of Areraging if 


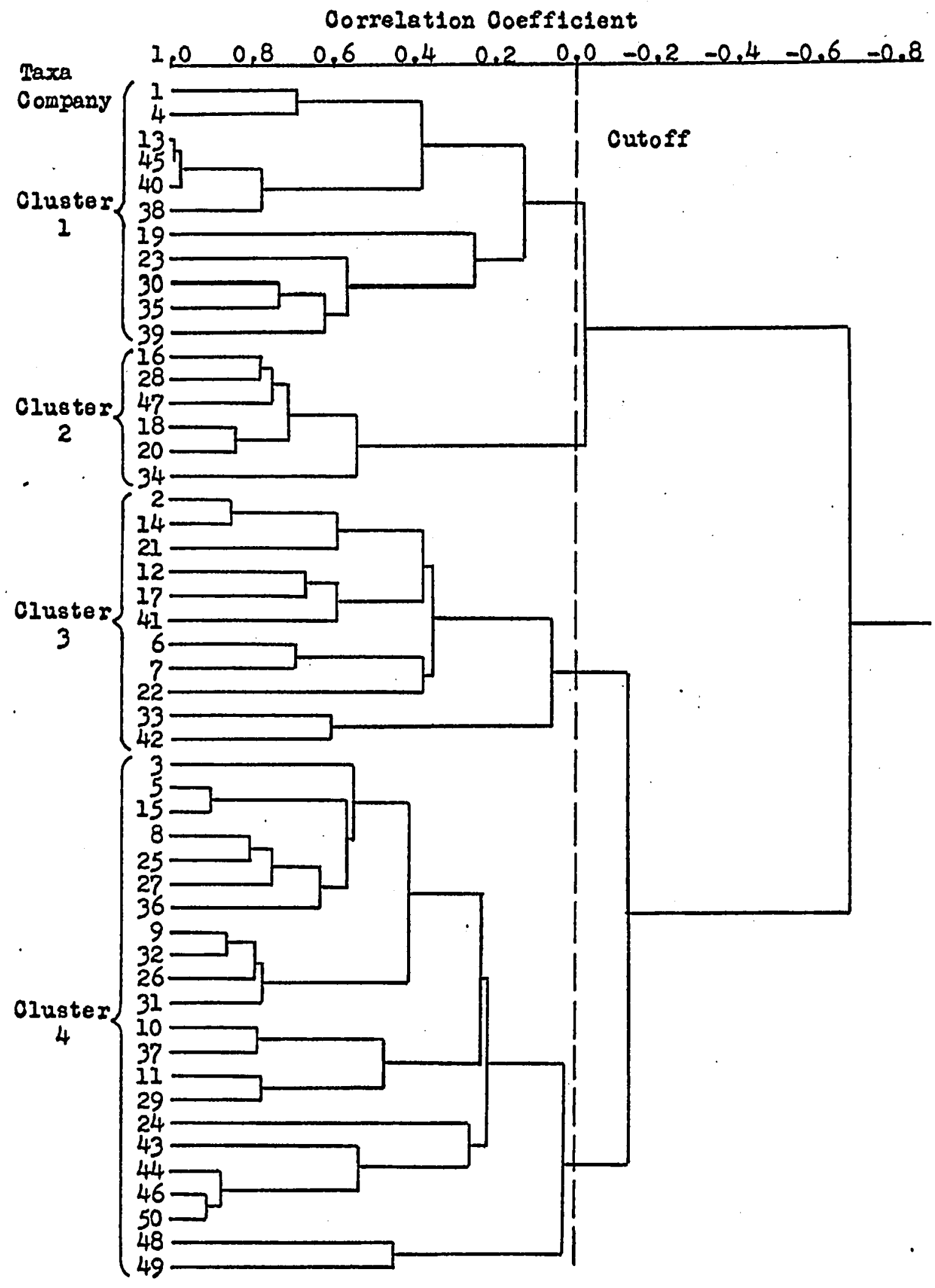

Figure B-3. Dendrogram Based on Correlation Coefficiento Joined by Average Iinkago (Applying Spearman's Sums of Vaxiables Method of Averaging.) 
the basis of correlation coefficients, the taxa within a cluster must have something in common. Therefore, it would be desirable to subject the clusters to a rigorous multivariate analysis; e.g., factor analysis. However, since the sample size is very small, such analysis will not be very meaningful. For this reason only the averages of the characteristics have been calculated and presented in Table B-2.

An inspection of Table B-2 reveals some rather interesting facts which are also indicative of the power of cluster analysis as a tool of numerical taxonomy. By definition clusters are relatively homogeneous groups. Differences within a cluster are relatively small and the differences from cluster to cluster fairly large. A comparison of the clusters shows that this is indeed the case. Keeping with the terminology of Chapter IV, Clusters 1 and 3 represent high volume manufacturers and clusters 2 and 4, small batch firms. Further, clusters 1 and 2 are made up of large firms and Clusters 3 and 4 represent small firms. In other words, the four clusters represent the four way classification on the basis of size and technology which was briefly mentioned in Chapter IV.

The comparison of Clusters 1 and 3 with Clusters 2 and 
TABLE B-2

Heans of 29 Selected Varlables for 4 Clusters Jolned with Average Iinkage on the Basis of Correlation Coefficients

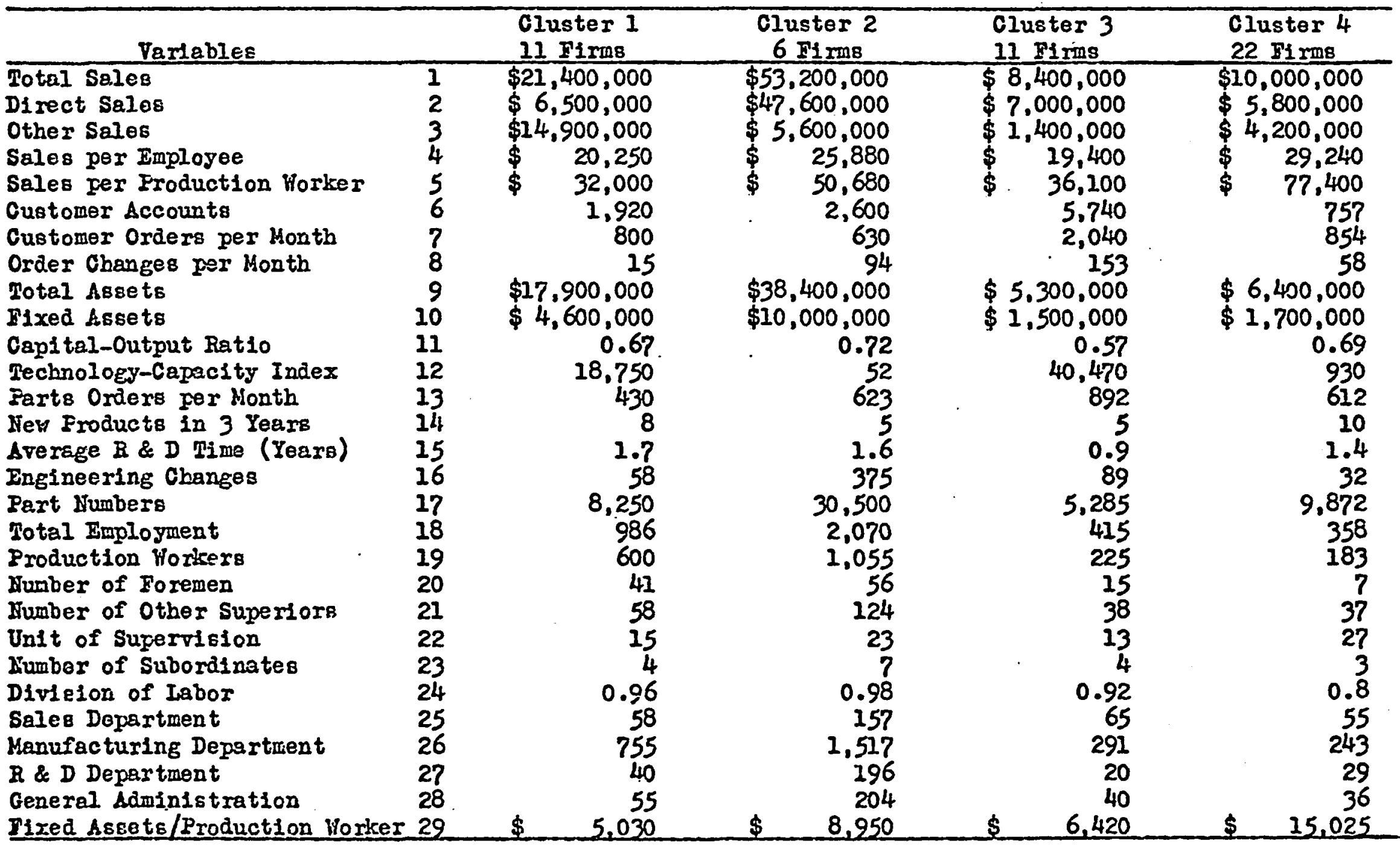


4 on such variables as Customer Accounts, Capital-Output Ratio, Technology-Capacity Index, Part Numbers, Unit of Supervision, $R \& D$ Department, and Fixed Assets per Production Worker supports the findings of Chapter IV: technology measurably influences the characteristics of industrial organizations independent of size. For example, the high volume firms in Clusters 1 and 3 have relatively more Customer Accounts than the small batch firms. The Capital-Output Ratio is higher for the large firms, but, in addition, the small batch firms producing complex products-Clusters 2 and 4--have also a higher co Ratio than the high volume firms in Clusters 1 and 3. Further, small batch. firms have relatively more part numbers, larger units of super-. vision, and expend more fixed assets per production worker. Thus on the basis of the evidence presented in Table B-2 it appears that numerical taxonomy is of great value for comparative analysis of business enterprises. However, because of the small sample size of each cluster and the relatively greater influence of missing data on the results, the analysis cannot be extended beyond a simple comparison of the means. Again this writer hopes that the practicing managers will find these results useful for comparing the characteristics of their company with the averages of 
related companies.

\section{Toward A Numerical Taxonomy of Business Enterprises}

Cluster analysis as presented in this appendix appears to have great promise for the analysis of business enterprises. By employing such sophisticated linkage criteria as average linkage and increasing the total sample size, it should be possible to derive very homogeneous clusters and make a fairly accurate assessment about the reasons for the similarity of the firms in the clusters. Also, as pointed out before, the variables to be employed for numerical taxonomy should cover a wider range of phenomena than those used for this study. In the final analysis this writer envisions a very comprehensive taxonomic system of business enterprises according to Figure B-4.

If the comparative method has value, then it should be possible to use a taxonomic system, such as presented in Figure B-4, as framework for micro-analysis of firms. For example, what are the major differences between manufacturing and mining firms, service establishments and financial institutions? How can a classification like manufacturers be subdivided for further analysis? What influence do 


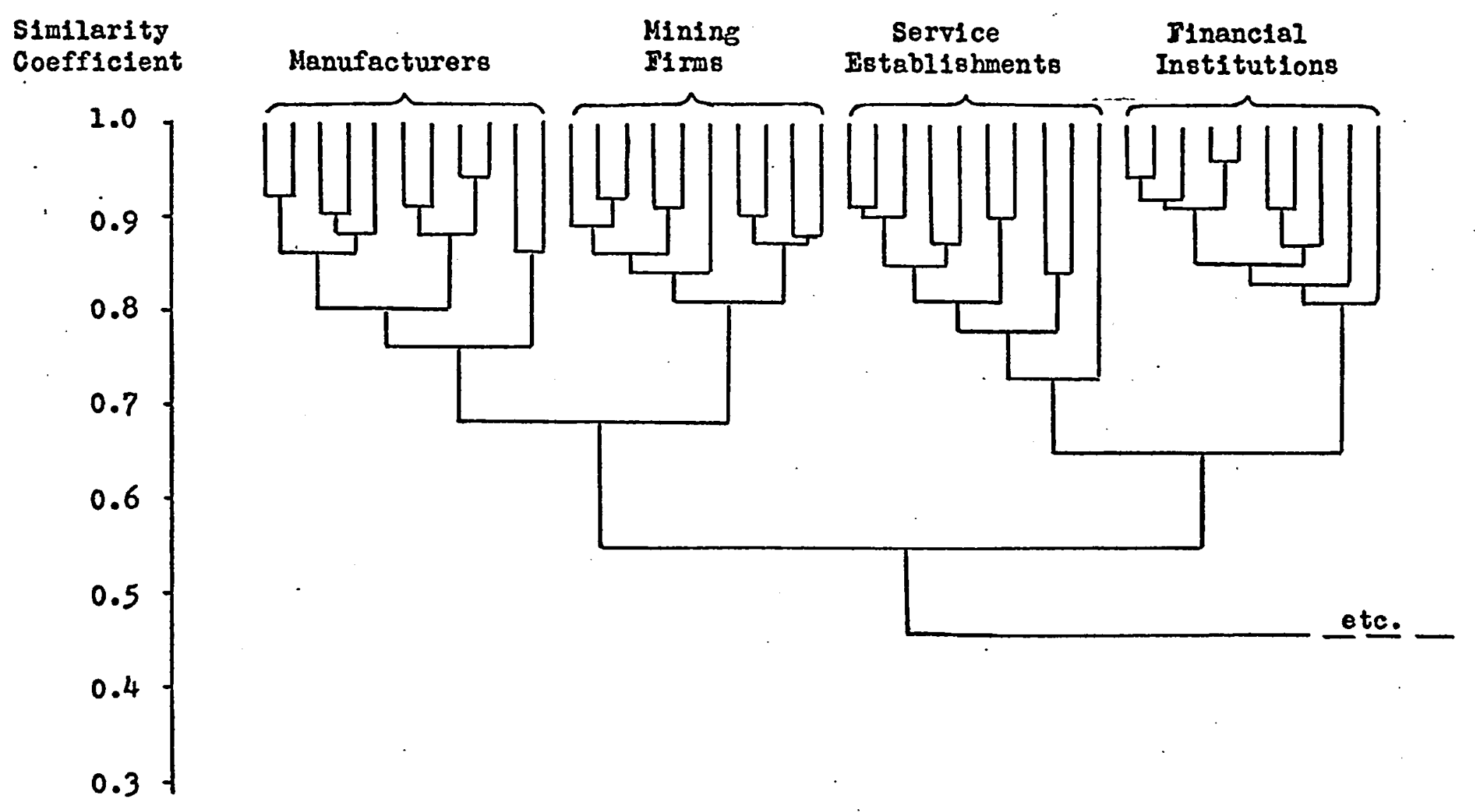

Figure B-4. Sketch of a Comphensive Taxonomic System of Business Bnterprises 
marketing and financial considerations have on such a subdivision? The number of characteristics on which comparisons can be made can be large in numerical taxonomy without rendering the method ineffective or computationally unfeasible. Whereas the human mind may find it difficult to evaluate and compare numerous variables simultaneously without subjectively attaching greater weight to some variables, computer-dependent numerical taxonomy remains objective throughout the classification process. Cluster analysis appears to be the objective method for establishing those comparable situations that are the core of comparative analysis. 


\section{BIBLIOGRAPHY}

$\underline{\text { Books }}$

Alexander, Ralph S., James S. Cross, and Ross M. Cunningham. Industrial Marketing (Homewood, Illinois: Richard D. Irwin, 1961).

Anderson, T. W. An Introduction to Multivariate Analysis (New York: John Wiley and Sons, 1958).

Ansoff, Igor H. Corporate Strategy (New York: McGraw-Hill, 1965).

Baumberger, H. U. Die Entwicklung der Organisationsstruktur in Wachsenden Unternehmen (Bern: Verlag Paul Haupt, 1961).

Bright, James. Research, Development, and Technological Innovation (Homewood, Illinois: Richard D. Irwin, 1964).

Brown, Murray. On the Theory and Measurement of Technological Change (Cambridge: The University Press, 1966).

Busse von Colbe, Walther. Die Planung der Betriebsgrosse (Wiesbaden: Betriebswirtschaftlicher Verlag Dr. Th. Gabler, 1964).

Cangelosi, Vincent E. Compound Statements and Mathematical Logic (Columbus, Ohio: Charles E. Merrill Books, 1967).

Chandler, Alfred D. Strategy and Structure (Cambridge: MIT Press, 1962).

Chapple, Eliot and Leonard R. Sayles. The Measure of Management (New York: Macmillan, 1961). 
Clyde, Dean J., Elliott M. Cramer, and Richard J. Sherin. Multivariate Statistical Programs (Biometric Laboratory, University of Miami, Coral Gables, Florida, 1966).

Cohen, Morris R. and Ernest Nagel. An Introduction to Logic and Scientific Method (New York: Harcourt, Brace and World, 1934).

Cooley, William W. and Paul R. Lohnes. Multivariate Procedures for the Behavioral Sciences (New York: John Wiley, 1962).

Cyert, Richard M. and James G. March. A Behavioral Theory of the Firm (Englewood Cliffs, New Jersey: PrenticeHa11, 1963).

Dale, Ernest. Planning and Developing the Company Organization Structure (New York: American Management Association, 1952).

1960): The Great Organizers (New York: McGraw-Hill,

Davis, Keith. Human Relations at Work - The Dynamics of Organizational Behavior (New York: McGraw-Hill, 1967).

Davis, Ralph C. The Fundamentals of Top Management (New York: Harper and Brothers, 1951).

- The Influence of the Unit of Supervision and the Span of Executive Control on the Economy of the Line Structure (Columbus, Ohio: Bureau of Business Research, The Ohio State University, 1951).

DeSpelder, Bruce E. Ratios of Staff to Line Personnel (Columbus, Ohio: Bureau of Business Research, The Ohio State University, 1962).

Drucker, Peter F. The Practice of Management (New York: Haxper and Brothers, 1954).

Edwards, Allen L. Experimental Design in Psychological Research (New York: Holt, Rinehart and Winston, 1964). 
Fayol, Henri. General and Industrial Management (London: Pitman and Sons, 1949).

Fisch, Gerald G. Organization for Profit (New York: McGrawHill, 1964).

Harman, Harry H. Modern Factor Analysis (Chicago: The University of Chicago Press, 1960).

Henryson, Sten. Applicability of Factor Analysis in the Behavioral sciences (Stockholm: Almquist and Wicksell, 1957) Stockholm Studies in Educational Psychology I.

Horst, Paul. Factor Analysis of Data Matrices (New York: Holt, Rinehart and Winston, 1965).

Jaques, Elliott. Measurement of Responsibility (Cambridge: Harvard University Press, 1956).

Kendall, Maurice G. Rank Correlation Methods (New York: Hafner Publishing Company, 1955).

- A Course in Multivariate Analysis (New York:

Hafner Publishing Company, 1957).

Kerlinger, Fred N. Foundations of Behavioral Research (New York: Holt, Rinehart and Winston, 1964).

Megginson, Leon C. Personnel: A Behavioral Approach to Administration (Homewood, III inois: Richard D. Irwin, 1967).

Newman, W. H. and J. P. Logan. Management of Expanding Enterprises (New York: Columbia University Press, 1955).

Parkinson, C. Northcote. Parkinson's Law (Boston: Houghton Mifflin Company, 1957).

Polanyi, Michael. The Logic of Liberty (Chicago: The University of Chicago Press, 1951).

Roethlisberger, F. J. and W. J. Dickson. Management and the Worker (Cambridge: Harvard University Press, 1939). 
Salter, W. E. G. Productivity and Technical Change (Cambridge: The University Press, 1966).

Sokal, Robert R, and Peter H. H. Sneath. Principles of Numerical Taxonomy (San Francisco: W. H. Freeman and Company, 1963).

Woodward, Joan. Industrial Organization: Theory and Practice (London:- Oxford University Press, 1965).

\section{$\frac{\text { Periodicals }}{i}$}

American Management Association. "Check Your Management Costs," Nations Business, (Jan., 1962), pp. 218-221.

Bartlett, M. S. "The Statistical Significance of Canonical Correlations," Biometrika, Vol. 32, (1941), pp. 29-37.

Beckmann, Martin J. "Some. Aspects of Returns to Scale in Business Administration," The Quarterly Journal of Economics, (Aug., 1960), pp. 464-471.

Behling, Orlando, George Labovitz, and Richard Kosmo. "The Herzberg Controversy - A Critical Reappraisal," Academy of Management Journal, (Mar., 1968), pp. 99108.

Burak, Elmer H. "Industrial Management in Advanced Production Systems: Some Theoretical Concepts and Preliminary Findings," Administrative Science Quarterly, (Dec., 1967), pp. 479-500.

Cattell, Raymond B. and J. L. Muerle. 'The 'Maxplane' Program for Factor Rotation to Oblique Simple Structure," Journal of Educational and Psychological Measurement, (Autumn, 1960), Pp. 569-590.

- and K. Dickman. "A Dynamic Model of Physical Influences Demonstrating the Necessity of Oblique Simple Structure," Psychological Bulletin, (Sept., 1962), pp. 389-400. 
"Factor Analysis: An Introduction to Essentials, I. The Purpose and the Underlying Models," Biometrics, (Mar., 1965), pp. 190-215.

Eddy, William B., Byron R. Boyles, and Carl F. Frost. "A Multivariate Description of Organization Process," Academy of Management Journal, (Mar., 1968), pp. 49-61.

Frank, Ronald A. and Paul E. Green. "Numerical Taxonomy in Marketing Research: A Review Article," Journal of Marketing Research, (Feb., 1968), pp. 83-94.

Garrett, Henry. "The Discriminant Function and Its Use in Psychology," Psychometrika, (June, 1943), pp. 65-79.

Gasser, Christian. "Die Optimale Organisationsstruktur," Industrielle Organization, (Dec., 1952), pp. 325-332.

Gibbs, Jack P. and Walter T. Martin. "Urbanization, Technology, and the Division of Labor: International Patterns," American Sociological Review, (Oct., 1962), pp. 273-295.

Harbinson, F. H., E. Kochling, F. H. Cassel, and H. C". Ruebmann. "Steel Management on Tro Continents," Management Science, (Oct., 1955), pp. 31-39.

Hicks, Herbert G. and Friedhelm Goronzy. "A Survey of Certain Economic Concepts Relevant to the Study of Management and Organization," Management International, (Forthcuming, 1968).

"A Survey of Some Recent Contributions of Economists to a Managerial Theory of the Firm," Management International, (Forthcoming, 1968).

"On Methodology in the Study of Management and Organization," Academy of Management Journal, (Dec., 1967), pp. 371-384.

Hil1, Lawrence S. "The Application of Queuing Theory to the Span of Control," Academy of Management Journal, Mar., 1963), pp. 58-69. 
Horst, Paul. "Relations Among m Sets of Measures," Psychometrika, (June, 1961), pp. 129-149.

Họtelling, H. "Relations Between Two Sets of Variates," Biometrika, Vol. 28 (1936), pp. 321-377.

Jaques, Elliott. "Two Contributions to a General Theory of Organization and Management," Scientific Business, (Aug., 1964), pp. 201-214.

Kaiser, H. F. "The Varimax Criterion for Analytic Factor Rotation," Psychometrika, (Sept., 1958), pp. 187-200.

Maroney, John R. and Jan W. Duggar. "Vertical Integration - and Capital-Output Ratios in US Manufacturing Industry," The Quarterly Review of Economics and Business, (Sumer, 1967), pp. 23-27.

Rushing, William A. "The Effect of Industry Size and Division of Labor on Administration," Administrative Science Quarterly, (Sept., 1967), pp. 273-295.

Seashore, Stanley E. and Ephraim Yuchtman. "Factorial Analysis of Organizational Performance," Administrative Science Quarterly, (Dec., 1967), pp. 377-395.

Sokal, Robert R. "Numerical Taxonomy," Scientific American, (Dec., 1966), pp. 106-116.

Steglitz, Harold. "Optimizing the Span of Control," Management Record, (Sept., 1962), pp. 121-129.

Suojanen, W. W. "The Span of Control - Fact or Fable?," Advanced Management, (Nov., 1955), pp. 5-13.

Udell, Jon G. "An Empirical Test of Hypotheses Relating to the Span of Control," Administrative Science Quarterly, (Dec., 1967), pp. 420-439.

Essays and Articles in Collections

Brewer, R. C. "The Measurement of Technical Variables," in Joan Woodward, Industrial Organization: Theory and Practice, Oxford University Press, London, 1965, pp. 268274. 
Graicunas, V. A. "Relationships in Organization," in Luther Gulick and L. Urwick, Editors, Papers on the Science of Administration, Institute of Public Administration, Columbia University Press, New York, 19:37, pp. 181-187.

Ramond, Charles K. "Factor Analysis: When to Use It," in Abe Shuchman, Editor, Scientific Decision Making in Business, Holt, Rinehart and Winston, New York, 1963, pp. 235-242.

Starbuck, William H. "Organizational Growth and Development" In James G. March, Editor, Handbook of Oxganizations, Rand McNally., Chicago, 1965, pp. 451-533.

Stogdill, Ralph M. "Dimensions of Organizational Theory," in James D. Thompson, Editor, Approaches to Organizational Design, University of Pittsburgh Press, Pittsburgh, 1966, pp. 2-56.

\section{Miscellaneous}

Bonham-Carter, C. F. "FORTRAN IV Program for Q-Mode of Non-Quantitative Data Using IBM 7090/7094 Computers," State Geological Survey, University of Kansas, Lawrence, Kansas, 1967.

Eber, Herbert W. "Toward Oblique Simple Structure: Maxplane," Unpublished Manuscript, Birmingham, Alabama, 1965.

Fiehler, Judith. "A FORTRAN IV Program to Analyze Musical Styles," Unpublished Computer Program, Louisiana State University School of Music, 1968.

Poor's Register of Corporations, Directors and Executives, Standard and Poor's Corporation, New York, 1967.

Rohlf, F. James, John Kishpaugh, and Ron Bartcher. "Numerical Taxonomy System of Multivariate Statistical Programs," The University of Kansas, Lawrence, Kansas, 1967. 
VITA

Friedhelm Goronzy, the son of Rudolf Goronzy and Auguste Goronzy, was born in Freundlingen, East Prussia in Germany on March 29, 1938. He entered primary school in 1944 in Freundlingen and, displaced by World War II, he finished his primary education in 1953 in Castrop-Rauxel, Westphalia. From 1953 to 1959 he worked for the dropforging company, Eisenwerk Rothe Erde, in Dortmund, Germany, as mechanic apprentice, journeyman, and technical draftsman. He completed his secondary education by attending night schools from 1954 to 1958 . He received the mechanical engineering degree after attending the Staatliche Ingenieurschule für Maschinenwesen in Essen, Germany, from 1959 to 1962. While studying engineering he worked during the summers of 1959, 1960, and 1961 in England, Sweden, and the United States, respectively. From 1962 to 1963 he worked for Woods of Colchester as sales engineer and estimator in Colchester, England, and Germany. After a six-month employment as student trainee in business. administration with Markem Machine Company in Keene, New 
Hampshire, he began graduate work in September of 1963 in the College of Business Administration at Louisiana State University in Baton Rouge, Louisiana. In 1965 he graduated with the degree of Master of Business Administration, and he is presently a candidate for the degree, Doctor of Philosophy. 
Candidate: Friedhelm Goronzy:

Major Field: Management

Title of Thesis: A Multivariate Analysis of Selected Variables of Manufacturing Business Enterprises

Approved:

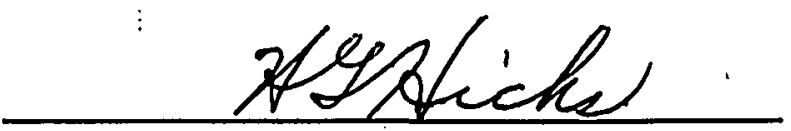

Major Professor and Chairman

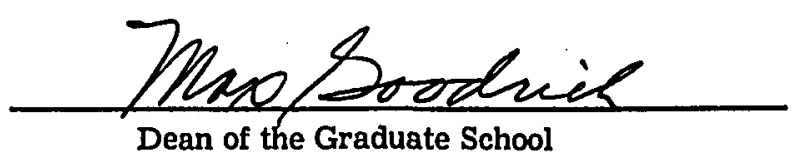

EXAMINING COMMITTEE:

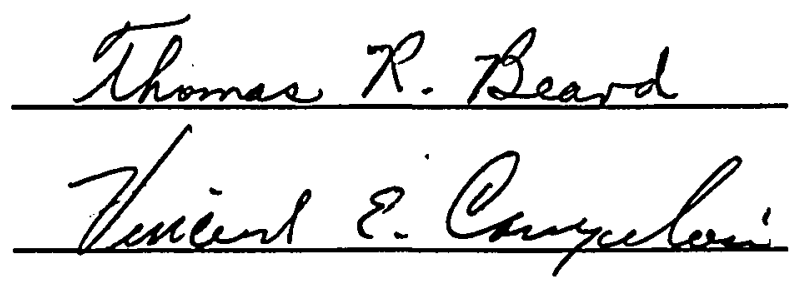

Bis R. Aarden

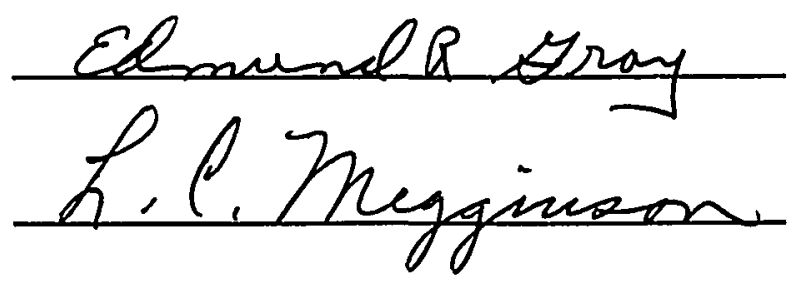

Date of Examination:

May 2, 1968 